Illinois State University

ISU ReD: Research and eData

Theses and Dissertations

7-7-2014

\title{
U.s.-Educated Multilingual Students In Community College: Transitioning From Esl To English 101
}

Melinda S. Harrison

Illinois State University, mharri94@gmail.com

Follow this and additional works at: https://ir.library.illinoisstate.edu/etd

Part of the Bilingual, Multilingual, and Multicultural Education Commons, Community College Education Administration Commons, Community College Leadership Commons, and the Linguistics Commons

\section{Recommended Citation}

Harrison, Melinda S., "U.s.-Educated Multilingual Students In Community College: Transitioning From Esl To English 101" (2014). Theses and Dissertations. 217.

https://ir.library.illinoisstate.edu/etd/217

This Thesis is brought to you for free and open access by ISU ReD: Research and eData. It has been accepted for inclusion in Theses and Dissertations by an authorized administrator of ISU ReD: Research and eData. For more information, please contact ISUReD@ilstu.edu. 


\title{
U.S.-EDUCATED MULTILINGUAL STUDENTS IN COMMUNITY COLLEGE:
}

\section{TRANSITIONING FROM ESL TO ENGLISH 101}

\author{
Melinda S. Harrison
}

218 Pages

August 2014

This thesis focuses on U.S.-educated multilingual students as they transition from a community college academic English as a Second Language program to and through a semester-long first-year composition course. Research on non-native English speakers has indicated that U.S.-educated multilingual students have both similar and varied background and literacy experiences compared to native English speakers and international students; they also often present unique literacy needs compared to their peers. These various and shifting similarities and differences sometimes complicate placement and instruction in college courses.

My case study focused on three U.S.-educated multilingual students' experiences in the final semester of a community college academic ESL program and in the first semester of first-year composition. I analyzed data from observations, semi-structured interviews, and written artifacts, such as syllabi, assignment sheets, and students' written compositions, to locate themes that helped me answer my research questions: What are the experiences of U.S.-educated multilingual students in mainstream composition courses in community colleges? And, how can community college ESL programs better prepare U.S.-educated multilingual students? 
The findings suggest that U.S.-educated multilingual students who successfully complete this community college's academic ESL program can be successful in first-year composition at this community college. The findings also suggest, however, pedagogical and administrative implications in providing U.S.-educated multilingual students with the necessary tools to succeed. Pedagogical implications include minor revisions to ESL program curricula to incorporate assignments that allow students to build upon their private literacy practices, the addition of more multimodal writing tasks and more lexically challenging reading tasks, and research to ascertain an institution's specific student population and literacy needs. Administrative implications for community colleges include increased collaboration among academic departments as well as crosstraining first-year composition teachers to meet the needs of multilinguistic classrooms. Finally, the findings also call for more research on U.S.-educated multilingual students in community college ESL and composition courses. 
U.S.-EDUCATED MULTILINGUAL STUDENTS IN COMMUNITY COLLEGE:

TRANSITIONING FROM ESL TO ENGLISH 101

MELINDA S. HARRISON

A Thesis Submitted in Partial

Fulfillment of the Requirements

for the Degree of

MASTER OF ARTS

Department of English

ILLINOIS STATE UNIVERSITY 
Copyright 2014 Melinda S. Harrison 
U.S.-EDUCATED MULTILINGUAL STUDENTS IN COMMUNITY COLLEGE:

TRANSITIONING FROM ESL TO ENGLISH 101

MELINDA S. HARRISON

COMMITTEE MEMBERS:

Lisya Seloni, Chair

K. Aaron Smith

Gerald J. Savage 


\section{ACKNOWLEDGMENTS}

In addition to serving as a contribution to a scholarly conversation, this thesis also serves as an example of academic and personal intertextuality. Present in this work are the echoes of multiple voices, all of which have had an impact on how I view composition, linguistics, education, and the world.

First, I must extend my gratitude to my thesis committee members, all of whom contributed their time, expertise, and encouraging voices to my research and writing. I was privileged to have Dr. Lisya Seloni direct my thesis, as her knowledge and insight in second language writing and research is invaluable. Dr. K. Aaron Smith provided scholarly guidance as well as key insights into linguistic aspects of not only the thesis topic but also my writing on that topic, for which I am very grateful. Finally, Dr. Gerald J. Savage for the past four years has served as an inspiring and caring mentor not only in the discipline of rhetoric and composition but also in life. This thesis and my future work will inevitably and fortunately reflect the influential voices of these three scholars and instructors.

I also owe many thanks to the participants of my research study as well as the supporting institutions. These participants sacrificed their time for this research and trusted me with their voices and stories. For the student-participants, specifically, I hold a special place in my heart, having worked closely with all three of them for almost a year.

The English Department at Illinois State University is truly special. The voices of past instructors and scholarly mentors resonate throughout this thesis. Influence from 
every course I have completed is interwoven in this work. Additionally, I would be gravely remiss to not thank my graduate student peers who shared their voices in class as well as in casual conversations about scholarship and research. I am especially grateful to my dear friend, Dr. Pennie Gray; words cannot express the amount of encouragement and inspiration she poured and continues to pour on me. Additionally, I must thank Dr. Ethan Lewis of The University of Illinois - Springfield, who twenty years ago was the first graduate instructor to encourage me to share my own voice in scholarly conversations.

Finally, I am truly blessed to have a family who continues to tirelessly support me throughout my academic career. My parents' voices echo in my head, encouraging me to never give up on any task. The voice of my father-in-law, whom I consider one of the best teachers I have ever known, continues to inspire me to consider learning a life-long joyful endeavor. Last but certainly not least, my husband has continually offered to me his unquestionable support not only in voice but also in action.

To all of you, I extend my gratitude and promise to carry your voices with me into every academic task I attempt. Thank you.

M.S.H. 


\section{CONTENTS}

\section{Page}

ACKNOWLEDGMENTS

CONTENTS

CHAPTER 1

I. THE PROBLEM AND ITS BACKGROUND 1

Overview 1

Statement of the Problem 5

Research Questions $\quad 6$

Methodology $\quad 8$

Organization of the Thesis $\quad 9$

II. THEORETICAL FRAMEWORKS AND REVIEW OF RELEVANT LITERATURE 12

Introduction $\quad 12$

Part I: Theoretical Frameworks 13

Defining U.S.-Educated Multilingual Students (or

Generation 1.5 Students) 13

Cross-Cultural Considerations and Second Language Writing $\quad 17$

Academic Literacies and Second Language Writing 20

Multimodal Composition and Second Language

Writing

Part II: Review of Literature on Academic Literacy Needs and Preparedness of U.S.-Educated Multilingual Students

Introduction

Differences Between the Writing of NESs and ELLs

Academic Literacy Needs of NNESs 
Academic Literacy Needs of U.S.-Educated Multilingual Students, Specifically

Building Upon U.S.-Educated Multilingual Students'

Private Literacies and Oral Competencies: Blogging

Part III: Literature Review on Placement Options and

Concerns for U.S.-Educated Multilingual Students

Introduction

Placing U.S-Educated Multilingual Students, Specifically

First-Year Composition as Contact Zone

Curriculum Considerations Appropriate for

U.S.-Educated Multilingual Students

More Cross-Cultural Considerations

Meeting the Literacy Needs of U.S.-Educated

Multilingual Students in the Writing Center

Failure to Transition to First-Year Composition

Summary of the Literature Review

III. RESEARCH METHODOLOGY

Introduction

Researcher's Positionality

Rationale

Research Design

Fieldwork Practices

Ethical Considerations

Methodological Limitations $\quad 80$

Conclusion

IV. CONTEXTUALIZATION OF THE DATA 82

Introduction $\quad 82$

Part I: U.S. Community Colleges and Gridley Community College

Part II: Gridley Community College's ESL Program

Part III: Gridley Community College's Mainstreamed English Courses

General Mainstreamed English Courses 
Part IV: The Fall 2013 AELP Level 4 Course and the Participants

The AELP

The AELP Level 4 Class

Early Participation of the U.S-Educated

Multilingual Students

113

Berenice

Jack

Chapter Summary

V. DATA ANALYSIS AND FINDINGS

Introduction

Similarities Between Jack and Berenice:

Using a Process Approach to Composition

Similarities Between Jack and Berenice:

Imbalance Between Oral and Written English

Theme \#1: Lack of Support and Explicitness

Theme \#2: Perceived Literacy Needs

Jack: Reading Academic Texts

162

Jack in English 101: Multimodal Composition and Genre Analysis

Conclusion

VI. CONCLUSION

Overview

Part I: Research Question \#1, Revisited

Part II: Implications and Research Question \#2, Revisited

Pedagogical Implications for Community College ESL Programs

Administrative Implications: Increase Collaboration

Among Academic Departments

Part III: Limitations of the Present Study and Areas for Further

Research

Concluding Comments 
APPENDIX B: Semi-Structured Interview Questions for the English 101 Instructor 212

APPENDIX C: Semi-Structured Interview Questions for the Student-Participants 214

APPENDIX D: AELP Level 4 List of Novels for Book Report Assignment

APPENDIX E: Jack’s English 101 Cowbird Assignment

218 


\section{CHAPTER I}

\section{THE PROBLEM AND ITS BACKGROUND}

\section{Overview}

The Immigration and Naturalization Act of 1965 reopened the doors for an immense number of immigrants arriving in the U.S. (Louie, 2009). This act reformed previous immigration policy and attempted to halt discrimination by abolishing the national origins quota system, a system that put limitations on how many immigrants could enter the United States; additionally, it enacted a preference system toward potential immigrants who had family already in the U.S., emphasizing family unity over simply numbers (Reimers, 1983). After this act took effect, numbers of immigrants from Southern and Eastern Europe as well as Asia increased substantially, while numbers of immigrants from other areas of the world such as Latin America also increased, though at not as steep a rate (Reimers, 1983). Projections are that, by 2015, the number of children of immigrants will make up 30\% of the total number of students in U.S. K-12 classrooms; many of these students speak a language other than English as their first or home language (Fix and Passel, 2003; Louie, 2009). As the members of this demographic seek education beyond that of the K-12 schools, the open-access of the community college presents fewer barriers than a four-year college or university and thus becomes a viable option for higher education (G. Patthey, J. Thomas-Spiegel, and 
P. Dillon, 2009; Blumenthal, 2002). These U.S.-educated multilingual students ${ }^{1}$, often also known as "Generation 1.5 students," present a unique opportunity for community college administrators in developing programs appropriate for their needs, as the term "Generation 1.5 " is now "a designation that reflects a pressing concern frequently addressed among community college ESL professionals" (Blumenthal, 2002, p. 49). Completing academic writing tasks in English is sometimes more challenging for ELLs than for their native English-speaking peers, as the writing of ELLs - including the writing of U.S.-educated multilingual students, or Generation 1.5 students - may differ from the writing of native English speakers (NESs) strategically, rhetorically, and linguistically, therefore suggesting that ELLs may have specialized literacy needs that may not be met in mainstream composition or content-area courses (Blumenthal, 2002; Silva, 1994).

Responding to the increase in the number of multilingual students present and soon to be present in higher education composition classrooms, the Conference on College Composition and Communication (CCCC) issued a statement in 2001, revised in 2009, underscoring the number of second-language students in the U.S. and the responsibility of writing program administrators at all levels to provide curricula that take these language learners into consideration. This official statement not only acknowledges the widespread presence of ELLs in all classroom levels in the U.S., but also charges writing teachers, writing program administrators, and university faculty responsible for teacher preparation curriculum to familiarize themselves with these

${ }^{1}$ Defined in detail in Chapter II, these students are different in educational background from international students or adult immigrants. 
learners and their various backgrounds and literacy needs as well as the resulting pedagogical implications:

Second language writers include international visa students, refugees, and permanent residents as well as naturalized and native-born citizens of the United States and Canada. Many of these students have grown up speaking languages other than English at home, in their communities, and in schools; others began to acquire English at a very young age and have used it alongside their native languages.... Second language writers take part in writing programs at all levels - from basic writing and first-year composition to professional writing and writing across the curriculum as well as in writing centers and graduate programs.... For these reasons, we urge writing teachers and writing program administrators to

- Recognize and take responsibility for the regular presence of second language writers in writing classes, to understand their characteristics, and to develop instructional and administrative practices that are sensitive to their linguistic and cultural needs.

- Offer teacher preparation in second language writing theory, research, and instruction in the forms of graduate courses, faculty workshops, relevant conference travel, and, when possible, require such coursework or other similar preparation for instructors working with writers in a higher-education context.

- Offer graduate courses in second language writing theory, research, and instruction and, when possible, require such coursework or other similar preparation for instructors working with writers in a higher-education context.

- Investigate issues surrounding second language writing and writers in the context of writing programs, including first-year writing programs, undergraduate and graduate technical, creative, and theoretical writing courses, writing centers, and Writing Across the Curriculum programs.

- Include second language perspectives in developing theories, designing studies, analyzing data, and discussing implications of studies of writing. (Part 1: General Statement)

As this excerpt asserts, the Conference also provides strong suggestions as to how writing programs should research their local ELL populations in order to best support these language learners at all levels of education in the community. As the guidelines acknowledge, second language writers can be found at all levels of college composition 
classrooms, from basic writing to first year composition. The statement gives specific guidelines on student placement, writing course structure, assessment, and instructor preparation. A common theme throughout the guidelines is that writing programs should research the populations they serve in order to appropriately meet the needs of those populations. Therefore, community college instructors, writing program administrators, and ESL directors should not only be cognizant of research in cross-cultural composition in general but also become comfortable completing their own local case studies of the specific English language learner demographic entering their institutions, keeping CCCC's statement on second language learners in mind.

Fortunately, research on second language writing at the post-secondary level has illustrated many curricular options for supporting these non-native English speakers. Examples of curricular options for second language learners include placement in traditional ESL courses or placement into mainstreamed first-year composition courses without any academic ESL preparatory course (Holten, 2009). Alternatively, some language learners are placed into intensive English programs (IEPs), which are usually focused on international students who have English as a Foreign Language experience in a country outside of the U.S. (Muchinsky and Tangren, 1999). Another additional option mentioned in research is for the college to provide an ESL-specific non-credit-bearing preparatory program that feeds into a mainstream writing program (Harklau, Losey, and Siegal, 1999). A challenge with this option, however, is that the design of mainstream courses often presents difficulty for those students for whom English is not their first language in that they may practice literacies that are different from those required in U.S. academic spaces. As Silva (1994) contends, second language learners' writing 
differs from the writing of their native-English speaking peers strategically, rhetorically, and linguistically. In a review of placement options for second language learners in college composition courses, Silva suggests that second language students placed in mainstream classrooms with native-English speakers may be held to unrealistic standards. Appropriate placement is important, as ELLs being placed in a mainstream course before they have acquired the appropriate academic literacy strengths for the course may result in second language students experiencing "resentment, alienation, loss of self-confidence, poor grades, and, ultimately, academic failure" (Silva, 1994, p. 39). Matsuda and Silva (1999) state that "Some ESL students tend not to do well in mainstream courses partly because many of them feel intimidated by their NES peers who are obviously more proficient in English and comfortable with the U.S. classroom culture" (p. 254). Thus, students whose first language is one other than English may need to gain crucial academic literacy skills and habits through academic ESL programs before they transition to mainstream composition courses.

\section{Statement of the Problem}

Despite the acknowledgement of the CCCC and others (Blumenthal, 2002; di Gennaro 2008; di Gennaro, 2012; Harklau, et al., 1999; Ortmeier-Hooper, 2008; and Roberge, 2009) regarding the heterogeneity of multilingual students in post-secondary levels of education, few studies have addressed how U.S.-educated multilingual students specifically transition into community college first-year composition courses. Representative of the lack of emphasis of current scholarship on U.S.-educated multilingual students is "an overview and synthesis of second language writing scholarship published during 2013" conducted by Silva, Thomas, Zhang, and Park 
(2014). At the 2014 TESOL International Convention and English Language Expo, Silva, et al., presented a year-in-review of scholarship on second language writing published in 2013 (March 26-29, 2014). The authors of this synthesis found only two studies focused on U.S.-educated multilingual students or Generation 1.5 language learners within the past year (conference handout). I found in my own research that several studies within the past fifteen years have focused on U.S-educated multilingual students at the university level and not in the community college venue, such as Blanton, 2005; Bloch, 2007; Holten, 2009; Jeffries and Yi, 2008; Murie and Fitzpatrick, 2009; Ortmeier-Hooper, 2008; Riazantseva, 2012; Thonus, 2003. Of the few studies that have addressed U.S.-educated multilingual students, or Generation 1.5 students, in preparatory community college ESL programs ( including Case, Williams, and $\mathrm{Xu}$, 2013; Doolan, 2010/2011; Harklau, 1999; Patthey, et al., 2009; Salas, Portes, D’Amico, and Rios-Aguilar, 2011; and Song, 2006), a small number of case studies examine these students' written literacy strengths and needs as they transition from such preparatory programs to mainstream community college courses (Allison, 2006; Miele, 2003; and Miller-Cochran, 2012). Therefore, my study attempts to add to this conversation by addressing the intersection of the U.S.-educated multilingual student's transition from a community college academic ESL program to first-year composition courses.

\section{Research Questions}

In conducting this study, I was particularly interested in how well-prepared U.S.educated multilingual students are in their first semester of a first-year composition course at a community college after having completed an academic ESL course sequence. The goal of this research project was to answer two overarching questions: 
(i) What are the experiences of U.S.-educated multilingual students in mainstream composition courses in community colleges?

(ii) How can community college ESL programs better prepare U.S.-educated multilingual students?

Aiming to address these two research questions, this year-long case study specifically compared the writing tasks and pedagogy presented in the academic ESL curriculum with the writing tasks and pedagogy presented in the first semester of the credit-bearing firstyear composition courses in which the student-participants of this study enrolled. As many theories exist for placement options for ESL students in first-year composition, my primary goal was to determine how U.S.-educated multilingual students specifically fared with this transition. Through analysis of observations, interviews, course materials, and students' written work, I sought to uncover challenges the students encountered in writing in a second language in their first-year composition courses at their community college; these challenges would then point me toward potential avenues in meeting students' academic written literacy needs in both the community college's ESL curriculum and first-year composition curriculum.

The research questions and sub-questions that focused my research are:

Research Question 1: What are the experiences of U.S.-educated multilingual students in mainstream composition courses in community colleges?

i. What types of writing tasks have these students been exposed to in their academic ESL curriculum and in mainstream FYC courses?

ii. What are instructors' expectations for students in meeting writing goals? 
iii. In what ways do students meet writing goals in both the academic ESL course and the mainstream FYC courses?

After analyzing the classroom contexts in which these students were learning, I was also able to suggest an answer to the second overarching research question:

Research question \#2: How can ESL programs better prepare U.S.-educated multilingual students?

i. What types of writing tasks are introduced to U.S.-educated multilingual students in the academic ESL program to prepare them for mainstream composition courses?

ii. How are those writing tasks presented to the students, and how do the students proceed and succeed in completing those writing tasks?

The observations and insights gained in order to answer these questions can be used to inform curricular development within similar programs in community colleges.

\section{Methodology}

In order to address my research questions on the experiences of these three U.S.educated multilingual students in mainstream composition courses, I adopted a case study methodology. Sources of data for this case study involved collecting data from classroom observations; collecting artifacts such as syllabi, class handouts, and student writing; conducting semi-structured interviews with the student-participants, instructors, and program directors; and reviewing language learners' self-reflections on their own writing practices. I hoped to uncover specific background information regarding the three student-participants during my research, so that I could include each participant's specific biographical data in my case study. 
Through participant observations and a close analysis of written artifacts, including syllabi and written compositions of these three students, in both the academic ESL course and the mainstream composition courses in which these students were enrolled, I hoped to gain insight into how writing tasks are presented by the instructors, the nature of support offered to the students, and how these student-participants approached the writing tasks. Specifically, I traced how writing instruction takes place in these courses, e.g., what in-class writing activities were employed and what outside-ofclass writing tasks were suggested or required, what specific genres were introduced, and how those genres were approached (explained or addressed) by the instructors.

Through the semi-structured interviews that I conducted with the ESL-program director, instructors, and students, I hoped to gain insight into how writing tasks were typically presented and structured for U.S.-educated multilingual students. These interviews were primarily to collect data about my participants' perspectives on writing and the writing process, as well as their individual biographical contexts, rather than to collect data on textual discourse features. The interviews with the director of the ESL program provided me context as to how the academic ESL curriculum has been structured to prepare students for academic writing tasks beyond the academic ESL program as well as how past U.S.-educated multilingual students have fared in their postacademic ESL courses at the community college.

\section{Organization of the Thesis}

This thesis has six chapters. In this first chapter, I have provided a brief overview of the study, a statement of the problem, an overview of how I intend to add to the conversation regarding U.S.-educated multilingual students' academic literacy needs in 
transitioning from a community college ESL program to first-year composition, and methodological practices I employed in my research.

The second chapter provides a review of theories upon which this study is grounded as well as a review of the literature relevant to this study. In Chapter II, I examine what has already been discussed about genre studies in second language writing, multimodal composition in second language writing, cross-cultural composition, the potential academic literacy needs of U.S.-educated multilingual students specifically, the heterogenic character of community college ESL programs, placement options for these ESL students of varying backgrounds and literacy needs, and the conclusions of case studies examining placement for ELLs, specifically U.S.-educated multilingual students.

The third chapter of this thesis focuses on my methodology. I define case study research and explain why I chose these particular research tools for my study. I also detail my specific methods of gathering data, such as interviewing, observing, and analyzing student texts and other artifacts.

In the fourth chapter, I tell my research "story." This story illustrates the context of my research. I will paint pictures of the community, the community college, the ESL program at this community college, the English program, and the specific courses and instructors involved. These contextual details serve as a backdrop for the stories of the student-participants, with their written texts, perceptions of writing in a second language, and biographical background serving as variables that will tie them together as well as distinguish them from one another.

Chapter V serves as a discussion of how the components of this research story the various pictures and underlying context - shape my findings. I share my discoveries 
and explain how these pictures and underlying contexts are intertextually woven together to create the main research story.

In Chapter VI, I present an analysis answering my first research question, analyzing the experiences of U.S.-educated multilingual students in community college mainstream composition courses. I address also my second research question, presenting a discussion of what community college ESL programs could in order to better prepare U.S.-educated multilingual students for first-year composition. In this chapter, I also suggest pedagogical implications for teachers of first-year composition in providing support for the literacy needs of multilingual students in their classrooms. Finally, I suggest further research trajectories in order to continue adding to the scholarly conversation on multilingual students - primarily U.S.-educated multilingual students in first-year composition courses at community colleges. 


\section{CHAPTER II}

\section{THEORETICAL FRAMEWORKS AND REVIEW OF RELEVANT}

\section{LITERATURE}

\section{Introduction}

The structure of this chapter encompasses three main parts. In the first part, I address the theoretical frameworks or lenses through which I view the findings of my study: defining U.S.-educated multilingual students, cross-cultural composition, academic literacies, and multimodal composition. The second portion of this chapter involves a review of relevant literature on the academic literacy needs and preparedness of U.S.-educated multilingual students. As posited in Chapter I, few studies have been conducted exclusively on how U.S.-educated multilingual students specifically have transitioned to credit composition courses from ESL programs at community colleges (Allison, 2006; Carroll and Dunkelblau, 2011; Miller-Cochran, 2012). Additional studies, though, have addressed the academic literacy needs and preparedness of U.S.-educated multilingual students moving into first-year composition courses at universities (Blanton, 2005; Jeffries and Yi, 2008; Riazantseva, 2012). All of these studies, whether they focus on students in the university setting or the community college venue, serve as essential foregrounding in that they add to an understanding of just what literacy competencies U.S.-educated multilingual students need to have in matriculating into first-year composition. This understanding is especially important when considering U.S.-educated 
multilingual students, who come from a variety of backgrounds in terms of L1 literacies, educational experiences, home situations, and various levels and types of cultural capital.

The third part of this chapter presents a review of literature describing placement concerns and options for non-native English speakers, particularly U.S.-educated multilingual students in universities and community colleges. Since the number of case studies focused specifically on U.S.-educated multilingual students transitioning into first-year composition at community colleges are few, (Allison, 2006; Harklau, 1999; Miele, 2003; Miller-Cochran, 2012; Salas, et al., 2011), it is important to look also at programs for ELLs and U.S.-educated multilingual students in universities as well, since sometimes concepts and understanding may be transferable from one venue to another (Murie and Fitzpatrick, 2009). Additionally, studies illustrating concerns about placement (such as Harklau, 1999; Ortmeier-Hooper, 2008; Patthey, et al., 2009; Salas, et al., 2011) as well as support (Song, 2006; Thonus, 2003) are included in order to present as clear a picture as possible of the variables involved in best equipping U.S.-educated multilingual students for first-year composition writing tasks.

\section{Part I: Theoretical Frameworks}

\section{Defining U.S.-Educated Multilingual Students (or Generation 1.5 Students)}

Texts by Harklau, Losey, and Siegal (1999) and Roberge, Siegal, and Harklau (2009) distinguish Generation 1.5 students from international students. International students are typically those whose tenure in the U.S. is temporary and dependent on their visa status as well as their goals for studying in post-secondary U.S. universities. International students are most likely to enroll in intensive English programs and have completed the equivalent of a U.S. high school diploma in their native country and may 
have studied English in a foreign language context. Generation 1.5 students, on the other hand, are those who immigrate to the U.S. sometime before they are adults and enter into U.S. K-12 schools. These students often miss out on a complete childhood of cultural and linguistic influence in their native country and attempt to negotiate their identity in a new country before they have had a chance to establish their identity as a member of their native communities.

Harklau, et al.'s introduction to the 1999 text sets the stage for this undefinable group of language learners by stressing the uncountability of Generation 1.5 students. Because community colleges and universities ask very little information about a student's native language, getting a grasp on just how many multilingual students are in college and are not temporary students with foreign visa status is complicated. Thus, even a ballpark number of how many students in post-secondary educational institutions are Generation 1.5 students is difficult to determine. As Harklau, et al.'s introduction contends, however, sites such as urban two-year colleges may soon realize that a majority of their students are from backgrounds in which English is not the first language.

Exactly what to call Generation 1.5 students is itself a discussion riddled with complexity. As Roberge admits early in the introduction to the 2009 text, "institutional labels can perpetuate educational injustice" as "some students (typically the economically privileged as well as those who more closely fit traditional, institutionally defined profiles) receive a curriculum more tailor-made to their individual needs" (p. 5). Roberge further explains that these students, often with

less economic or social capital and those whose histories, experiences, and individual needs don't match traditional institutional profiles...may be marginalized, their educational support being 'outsourced' to tutoring 
centers, basic skills programs, or even other institutions, as is the case when universities send matriculated students 'away' to community college for ESL or developmental writing courses. (p. 4)

In other words, unless a language learner falls neatly into a defined box, he or she may be mislabeled and thus miseducated.

Naming and defining Generation 1.5 students are issues that are continually debated. To call this demographic - language learners whose first language is not English and who have experience in U.S. K-12 schools - "Generation 1.5" is contested. The term "Generation 1.5" comes from the field of immigration studies, where it was used as a term to classify immigrants who were not first generation (born and raised into adulthood with the linguistic and cultural influences of a native country) nor second generation (children born in the U.S. to first generation immigrant parents). Benesch (2008) argues that this term, because of its background, reinforces the binary of Self and Other, native and nonnative, instead of recognizing "the fluidity and complexity of identity in a globalized world" (p. 299). Partly to blame, according to Benesch, is a society - and a post-secondary educational institution - that is still deeply entrenched in monolingual and monocultural ideologies.

Harklau, et al. (1999) note in their introduction that the identities of Generation 1.5 students are often quite varied. Some students immigrated to the U.S. as young children, while others might have come later during the U.S. high school years. Others may have been born in the U.S. but have a home language - thus a first language - that is not English. Some students who immigrated might have had instruction in English as a foreign language while others may not. As Harklau, et al. attest, "the picture that emerges...is of a tremendously diverse student population along continua of language 
proficiency, language affiliation, and academic literacy backgrounds" (p. 5). The characteristics of these students cannot be described by one simple definitive sentence. As Roberge (2009) admits, "Generation 1.5," as used in the field of education, has the propensity to erase identity and obscure unique experiences. It also can be used as a tool, either purposefully or inadvertently, to marginalize students, setting them apart as different and in need of remediation. Thus the term reifies what Roberge calls "nativist normativity," or "the assumption that growing up as a monolingual native speaker is the norm" (p. 5).

Matsuda and Matsuda (2009) explain that the term Generation 1.5 is fraught with marginalization and imprecision. Resident ESL writers, what Matsuda and Matsuda call Generation 1.5 learners, have had their histories and unique characteristics erased by a term that has sometimes been used as a catch-all for non-native English speakers who are not international students. In being lumped together under one term, Generation 1.5 students lose their various identities. Matsuda and Matsuda also argue that the term itself is imprecise, as 1.5 would denote a place between a person belonging to a first generation (1.0) and a person belonging to a second generation (2.0). Ascribing a numerical value a precise value - is misleading in describing a group so nebulous and variable.

On the other hand, the term may have been adopted from immigration studies with the intent of complicating the traditional placement binary divide between college ESL (typically international students) and courses in basic writing (typically NESs with written literacy needs). This binary was reinforced by nativist normativity, in grouping all students for whom English was not a first language in opposition to NESs. Adding in a third "category," so to speak, not only extinguishes the binary but also complicates the 
definition of non-native speaker (Roberge, 2009). In addition, both volumes mentioned at the beginning of this section that focus on this "group" of students have presented arguments for and against the term Generation 1.5 and have decided to utilize it in the title of their texts. Roberge (2009) makes an excellent case for usage of the term "Generation 1.5" in his introduction, where he points out how the term has served operationally to bring about positive change in once-stagnant policies, program structures, and pedagogies.

Matsuda and Matsuda (2009), however, caution against the use of any term that would mask the individual characteristics of students. Rather, they urge teachers and researchers "to describe explicitly and multi-dimensionally each and every time" the student population that is being considered (p. 61). They assert that "the ESL or multilingual student population [including both resident and international students] is far more complex and diverse than a single, imprecise term can capture" (p. 61). Therefore, in this case study, the term "U.S.-educated multilingual student" will be used to describe my three student-participants. However, my description and discussion of any case study will use the terms operationalized by the field, including "resident language learner," "Generation 1.5 student," "long-term resident language leaner," or "U.S.-educated multilingual student."

\section{Cross-Cultural Considerations and Second Language Writing}

As shown in Chapter I, the students in community college writing classrooms are widely varied in cultural and background experiences; and as also previously explained, U.S.-educated multilingual students, too, are just as diverse and varied in background experiences. With such variation in cultural experiences and identities in the writing 
classroom, community college writing instructors need to be aware of differences without essentializing or stereotyping students or the features of those students' written texts.

Connor (2003) states that contrastive rhetoric "examines differences and similarities in writing across cultures" (p. 218). In the past, contrastive rhetoric has been critiqued for promoting or allowing for racist, colonialist, prescriptivist, and English-only policies and practices (Casanave, 2004; Connor, 2003; Connor, 2004; Kachru, 1999; Matsuda and Atkinson, 2008). Kubota and Lehner (2004) state that

Despite its unique cross-cultural focus on writing and its well-meaning effort to facilitate second language learning, contrastive rhetoric has tended to construct static, homogeneous, and apolitical images of the rhetorical patterns of various written languages. It has also implicitly reinforced an image of the superiority of English rhetoric and a deterministic view of second language (particularly English) learners as individuals who inevitably transfer rhetorical patterns of their L1 in L2 writing. (p. 9)

The theory of contrastive rhetoric has been viewed as problematic since Kaplan's 1966 article on the topic in which he illustrates rhetorical patterns of other languages in diagrams or "squiggles" (Matsuda and Atkinson, 2008). As Matsuda and Atkinson point out in their 2004 academic conversation on the theory of contrastive rhetoric (published in 2008), Kaplan's theory shows merit, in that it contends that rhetorical patterns exist different from the prototypical Western pattern that many English speakers may be accustomed to; however, like the term "Generation 1.5," "contrastive rhetoric" thus became problematic as various fields leapt to critique Kaplan's theory as othering and overly-simplistic.

Kubota and Lehner (2004) propose a new perspective on contrastive rhetoric, a critical contrastive rhetoric, which draws upon concepts such as postmodernism, 
poststructuralism, postcolonialism, and critical pedagogy from applied linguistics. The practical applications of these concepts are relevant to this case study in that putting critical contrastive rhetoric into practice, the framework "encourages teachers and students to critically reflect on classroom practices such as comparing and contrasting L1 and L2 rhetorical patterns and teaching/learning 'preferred' discourse patterns of the target language and to reevaluate how these practices might reinforce cultural binaries and assimiliation" (Kubota and Lehner, 2004, p. 9). Without this critical reflection upon classroom practices, teachers could inadvertently "reinforce a cultural deficit view in which certain groups are seen as innately deficient because of their cultural or linguistic background" (p. 15).

While theories on contrastive rhetoric (or intercultural rhetoric, or cross-cultural composition) have traditionally been criticized for essentializing second language writers, instilling prescriptivism with English rhetoric, and privileging the writing of NESs, Hyland (1996) suggests that a revised cross-cultural or intercultural rhetorical theory can "remind us to avoid stereotyping," as these theories show "how different writing styles can be the result of culturally learned preferences, helping us to recognize that student difficulties in writing may be due to the disjunction of the writer's and reader's view of what is needed in a text" (p. 49). This is where an awareness of cross-cultural composition can be of use to teachers of second language writers. Matsuda (2006) accuses writing programs of neglecting to prepare composition instructors for the responsibility of meeting the needs of second language writers in their classrooms. Composition studies should be moving toward a reconceptualization of composition as cross-cultural composition, as Matsuda points out that homogeneity in the composition 
classroom is "a myth" (2006). Identifying areas of difference in composition without inadvertently promoting an English-only ideal or essentializing writers should be a goal of all composition instructors. As Matsuda asserts, "To work effectively with the student population in the twenty-first century, all writing teachers need to reimagine the composition classroom as the multilingual space that it is, where the presence of language differences is the default" (p. 649). This latter point, echoed by the CCCC's Statement on Second Language Writing and Writers, is especially important in my case study, as the U.S.-educated student-participants move into an English 101 section taught by an instructor who has had no exposure to the field and theories of second language writing.

\section{Academic Literacies and Second Language Writing}

In recognizing that differences in discourse and composition are inherent in multilingual composition classrooms (as conceptualizing the composition classroom as multilingual is the goal), we also need to acknowledge that this heterogeneity also means that composition students will enter the classroom with various literacy backgrounds. Work focused on academic literacies has identified that literacy is multiple, that any conceptualization of "literacy" as a single, fixed practice is short-sighted (Barton, et al. 2000; Street, B. 1997, 2004; Street, B. V., 2001, 2005). Often, Street (2001) argues, we treat literacy as a set of "technical skills" to be acquired or mastered when the concept is actually much more complicated. Literacy "is not a single essential thing with predictable consequences for individual and social development," Street writes; "Instead, there are multiple literacies that vary with time and place and are embedded in specific cultural practices" (1997, p. 48). 
The importance of this framework to my study is in its impact on pedagogy in the multilingual composition classroom. As I have already shown, these classrooms are heterogeneous, populated by students with various background experiences. An understanding of literacy as "multiple, patterned by power relationships, purposeful, historically situated, and changing over time" (Barton, Hamilton, \& Ivanič, 2000, p. 2) can guide instructors in adopting pedagogical practices that are sensitive toward their specific class demographics. In Chapter VI, I will discuss pedagogical implications for writing instructors in which instructors take various literacy backgrounds in the classroom into account.

Viewing literacy as multiple allows us to discuss academic literacies as a type. As language users, students possess multiple literacies, being able to participate in various literacy events. Their literacy practices, however, may not be the same as the ones they may be asked to produce in academic contexts; their non-school literacies, which often include private literacy practices, may compete with schooled literacy practices, which are often considered examples of public literacies, possibly creating a conflict. Courage's 1993 study reports on two adult ESL students in a basic writing course in New York City. This course, as Courage remarks, was "designed 'to remedy academic deficiencies"” (p. 485). Courage illustrates how these two students pulled from their personal literacy practices or "customary uses of language" (p. 488) to construct texts that fit the purpose, audience-focus, and rhetorical pattern of the academic texts required in the composition course. While these two students often struggled to hit the appropriate academic registers of the assigned narrative and expository writing in the basic class, they both eventually succeed by building upon elements of their private literacy practices. Although my 
participants are not adults in a basic writing classroom, this study shows that using a multiple-literacies perspective in writing course design and instruction is beneficial, especially to second language students, in that those students can be encouraged to compare elements of their private literacies - those literacies they often practice - with those of the academic literacy tasks required of them in the composition classroom.

In concluding his discussion, Courage (1993) posits questions that instructors and students should ask themselves. First, instructors should investigate students' literacy practices that we may deem "private," or those that students practice outside of the composition classroom. In identifying and analyzing these literacy practices, we can encourage students to build upon them appropriately in order to add the necessary academic literacies to their toolbox, which then provides them with valuable cultural capital. Second, instructors should encourage students to ask themselves about their own literacy practices, or become self-ethnographers or their own language use: What nonschool literacies can students identify? What are their patterns of language use? Once students identify their own non-school literacies, instructors can guide them toward building upon those with academic literacies (Courage, 1993). A multiple literacies approach, then, with academic literacy as only one type, ascribes foundational value to whatever literacies students bring to the writing classroom, avoiding a deficit model of language use in which students with academic literacy needs are viewed as deficient.

The U.S.-educated multilingual students in my case study, since they attended some of their K-12 schooling in the U.S., have had experience completing academic tasks in English, yet I found that their academic writing presented some structural or rhetorical variations. For example, writing tasks in the English 101 course for one of my student- 
participants emphasized genre analysis in determining the rhetorical and structural features of the course's three main academic writing tasks. Such an approach to composition allows students to engage in social practices; as Hyland (2004) asserts, "The concept of genre enables teachers to look beyond content, composing processes, and textual forms to see writing as an attempt to communicate with readers - to better understand the ways that language patterns are used to accomplish coherent, purposeful prose" (p. 5). In other words, using a genre studies approach in a multilingual composition classroom enables students to see the L2 as a tool to accomplish communication and perform a social task. As explained later in the chapters in which I contextualize and analyze my data, this instructional model, and therefore these academic writing tasks, were slightly different than those in the academic ESL program from which the student-participants were transitioning.

Awareness of literacy as multiple and situated, specifically, is an important concept to this case study, in that multilingual students moving into a FYC classroom may or may not have academic literacies as part of their public literacy repertoire, and are therefore at risk of being viewed from a deficit perspective. As discussed earlier, a deficit perspective on language and literacy is one that teachers could inadvertently apply toward second-language writers if a multiple-literacy perspective is not kept in the foreground, as Kubota and Lehner (2004) attest. Therefore ESL instructors as well as FYC instructors who have an awareness and understanding of literacy as multiple can better equip and encourage these students to build upon the literacies they already possess. A review of literature on academic literacy as it pertains to writing needs of ELLs, specifically U.S.educated multilingual students, will be analyzed more in-depth later in this chapter. 
In discussing the multiple literacies of U.S.-educated multilingual students, terminology presents a certain dilemma. Throughout this study, I acknowledge that the student-participants - like all writers, ELLs and NESs alike - successfully utilize linguistic tools and literacy practices, some of which may overlap with the academic literacy practices expected in the U.S. classroom in English and some which may not. I speak about these practices using terminology such as "needs," "capabilities," or "competencies" that these students have not as deficits but as characteristics in academic writing that these students bring to the classroom that may differ from those "needs," "capabilities," or "competencies" brought by their native English-speaking or international student peers. Choosing terminology to describe which literacies are or are not part of a student's public or private literacy repertoire is a dilemma, as a deficit perspective could be perpetuated simply by one's choice of words to describe students. While this dilemma cannot and will not be solved in this case study, the dilemma must be acknowledged, due to the underlying powerful ideologies that may subvert non-native English speakers.

\section{Multimodal Composition and Second Language Writing}

Kress (2010) asserts that a multimodal text is one that is written utilizing multiple modes, modes other than just written script with letters that form words that have meaning. Other modes of composition, such as sound, visual form, color, etc., also carry meaning, depending on the reader of the text. These other modes of composition are what Murray (2009) calls "non-discursive" modes. Murray argues that the definition of language should be expanded to include not only discursive modes of composition - what we think of as word-based systems - but also non-discursive rhetoric, which he defines as 
"symbolized language...not limited to the chain-of-reasoning we require in discursive text” (p. 5).

In 2003, the National Council of Teachers of English (NCTE) recognized the impact of new media on composition studies and, ultimately, on composition pedagogy:

Today our students are living in a world that is increasingly nonprintcentric. New media such as the Internet, MP3 files, and video are transforming the communication experiences of young people outside of school. Young people are composing in nonprint media that can include any combination of visual art, motion (video and film), graphics, text, and sound -- all of which are frequently written and read in nonlinear fashion. We affirm, in our theory and practice of teaching English language arts, that reading and writing are ultimately different but inherently related aspects of the same process of meaning making. Why, then, would we treat the reading and writing of new media texts in any different manner? With multiple opportunities for student expression in the English language arts classroom, these nonprint media offer new realms for teachers of composition. (NCTE Position Statement: Resolution on Composing with Non-Print Media, 2003)

Just as the CCCC issued a resolution regarding second language writing and writers in the composition classroom, so, too, NCTE issued a resolution acknowledging new media as part of composition instruction and urging writing programs to integrate multimodal composition into the writing curriculum.

In a 2008 study, Shin and Cimasko analyzed the use of multiple modes of composition by writers in a university ESL FYC course. With this study, the researchers were hoping to discover how 14 ESL students would define and then employ multiple modes of composition in writing academic texts. The students were required to complete five writing assignments, the first three of which were print-based texts that the students posted to their respective websites. The fourth assignment invited but did not require students to employ multimedia in writing their essays. The fifth assignment, an 
argumentative text, required multimodal elements in that the students' arguments must be “fully realized web pages, hypermedia documents that could not be replicated in nondigital print" (Shin and Cimasko, p. 380). Before this fifth assignment was given, the instructor discussed with students how multiple modes of composition work together to form a unified argument. Students also had one-on-one conferences with the instructor as they began writing their texts. However, the instructor also provided sample texts for the students to analyze, employing a genre studies approach to the project. The researchers found that, with the fifth and final project - the one requiring non-discursive composition to create an argument - two remained fully discursive except for hyperlinked bibliographies. Only one of the fourteen students consistently employed multiple modes of composition, or non-discursive composition, throughout all drafts of his fifth project.

The researchers report that the instructor's written reflection indicated that the students relied more on linguistic design than they did on multimodal composition, even when required to compose a text using non-linguistic elements. Student reflections also point toward students placing priority on word-based language for composing as their research and Internet experience focused on research methods rather than on composition tools. The students who employed multimodality in composition did so primarily through visual rhetoric, using still images to either show events in a particular context or to describe the author's emotional experience regarding the topic. Only one project employed the use of audio; the researchers surmise that students' hesitation to use audio as part of their composition is an example of how "audio design represents a strong departure from, and thus a potential breach of, traditional academic discourse norms" (Shin and Cimasko, p. 385). Even when students incorporated multiple meaning-making 
modes of composition in the final project, they rarely integrated those multiple modes with traditional print-based texts, using hyperlinks primarily in their bibliographies, despite the instructor spending class time exposing students to how and for what purposes hyperlinks can be utilized within the multimodal texts themselves.

The researchers remarked that all of this data "point to views of multimodal academic composition defined by traditional views of academic discourse in which the linguistic mode is dominant in all instances, rather than existing as an important but not automatically determined mode" (Shin and Cimasko, p. 389; Shin's and Cimasko's italics). In other words, students viewed academic discourse as primarily discursive. The results of Shin's and Cimasko's study are important to my own case study in that one of my student-participant's English 101 instructor required that the students research a particular new media genre and then create a composition in that genre. Such an academic literacy task was not required in the academic ESL courses the studentparticipant had been enrolled in, and so this task was a new type of composition for the student, as I will detail in Chapters IV and V.

\section{Part II: Review of Literature on Academic Literacy Needs and Preparedness of U.S.-Educated Multilingual Students}

\section{Introduction}

Determining academic literacy needs for U.S.-educated multilingual students is important in developing appropriate academic ESL preparatory programs, determining placement of students, and in training FYC instructors how best to guide these students in their composition classrooms. One study (Matsuda, Saenkhum, and Accardi, 2013) views instructor reports as a viable source of information on the literacy needs of non-native 
English speakers. Another study (Singhal, 2004) attempts to define what academic English actually is, and then provides three components to guide learning outcomes for U.S.-educated multilingual students in FYC, while Riazantseva's (2012) case study also attempts to define what academic strengths are required for FYC success as well as the challenges U.S.-educated multilingual students might encounter in a university.

Some research has been conducted on the academic literacy needs of U.S.educated multilingual students specifically; for example, one survey study attempts to locate these needs in relation to those of NESs and international students (Silva, 1997). Focusing also on U.S.-educated multilingual students' literacy needs, Blanton (2005), Bloch (2007), Jeffries and Yi (2008), and Schleppegrell (1996) make connections between U.S.-educated multilingual students as "ear-learners" (Reid, 2011) and the writing they produce that might be influenced by their strong oral literacy. Blanton (2005) discusses how these students' L1 literacies are often "arrested" at the time of immigration, and as a result, these students rely more on their oral English capabilities when writing than native English speakers do. Bloch (2007) presents a case study in which a U.S.-educated multilingual student improved his academic writing by blogging; blogging, as an informal writing task, provided a springboard from the student's "private" literacy to an academic "public" one (See Courage, 2003). And Schleppegrell (1996) analyzes speechlike writing of U.S.-educated multilingual students, causing these students to inappropriately use the conjunction "because" in their academic writing tasks.

\section{Differences Between the Writing of NESs and ELLs}

Silva's (1997) report on empirical studies examining differences in writing between ESL undergraduates and NESs groups all ELLs into the category of ESL; he 
does not distinguish between international students and U.S.-educated multilingual students. Despite the absence of delineation between these two groups of ESL students, Silva's study is helpful in that it provides a good foundation in second language writing (SLW) research and in beginning to understand the needs of U.S.-educated multilingual students.

Silva (1997) attests that the majority of the studies he examined concluded that the writing of ESL undergraduates was "less effective" than writing by their NES peers (1997, p. 210). ESL writers' compositions were shorter and evidenced more errors in general than NESs. Empirical studies measuring complexity of texts generally concluded that ESL writers, unlike NES students, often used circular or indirect patterns of discourse rather than linear, direct patterns. The texts of ESL writers were also found to be less cohesive, employing a much lesser degree of support and detail for posited claims than the texts of NESs. And, when following a process approach to writing, ESL students were reported to spend less time in the recursive planning and reviewing stages than NESs.

Silva concludes his literature review with a general statement:

This body of research suggests that in general the ESL subjects' writing was distinct from and often simpler and less effective, in the eyes of NES judges, than their NES peers'. The ESL writers' composing processes seemed constrained in some salient and important ways. Compared with NES subjects, they planned and reread their writing less, wrote with more difficulty because of a lack of lexical resources, and exhibited less ability to revise intuitively by ear. (p. 215)

Silva's conclusion, then, is that the writing of ELLs in general differs from that of their NES peers in process, effectiveness, cohesion, and development. 
Adding to the discussion of whether or not second language writers face more and/or different academic literacy challenges compared to their NES peers is a survey of writing teachers on the presence and needs of second language writers in their classrooms. Basing their rationale on the CCCC's Statement on Second Language Writing and Writers (see Chapter I) as well as previous research focusing on L2 students in FYC classrooms, Matsuda, et al.'s 2013 study seeks to determine whether FYC instructors at a large university with a large international student population noticed ESL writers in their classrooms; how these teachers identify these ESL students; what the teachers believe the needs are of ESL students in FYC classrooms; how these instructors work with ESL students in their classrooms; and how these teachers think they could be better prepared to help meet the needs of ESL students in their FYC classrooms.

The results of the online survey indicated that the majority of teachers in the study recognize that multilingual writers are in their classrooms. Nineteen of the 74 teachers participating in the survey expressed concern about multilingual writers in their FYC sections and indicated strategies that they had employed to help those writers meet their academic literacy needs. However, 7 teachers "reported that they did not make any special provisions to address the unique needs of L2 writers" (p. 82). A large number of teachers expressed a need for additional preparation and training in meeting the needs of multilingual students as well as instructional materials appropriate for both L1 and L2 students.

The impact of this study is, admittedly, specific to the institution in Matsuda, et al.'s study; however, implications upon this institution included the development of a new position at the university to oversee L2 writing issues within the writing program. 
While this study took place in a four-year institution and included all multilingual students and not just U.S.-educated multilingual students, this study is important to my own case study because it reiterates two conclusions already examined in the literature. First, this study underscores the idea that the writing of multilingual students, according to the perceptions of FYC instructors, varies from that of their NES peers. And, secondly, this study demonstrates a need for specialized awareness and training on behalf of the instructors involved.

\section{Academic Literacy Needs of NNESs}

One way in which multilingual students' writing differs from that of their NES peers is in academic contexts. Singhal (2004) reported on the literacy needs of Generation 1.5 students compared with NESs by detailing what academic literacy strengths students in college ${ }^{2}$ composition classrooms should have in their repertoire. Singhal asserts that academic English "is not a static entity, but rather evolves with technological advances and research discoveries within each discipline or area of study" (p. 3) that "requires the mastery of academic literacy” (p. 4). Literacy proficiency requires speaking, reading, writing, and listening skills, and so academic literacy requires that students be able "to communicate in a range of academic situations," depending also on the registers of specific academic disciplines (p. 4).

Singhal (2004) divides academic English into three components. The first component - linguistic - encompasses students' knowledge of lexical, morphological, and phonological elements of language. This linguistic component also requires students

${ }^{2}$ Singhal does not distinguish in this paper between students in a four-year institution and a two-year institution. 
to possess and appropriately use academic vocabulary, to appropriately consider context, audience, and purpose in rhetorical situations, and to use "discourse devices, transitions and transitional expressions" to "create logical relationships" in writing that will lead to cohesive texts (p. 4). The second component of academic English, according to Singhal is cognitive, which encompasses the scope of Bloom's Taxonomy. Singhal claims that academic English requires students to be able to use higher-order cognitive skills in speaking, writing, listening, and speaking. Critical thinking is a necessary part of academic English, Singhal reports, and involves

numerous types of activities such as determining the credibility of evidence, reading between the lines and inferring information, determining how claims and evidence in readings can be accounted for in different ways, analyzing issues and information to decide what constitutes valid and logical evidence and arguments, and recognizing relevant information and research and synthesizing and arranging it effectively to create a cohesive and coherent whole" (p. 6)

The third component of academic English, according to Singhal is a language discovery component, which includes analyzing and synthesizing information from secondary sources, avoiding plagiarism and citing secondary sources appropriately, and having metalinguistic knowledge to ascertain how written language is used to accomplish a task. Singhal argues that students who succeed in academic contexts have strong communicative skills in reading, writing, speaking and listening, highly-developed critical thinking skills, and strong research skills. Writing instructors should focus on “developing competent writers and critical thinkers who understand that academic writing is multifaceted and involves considerable time and effort" (p. 10). 
Singhal's report is not a case study, nor does she discuss second language writers in depth. But she does an appropriate job of outlining what academic literacy is, including its fluidity and unstable nature, and the types of literacy practices that comprise academic literacy. Such an outline can be a basis toward understanding the practices and mastery expected of college level writers in order to gauge the needs of second language writers as they transition into academic writing contexts.

\section{Academic Literacy Needs of U.S.-Educated Multilingual Students, Specifically}

Struck by the similarities in background and literacy needs between two of her students in an intensive ESL program, Blanton (2005) conducted a teacher-researcher case study in a four-year university to ascertain how U.S.-educated multilingual students can be better served in the college environment. Absent from literature on second language writing, Blanton claims, is a focus on "L2 adult students with limited proficiency in writing their first language" (p. 110). Two of her students, Meseret and Tran, immigrated to the U.S. as teenagers. At the time of immigration, Blanton claims, literacy development for the two students ceased. They were inadvertently caught between their first language and their second language, with still-underdeveloped academic literacy in their L1 and very low literacy of any kind in English. Blanton rues a college composition program that would lump U.S.-educated multilingual students in with remedial L1 writers or, just as unfortunately, with international students, who have highly developed L1 literacy and are rapidly developing their L2 speaking, listening, reading, and writing capabilities.

Foreshadowing what Reid (2011) would later say about U.S.-educated multilingual students being “ear-learners,” Blanton (2005) distinguishes U.S.-educated 
multilingual students from both L1 writers needing remedial classes and from international students, noting that, in the literature, "largely invisible are these immigrant L2 students, whose written English proficiency lags far behind their spoken fluency, but whose L2 writing, however deficient it is considered to be, may actually be more developed than their L1 writing" (p. 110). Blanton examines literature on literacy development in young children in order to arrive at a conclusion with suggestions as to how to help U.S.-educated multilingual learners springboard from their strong oral English literacy to written English literacy. Literacy immersion - placing students in a textually rich environment - can help U.S.-educated students jump-start literacy learning that may have stalled at the point of transition or immigration. Using literacy tasks to achieve a goal, and making those tasks based on oral literacy first in order to build up written literacy, is a good practice in teaching composition to U.S.-educated multilingual students (p. 117; see also Courage's 1993 discussion of utilizing students' private literacies to ground emerging academic literacies, summarized earlier). She concludes her study by explaining that not all U.S.-educated multilingual students have the same literacy needs as the two in her study; rather, her message is that instructors should understand that these students - unlike native English speakers and international students - can have educational backgrounds in which their literacy development in both the L1 and L2 is suspended. Recognizing this, second language instructors and composition instructors can help restart literacy education by immersing students in programs that are textually rich and that use the students' prior literacy knowledge as a springboard for future literacy development. 
Riazantseva's (2012) study explains how three Generation 1.5 students succeeded in academic writing tasks at the college level, despite their academic literacy challenges. Riazantseva's study consisted of three Generation 1.5 students who had immigrated to the U.S. from Russia as teenagers. They were fluent speakers of Russian, and they also had Cum Laude academic standing (3.5 GPA). Through conducting interviews with and analyzing the written academic papers and self-reflections of these three students, the researchers hoped to answer the following questions:

- What English academic writing skills do three successful Russianspeaking Generation 1.5 college students have, and could these students' success in college be attributed to their (strong) academic writing skills?

- If it could, how did these students develop their academic writing skills in English? If it could not, how did these students succeed in college without strong academic writing skills in English? (p. 186)

The results of this study reveal complex findings. On one hand, the instructor feedback on the three students' texts indicates that the students often copied almost verbatim source texts in composing papers. Riazantseva (2012) acknowledges that this has been discussed in the literature as a serious offense of academic dishonesty, but she also cites Pecorari's 2008 study that concluded that copying is perhaps a necessary step in the L2 writing process. The findings also indicate that all three students were highly motivated. All had families highly involved and interested in academics and had high expectations for themselves as students. They perceived themselves as some of the brightest students at the college, according to Riazantseva. When asked about the instructors' critical comments on their writing, the students were either dismissive or quick to point out how they had been misunderstood or how the teacher was inflexible and lacking in training in dealing with non-native writing: "They disagreed with most of 
the comments insinuating that the instructors did not have enough knowledge to see their writing beyond the surface errors and major reason why they were planning to switch to 'better schools' for their graduate work" (Riazantseva, p. 190).

On the other hand, even though Riazantseva (2012) acknowledges that these students could do college level work in English, she admits the fact that the students often resorted to copying and the fact that their writing performance was inconsistent as well as "at times simply poor" (p. 189). These two issues - plagiarism and often sub-par writing relative to their NES peers - conflicted with the positive assessment provided by the instructors. Riazantseva concludes that these students were yet still considered highly successful for a number of reasons. First, all three students had extraordinary oral communication skills. They participated regularly in leading class discussion and in daily participation, and they were highly engaged during class. Second, the students were "meta-aware" of their strengths and of their weaknesses, and so they participated in such a way as to make the most of their strengths to hide their weaknesses. The students capitalized on their strong oral English performance and downplayed their weaker competencies in writing in English. Finally, all three students were part of families who instilled a strong belief in education and literacy in their children. As Riazantseva explains, these students had the cultural capital to continue on with their studies in English, because they valued the literacy education they were receiving. This study is relevant to my current case study in that it demonstrates that multilingual students do not necessarily need to be extremely proficient in all areas of the target language in order to succeed. This study also shows how students can adequately hide behind oral literacy strengths with their academic literacy needs. 
Another study showing the strong oral English capacity of U.S.-educated multilingual writer in comparison with their academic literacy needs is that by Jeffries and Yi (2008). Jeffries' and Yi's teacher-researcher case study examined the connection between oral and academic written English strengths and needs of one U.S.-educated multilingual student, Mary, in a college ESL composition class at a four-year university in which Jeffries served as the instructor. Of the thirteen students in the class, Mary was the only U.S.-educated multilingual student, having immigrated to the U.S. from Germany at the age of 16 . After spending two years in the U.S, mostly in mainstreamed high school classes, due to her coursework in learning English during her years in school in Germany, Mary entered the university composition course for non-native English speakers.

The authors of the case study reviewed all of Mary's written assignments as well as transcripts of her oral presentations for the course, comparing the written discourse with the oral discourse. The researchers had two questions they were seeking to answer. First, they wanted to know the relationship between a U.S.-educated multilingual student's spoken and written texts. Second, they wanted to know if explicit awareness of and instruction in modifying "speechlike writing" was effective. They found that Mary used colloquial speech, such as "totally" and "like" in her academic writing as well as her oral presentations. While the oral presentations for the class were intended to be "academic" in register, the instructor required the students to rely on notes rather than a written speech; therefore, it was expected that the students' ad libbed commentary during their presentations would often veer into a more informal register. While an informal register was accepted for the oral presentations, the written assignments were expected to 
be polished and to use a more formal, academic register. Mary's written texts, though, resembled her oral presentations in language use. The authors also found that Mary's written and oral presentations lacked explicitness; often, Mary would not make connections for her audience, nor would she support her claims with adequate and appropriate evidence, often requiring her audience to fill in rhetorical gaps rather than explicitly stating her supporting evidence.

The second finding of the case study answers the authors' second research question, which is how effective explicit instruction is in reducing "speechlike" academic writing. To reach a conclusion, the researchers (one of whom was the instructor) kept a record of interaction and points of discussion between herself and Mary regarding Mary's speechlike writing. While they found evidence of Mary's awareness of her oral register invading her academic written texts, Mary was largely unsuccessful in appropriately revising her texts or effectively refraining from using speechlike writing in her academic assignments. The researchers concluded that Mary perhaps does not have the metalinguistic knowledge or the appropriate academic vocabulary to change her current practice.

A case study linking strong oral literacy with speechlike writing is that by Schleppegrell (1996). Schleppegrell's case study focused on showing "how ESL writers use strategies for conjunction that are typical of spoken English" (p. 272). To meet the goal of her study, Schleppegrell analyzed freshman ESL students' use of the conjunction "because" in responses to a writing prompt in which students were asked to respond to a reading passage by writing an essay. The ESL students in Schleppegrell's study were predominantly Asian U.S.-educated multilingual students. 
What Schleppegrell (1996) found is that the ESL students in her study operated the conjunction "because" in their written composition in ways that were more common in spoken discourse; in spoken discourse, the conjunction "because" is typically used "to provide knowledge-based linking, to add information in independent segments, and to link larger segments of discourse" (p. 280). To use "because" in written texts for these aims - aims more standard in spoken discourse - may appear to readers as "inappropriate or illogical," according to Schleppegrell (p. 280).

This study, while it focuses on the analysis of the usage of one word in both spoken and written registers, is important to my study, as my participants, as mentioned earlier, tend to apply their oral literacy tools to composing in written registers. Schleppegrell's (1996) study provides an example of how a teacher-researcher can analyze a particular word usage for clues of discourse marking in order to more effectively demonstrate to the student the differences between usage in spoken and written registers.

\section{Building Upon U.S.-Educated Multilingual Students' Private Literacies and Oral Competencies: Blogging}

Blogging in a second language writing classroom is one way in which writing instructors can help create a textually-rich curriculum that employs U.S.-educated multilingual students' prior literacy knowledge and oral competencies in order to build up academic literacy. Bloch (2007) conducted a case study of how one Generation 1.5 student's blogs led to increased academic literacy in the university composition classroom. Bloch argues that blogging is a low-cost, low-maintenance real-world literacy practice that can be incorporated into a second language writing curriculum. Because 
"blogging may foster a more oral and personal style of writing with which some students may feel more comfortable" (p. 132), blogging for U.S.-educated multilingual students is an ideal literacy task for the composition classroom, as the genre capitalizes on strong oral literacy applied to a writing task. Bloch's participant, Abdullah, immigrated to the U.S. from Somalia and completed three years of high school in the U.S. Like Meseret and Tran in Blanton's (2005) case study described previously, Abdullah's literacy education was interrupted, due to both the civil war in Somalia and his transition and adjustment to the U.S.

What Bloch (2007) concluded with this study is that Abdullah's rhetorical control improved with academic writing, but his grammatical control did not. However, as Bloch explains, since the goal of the blog as a literacy task was to serve as a bridge between students' strong oral literacy and their developing academic literacy, students were told to not concern themselves as much with grammatical conventions. Students were instructed to write blogs in an informal manner, and then they translated what they had written to a more academic genre, such as a research paper. By de-emphasizing grammar, students were then able to focus more on rhetorical conventions and argument, key concepts in successful academic writing. Additionally, the genre of the blog allowed students to enter their voices in conversations about real-world issues and topics, adding relevancy to the writing tasks as well as allowing students to practice engaging in critical thinking while writing (see Singhal, 2004, discussed earlier). 


\section{Part III: Literature Review on Placement Options and Concerns for U.S.-Educated Multilingual Students}

\section{Introduction}

Literature on second-language writing at the college level has focused on many areas of pedagogy, from appropriate placement of the various types of multilingual learners, to mainstreaming ELLs into first-year composition and content-area courses, to identifying literacy needs and providing support. While past research has focused on providing literacy support for second language writers (specifically for international students) in college ESL programs, recent research has begun to address how the literacy practices and needs of U.S.-educated multilingual students in post-secondary academic institutions both affect and are affected by course and program placement. To revisit what has been discussed previously in this chapter, the nebulous group of students known sometimes as Generation 1.5 or as U.S.-educated multilingual students is hard to define.

Di Gennaro (2008), Harklau, et al. (1999), Ortmeier-Hooper (2008), Roberge (2009), and others have attempted to arrive at some sort of definition for this group that allows for the immense variation in individual language backgrounds and immigration experiences. The most common denominator in these various definitions, according to di Gennaro (2008), is that the U.S.-educated multilingual student most likely has completed secondary education in the United States. However, as di Gennaro rightly acknowledges, just how much education a U.S.-educated multilingual student has experienced in the U.S. varies within the demographic, creating blurred lines of acquired L2 literacy and differentiated literacy needs. 
Regardless of how these U.S.-educated multilingual students are formally defined, scholars generally agree upon two points: first, that some U.S.-educated multilingual students have backgrounds in learning English and experiencing culture in the U.S. that differ from the backgrounds and experiences of international students; and second, some U.S.-educated multilingual students have different literacy needs than international students or native-English speakers, who may fall into basic or remedial language instruction courses at the community college level (e.g., di Gennaro, 2008; Matsuda and Matsuda, 2009; Roberge, 2009). According to Reid (2011), U.S.-educated multilingual students, often unlike their international student peers, are "ear learners," having acquired English predominantly through listening and speaking. These learners' writing "displays the conversational, phonetic qualities of their 'ear-based' language learning, as well as the use of their self-developed language 'rules' that may, upon examination, prove to be overgeneralized or false" (p. 83). These written literacy needs in particular require a variety of ESL approaches in community colleges in order to appropriately support the variation language learners' backgrounds and needs. Di Gennaro, in discussing different literacy needs between international students and U.S.-educated multilingual students, suggests that an analysis of ESL students' "writing abilities" should fall along different continua, one for typical international ELLs and an overlapping one for U.S.-educated multilingual students (p. 71).

\section{Placing U.S.-Educated Multilingual Students, Specifically}

Research on U.S.-educated multilingual students in U.S. college classrooms is revealing a wide range of program models that target these students' various literacy needs. Holten (2009) examines, through a case study of her own institution (the 
University of California at Los Angeles), how best to place U.S.-educated multilingual students in university writing courses. Questions and concerns driving Holten's case study include how to assess and place U.S.-educated multilingual students; what pedagogical tools to utilize; how to identify and share with students the students' literacy needs while not discounting students' prior academic successes; and how to determine the instructional standards by which to measure student success. The overarching problem Holten and her colleagues recognized was that U.S.-educated multilingual students exhibited literacy needs with grammar and mechanics that suggested placement in traditional ESL courses; on the other hand, these students' bilingualism and cultural background, as well as their pre-college U.S. K-12 educational experience, suggested placement in mainstream first-year composition courses. Recognizing that neither option was appropriate for U.S.-educated multilingual students, Holten and her colleagues implemented a hybrid composition course for U.S.-educated multilingual students taught by a second language writing instructor but offered by the university's writing program. This course focused on supporting students' development of academic literacy through specific writing tasks based on academic texts; through participation in class discussions based on the academic readings; through targeted grammar correction based on each individual's needs; and through student-instructor conferences.

What Holten (2009) and her colleagues found after gathering data for five years on the U.S.-educated multilingual students who completed this hybrid FYC course is that such a hybrid program can provide appropriate placement. Through the case study, Holten found that she and her colleagues were much better able to identify who U.S.educated multilingual students actually are. They also found, through students' self- 
reports, that the students valued the instructors' individual attention during conferences and through writing assessment. Students also acknowledged the value of individualized targeting of grammatical problems in student writing, as well as the course's heavy workload, which mimicked that of the first-year composition course completed by their native English-speaking peers. This hybrid course case study provides an example of a successful first-year composition course targeted toward the specialized literacy needs of U.S.-educated multilingual students.

Often, programs specifically focused on U.S.-educated multilingual transitioning to first-year composition arise out of necessity and increasing numbers of the demographic in classrooms. Miele (2003) at a New Jersey community college conducted a case study on the Language Minority Crossover Student Project, which she says was a response to increasing numbers of U.S.-educated multilingual students enrolled at the college, whom the administrators termed "crossover students." The Language Minority Crossover Student Project, "a 2-year interdisciplinary campus-wide institutional and curriculum development initiative to support academic success" for U.S.-educated multilingual students was implemented and funded for three years (pp. 604-605). This interdisciplinary and interdepartmental project had three goals: to enhance testing and advisement for U.S.-educated multilingual students in order to ensure appropriate placement; to form the Crossover Program, a series of options for ESL students to ensure advancement and success; and to implement supplemental instruction for U.S.-educated multilingual students in the already-existing English Language Resource Center (a computerized language-learning service) on the campus. 
The Language Minority Crossover Student Project identified and placed U.S.educated multilingual students via an aggregate of testing and diagnostic measures (Miele, 2003). The administrators analyzed writing samples, placement scores, demographic information, and Compass/ESL test results to determine placement. Crossover instructional options included courses in which syllabi, student guides, and course materials were written and selected to reflect the learning objectives of the course, which targeted literacy needs of the students. At the conclusion of the funding period, the administrators of the program realized several project outcomes. First, they realized increased and more focused collaboration between the disciplinary areas on campus. Second, testing accuracy and placement were improved for U.S.-educated multilingual students. Third, logistical matters in computerized testing were improved. Fourth, curricular options more focused on the needs of U.S.-educate were implemented and refined. And, finally, curriculum and materials were adjusted to reflect the unique needs of U.S.-educated multilingual students. Miele (2003) also reports that the entire campus faculty, advisors, and support personnel - have increased their knowledge of the unique needs of U.S.-educated multilingual students at the college; as a result of the study, the campus intended to continue to plan and further accommodate U.S.-educated multilingual students on its campus.

However, if refined placement measures and advisement are not conducted reflectively, and appropriate curricular options are not implemented, placement of U.S.educated multilingual students into ESL programs can sometimes negatively affect advancement into first-year composition and later academic success. Salas, et al. (2011) explain how "widespread 2-year college placement policies concerning English 
remediation potentially locate and retain U.S.-educated Latino adolescents at the margins of higher education through well-intentioned yet deficit-driven postsecondary cultural practices" (p. 121). Reporting from a cultural historical perspective, these authors show how community colleges can further marginalize U.S.-educated multilingual students by placing those students into remedial tracks, tracks that present more hurdles for students than those present for native English speakers. Drawing on a narrative study Salas published in 2008 of Sweetwater Community College, the authors contend that community colleges "need to reconsider how they think about and respond to the students they are charged with educating" (Salas, et al., 2011, p. 123). Therefore, placement of U.S.-educated multilingual students into ESL programs at community colleges needs to be conducted with awareness of cultural historical representations of marginalized groups so as to avoid creating a program that serves more as a gatekeeper to credit-bearing community college courses than support.

In an attempt to avoid a model of marginalization and instead build upon the literacy strengths of U.S.-educated multilingual students enrolled at a four-year university, Murie and Fitzpatrick's (2009) case study illustrates a curriculum that pushes these students to build their academic literacy through extensive reading, writing, research, and critical thinking. The authors argue toward viewing U.S.-educated multilingual students through "a wider lens" that takes into account their "needs and strengths" as students with educational experience in the U.S. who also may be firstgeneration college students (p. 155). By asking themselves how they could avoid placing these students in a regular ESL classroom or in a mainstream first-year composition course that would require academic literacy experiences not yet acquired by these 
students, the authors evaluate the appropriateness of alternatives such as the Commanding English Program at the University of Minnesota. The authors describe this program as "a first year program...for multilingual students who have been in U.S. schools for 8 or fewer years and whose test scores indicate a need for 'ESL/academic' support" at the university (p. 156). When enrolled in this program, students complete four or five academic courses each semester, often taken within a cohort of students. Unlike the program illustrated in Holten's (2009) case study, the program described by Murie and Fitzpatrick is a full-year, cross-disciplinary program. Students are required to enroll in the program's college reading, writing, and oral communications courses (led by trained ESL faculty) and could choose special program electives from among Sociology, Art, Biology, and Anthropology, all for college credit and all instructed by faculty trained to support second-language students. While both studies identify common goals for academic competence for long-term language learners, such as meeting college-level expectations for reading, writing, and oral communication, Murie's and Fitzpatrick's study illustrates specific second-language writing learning objectives that second language students should meet in preparation for college courses:

- analyzing content, making meaning, developing a stance;

- writing from source material, knowing when and how to cite;

- developing a thesis and coherence, using the language of coherence;

- supporting main points with specific information and discussion;

- organizing ideas effectively;

- drafting, reviewing, and revising;

- using strategies for proofreading and editing;

- developing fluency in academic style. (p. 159)

What Murie and Fitzpatrick concluded with their case study is that such a program that provides students a credit-bearing option informed by ESL pedagogy geared toward their 
specific literacy needs is a preferable alternative for students over regular ESL-support courses or first-year composition and content-area courses. This study, like Holten (2009), illustrates an alternative first-year option and further informs my research with an exemplary list of learning objectives crucial to successful academic writing for U.S.educated multilingual students. And, while the studies I have discussed so far offer alternatives to ESL programs that are not offered currently at the community college I am researching, they do provide implementable ideas and strategies for revamping curricula to better support all ELLs.

The case studies illustrated thus far are programs that encourage U.S.-educated multilingual students to commit to longer and deeper writing tasks and more challenging reading and oral communication assignments than they might have experienced previous to their first year of college, therefore demanding a high level of investment from these students. Several scholars have expressed that U.S.-educated multilingual students are tenacious with college coursework and are also discriminating when it comes to how they perceive their cultural identities situated in classroom spaces. In a study comparing international ESL students, U.S.-educated multilingual students, and the community college L1/NES population as a whole, Patthey et al. (2009) found that, although U.S.educated multilingual students in the studied community college population had the most challenge of all three groups on academic writing tasks, their persistence in the community college space resulted in more transfer units to the state's four-year college system than those earned by L1/NES students or by L2/international students. The authors attribute this result not to superior training or curriculum but rather to the tenacity of this demographic (U.S.-educated multilingual students may have transferred more 
credits, but their grades in those transferred courses were lower than those in the other two groups, showing significant struggle in those courses). This study suggests that U.S.educated multilingual students "are using the community college system in precisely the way it was meant to be used, as an opportunity to complete college-preparatory coursework and then proceed with college-applicable coursework" (p. 145). Despite encountering challenges in community college coursework, these students persevere, moving on to the four-year school with more transfer credits than the general community college population in this study.

\section{First-Year Composition as Contact Zone}

Often, due to a lack of placement options or resources, community colleges place international ESL students and U.S.-educated multilingual students together in college courses, resulting in cultural "contact zones" (Pratt, 1991, p. 38). In a study on the results of mainstreaming students with different background experiences in the U.S. with their respective literacy strengths and challenges, Harklau (1999) found that U.S.-educated multilingual students who were placed in regular ESL classrooms alongside international students were often "far from satisfied with their ESL courses" (p. 112). Upon investigation of four long-term U.S. resident language minority students' experiences in first-year composition courses, Harklau found that, even though the FYC instructors were experienced and knowledgeable, emphasized writing in various genres, employed "sound pedagogical techniques such as dialogue journals, multiple drafting of writing assignments, portfolio assessment, peer editing, and utilizing computers in order to promote fluency and editing skills," the four case study students reported frustration (p. 112). Despite the fact that the teacher was knowledgeable and reflective of the ESL 
students in her classroom, the U.S.-educated multilingual students still felt "the sense of discomfit, perplexity, and frustration" due to the culturally polarizing effects of classroom literacy tasks. These students exhibited resistance through their behavior and their attitudes (p. 113), demonstrating that a hybrid international ESL student/U.S.educated multilingual student classroom can be a less-than-ideal space for U.S.-educated multilingual students if cultural and background variations are ignored.

Ignoring language learners' cultural and background variations in these contact zones can result in diminished student motivation. Harklau (1999) invokes Peirce's (1995) ideas regarding learner motivation in such contact zones, in which students develop writing skills through exploring their lived experiences and through "the exploration of culture and social identity by students" (Peirce, 1995 in Harklau, 1999, p. 125). Another scholar who utilizes lived experiences in motivating U.S.-educated language learners in the composition classroom is Johns (2009). Johns advocates building a syllabus focused on students drawing from prior knowledge and applying that knowledge to writing tasks that ask them to practice English literacy in a variety of genres. This variety mirrors the flexibility that rhetoric students will need to draw upon in content-area classrooms while enhancing learner motivation and retention.

\section{Curriculum Considerations Appropriate for U.S.-Educated Multilingual Students}

In order to ascertain just what types of writing tasks students might be asked to complete beyond the college ESL curriculum, Carroll and Dunkelblau (2011) conducted a survey of writing tasks required by content-area courses at community college in order to inform the college's ESL curriculum. The two authors taught a non-credit advancedlevel ESL writing course, which was part of the Basic Skills Department that served both 
ESL students and native English speakers. The authors wanted to know how well their curriculum matched with that of content-area course writing requirements. The survey questions focused on the types of writing assignments required, the frequency, length, minimum expectations, and required skills of those assignments, and how much - if any - additional assistance was offered to non-native English speakers.

The results reveal that students are asked to complete complicated writing tasks in content-area courses. Essays were the most commonly assigned writing task, followed by summaries and research papers. Expectations for structure and requirements for critical thinking of all of these assignments varied. Some instructors required multiple paragraphs, as in the case of essays. Others, especially for research papers, required multiple paragraphs that included an introduction, body, and conclusion. Critical thinking skills required for these assignments were sometimes simply summarizing and paraphrasing; however, more often than not, instructors reported expectations for students to employ analysis, synthesis, and evaluation strategies, which are higher-order thinking skills than summarizing and paraphrasing.

The authors concluded that "writing instructors should not shy away from introducing challenging assignments that require students to directly engage with a text," as the assignments in content-area courses appeared to be lengthy and challenging (Carroll and Dunkelblau, 2011, p. 278). The authors contend that typically, ESL teachers do not require students to directly interact with a text. Because "real" assignments in content-area courses at the community college in Carroll and Dunkelblau's study require much more analysis and synthesis with secondary texts, the authors concluded that their 
ESL writing course, too, should "teach students how to confidently engage with a text" (p. 279).

In augmenting their curriculum, Carroll and Dunkelblau (2011) proposed a curriculum that was theme-centered that would allow instructors to guide students progressively through higher-order thinking skills with reading and writing texts. The authors also call for collaboration between ESL instructors and content-area departments to stay abreast of the types of writing assignments students would be asked to complete as well as the expectations for those assignments. They suggest that "faculty in all disciplines...come to a deeper understanding of the educational needs of their non-native English-speaking students" (p. 279). Carroll and Dunkelblau's study is important to the present case study in that it shows the types of academic literacy tasks required in community college credit-bearing courses as well as the changes the ESL program implemented to bring its program in line with the types of academic writing tasks their students would be asked to do in the future. It also shows the necessity of interdisciplinary collaboration in the community college venue.

Like Carroll and Dunkelblau's (2011) study, but unlike studies that base curriculum and writing tasks around lived experiences (see Harklau, 1999, and Johns, 2009), Miller-Cochran's (2012) teacher-researcher case study illustrates a model that focuses on academic research and writing rather than on assignments based on lived experiences; her goal is to situate learners for writing tasks appropriate for other contentarea classrooms. This cross-cultural composition course was a first-year course in a community college. The course was comprised of both ELLs and NESs; ELLs had been offered this course based on placement exams such as the SAT, ACT, TOEFL and 
CELSA. While the course emphasized academic research and writing rather than personal explorations of students' linguistic and cultural backgrounds, the capstone research project focused on students' own literary and linguistic interests. Miller-Cochran grouped the students for collaborative work, such as peer reviews and small group discussions, in order to facilitate cross-cultural interaction among the students. While Miller-Cochran found benefits with such a model, she acknowledges several challenges. First, materials appropriate for both native-English speaking students and ELLs are difficult to find, due to the varying linguistic background and literacy needs. Second, students may be apprehensive about enrolling in such a course; native-English speakers may view ELLs as remedial learners, while ELLs may feel the need to measure up to their native-English speaking peers. Third, success for all the students is dependent upon instructors who are cross-trained - experienced in not only mainstream FYC courses but also in ESL courses. This point of cross-training instructors speaks directly to the "division of labor" between the college composition and ESL areas, in which collaboration between the two happens rarely, if at all (Matsuda, 1999).

Another teacher-researcher case study, one by Allison (2006), focuses on a community college in Gainesville, Georgia, as it attempts to identify specific literacy needs for its increasing number of ESL students, predominantly U.S.-educated multilingual students. Faculty at the community college in Gainesville began to notice that the U.S.-educated multilingual students were challenged in content-area courses, despite having successfully passed through the college's ESL classrooms and earned adequate Compass scores. Three things became apparent to the curriculum planners at this college: 
1. A discrepancy existed between students' perceptions of college instructors and the realities of those instructors,

2. A discrepancy existed between students' assumptions of course content and assessment at the college level and the realities of that content and assessment, and

3. A discrepancy existed between the kinds of information and amount of information and sources students were expected to handle and the realities of what they were prepared to handle. (p. 53)

With these discrepancies in mind, this case study reflects on the changes she made in her own instructional methods in order to fill these gaps. The result is Allison's remodeled ESL classroom for U.S.-educated multilingual students, which incorporates more cooperative learning activities, varied literacy practices (such as research and writing activities), and a conscientious cross-cultural approach, all while incorporating appropriate multi-modal technologies in the classroom in order to better prepare students for mainstream college coursework. While Allison's study does not mention how her students fared in transitioning to mainstream courses using these advanced literacy practices, her study does illustrate how teachers can become teacher-researchers, researching, reflecting, questioning, and ultimately designing a classroom curriculum that best suits their particular students' needs in order to preparing U.S.-educated multilingual students for mainstream content-area coursework.

\section{More Cross-Cultural Considerations}

The researchers I have cited thus far in this chapter have developed programs in colleges to serve ESL students in general and U.S.-educated multilingual students specifically, in accordance with the CCCC Statement on Second Language Writing and Writers. In this line of second language writing research, scholars have even begun to 
investigate how to prepare U.S.-educated multilingual students to pursue academics beyond the ESL programs. However, literature on U.S.-educated multilingual students transitioning to the mainstream classroom is sparse. Of the research that follows U.S.educated multilingual students into mainstream classrooms, a few studies analyze this transition, albeit through different lenses. Ortmeier-Hooper (2008), in a case-study following three U.S.-educated multilingual students through their transition to a mainstream FYC course, focuses on sociocultural considerations. Her research questions focused both on how U.S.-educated multilingual students are labeled and how those labels or categories affect how those students negotiate their identities as NNESs who are also quite acclimated as young adults in the U.S. In following these three students, she presents illustrations of students whose first language is not English and may have cultural and ethnic backgrounds unlike those of their English-speaking peers but who also are not international students. She concludes that second language learners in general and U.S.-educated multilingual students in particular must often negotiate their identities in mainstream classrooms due to literacy tasks in those classrooms. Ortmeier-Hooper thus calls upon instructors to constantly reflect on how ELLs are identified, placed, and instructed in mainstream and ESL classrooms.

Case, et al. (2013) conducted a case study of teacher feedback of four adult ESL instructors at a community college. These four instructors' students included a mix of U.S.-educated multilingual students (20), international students (20), and basic writers who were L1 speakers of English (7). The goal of the study was to ascertain whether teachers provide feedback on student writing that varies according to the "category" of the ESL student (either a U.S.-educated multilingual student, an international student, or 
a native English speaker). And, if the amount and type of feedback correlated to the "type" of ESL student, the researchers also wanted to find the reason behind the correlation.

What the researchers discovered is that, overwhelmingly, instructors in their study provided more feedback on all four features for U.S.-educated multilingual students than they did for international students or native English-speaking students. Native Englishspeaking students received the least amount of written feedback from instructors in all four categories. The feature of academic form or composition structure garnered the most feedback for all students.

While the quantitative data from instructor feedback exemplified an emphasis on responding to writing by U.S.-educated multilingual students, the qualitative interview data revealed that instructors did not consciously target this group of students with their feedback; rather, instructors asserted that they "responded to their students as individuals" rather than by type of ESL student. (Case, et al., 2013, p. 95). Instructors reported through the interview data that they considered who the students were, the demands on their time, and whether they were diligent and engaged in class. However, teachers also admitted to assumptions that international students had fewer demands on their time outside of class than U.S.-educated multilingual students and native English speakers did.

\section{Meeting the Literacy Needs of U.S.-Educated Multilingual Students in the Writing Center}

Thonus's (2003) study of tutor-student interactions and interview data at two U.S. university writing centers concludes that writing centers can be extremely valuable assets 
to U.S.-educated multilingual students. Thonus (2003) reaffirms that U.S.-educated multilingual students have been largely ignored by research on second language writing, which tends to focus on international students' writing, and research on L1 writing by NESs (2003, p. 17). Additionally, experience in U.S. K-12 schools, which often includes mainstreaming or miseducation of U.S.-educated multilingual students, leads to the obscured identity of these students, either by the educational institutions or by the students themselves, in an attempt to escape what they may view as an identity-erasing label of "ESL" (see also Roberge 2009, discussed earlier).

Drawing on differences between U.S.-educated multilingual writers and NESs as well as international student writers, Thonus (2003) suggests five principles, based on differing needs between populations, that university writing centers can employ to better serve this group of students. Thonus claims that the differences between U.S.-educated multilingual students and other college-level writers (NESs as well as international students) include different socioeconomic and sociocultural backgrounds and current issues; possible "othering" or miseducation during the K-12 school years in the U.S.; a propensity for learning easier with the ear than the eye, which leads to stronger oral literacy fluency than written fluency; and a better familiarization with composition approaches in English that emphasize process than ESL/EFL writers possess (18). Thonus' (2003) five principles for writing centers to employ with U.S.-educated multilingual writers are:

1. Teach students metalinguistic and sociopragmatic concepts. In other words, writing center tutors and instructors should ensure that writers are able to talk about how language is used (metalinguistic awareness) as well as how writing center tutorials are structured (defining the role of the tutee and the tutor). 
2. Acknowledge students' cultural and linguistic backgrounds with affirmation from the student rather than an assumption or prescription by the tutor or instructor.

3. Focus on rhetorical concerns with writing rather than just grammatical or sentence-level concerns.

4. Use explicit suggestions and directions rather than implicit ones that may leave the tutee/writer unsure of the advice.

5. Avoid assumptions of tutees' target-language knowledge. (22-23)

These suggestions, Thonus (2003) claims, can help writing center staff better serve the literacy needs of U.S.-educated multilingual writers. These writers, who may be reluctant to self-identify as ESL but still realize that they need writing assistance, may seek out the services of university writing centers. Thonus does not discuss how writing center staff should identify these writers if they do not self-identify; however, Thonus' principles could be employed with all students - L1 and L2 - who seek help at writing centers, as the principles are based on best practices for writing instruction pedagogy and can easily be applied to situations with all types of college-level writers. Additionally, while Thonus' study focuses solely on the arena of the writing center, these principles could easily be applied to an academic ESL program or FYC classroom (recall that Matsuda, 2006, claims that linguistic homogeneity in the composition classroom is a myth), as I will support in Chapter VI.

\section{Failure to Transition to First-Year Composition}

Sometimes, despite careful placement of students into ESL programs and providing appropriate support, students do not succeed and transition into FYC courses. Song's (2006) case study examines factors that may inhibit ESL students from transitioning from ESL classes to FYC classes. Song reported on instructors' and students' perceptions of factors involved in students failing ESL courses. This study 
provides important insight into factors contributing to student failure (or lack of success) in ESL classes and is pertinent to my case study as one of my student-participants did not pass the fourth level of the ESL program at Gridley Community College ${ }^{3}$.

What Song (2006) found is that instructor perceptions and student reports in interviews matched the difficulties students faced in passing the final ESL course. Song found factors (some of which have been already discussed in this review) including negative attitude, lack of motivation or investment, insufficient target-language use, and deficient first-language literacy, misplacement in ESL courses or programs, and lack of support for educational and personal needs. What Song (2006) also found, however, is that "instructors most frequently cited family and job responsibilities as significant factors contributing to their students' failure in the course" (p. 428).

This final point - the factor of family and job responsibilities - is an important one to my case study. Harklau, et al. make mention of this factor for U.S.-educated multilingual students in the Introduction to their 1999 text: "The financial status of immigrant families often leads students to assume heavy workloads off campus with negative effects on academic performance" (p. 5). Likewise, Roberge (2009) discusses the changed economic situation of immigrants since 1965: “...over the past four decades, technological changes, globalization, and the movement of manufacturing to offshore locations have eliminated many well-paying skilled industrial jobs in the U.S." that were traditionally filled by immigrants to the U.S. (p. 9). Roberge remarks that, as a result, the children of immigrants to the U.S. who do not have a strong educational background before they immigrate or attain one afterward face the possibility of downward economic

3 “Gridley Community College is a pseudonym. 
assimilation and have less social and economic capital than they would have if they had remained in their countries of birth. One student participant in my study failed to pass the final ESL course of the series at Gridley Community College, and my data point toward financial and family responsibilities factors in that failure, which I will discuss in Chapter IV.

\section{Summary of the Literature Review}

What the literature on U.S.-educated multilingual students demonstrates is that this population often has varying literacy needs. The literature also focuses on identifying and supporting these students through college ESL programs and other alternatives while emphasizing the infinite cultural considerations of this definition-defying demographic.

While studies have begun to consider U.S.-educated multilingual students in mainstream academic settings, few have taken into consideration how these students' writing meets academic literacy standards in mainstream composition and content-area courses beyond the ESL support program and how to better prepare students to meet those expectations. If one of the goals of ESL support services in the community college is to prepare these students for academic writing, then we need to observe these students and analyze their literacy practices and needs to determine just how well ESL support curricula have prepared them to employ their written literacy in mainstream academic courses. The remaining chapters outline my research and the analysis of my data. The next chapter, Chapter III, explains the case study methodology I employed in conducting my research, while Chapter IV contextualizes the data I have gathered. Chapter V more deeply contextualizes and analyzes that data: data on the educational institution, the instructors, and my research participants and their written texts and transcribed interviews. In 
Chapter VI, I provide discussion regarding how and to what extent my findings answer my research questions and suggested pedagogical implications for the specific academic program as well as similar programs. 
CHAPTER III

\section{RESEARCH METHODOLOGY}

\section{Introduction}

The purpose of this chapter is to explain and justify the methods used to conduct research for this case study, discuss the data that I collected, and elaborate on the ethical considerations I attended to while conducting my study. As detailed in Chapter II, many scholars who have explored tangential issues - U.S.-educated multilingual students in college courses, academic literacies, placement options, and curriculum, for example did so by conducting case study research. I employed an ethnographic framework in gathering data for this case study, as I was interested in how the participants transitioned over a period of time through the culture of the ESL program as well as the culture of the overarching institution of the community college the participants attend.

As mentioned, the primary research questions for this study focus on two areas: the participants and ESL programs at community colleges. My first research question involved the participants themselves and asked, "What are the experiences of U.S.educated multilingual students in mainstream composition courses in community colleges" To answer this question, I had to determine what types of writing tasks the students were asked to complete in both the ESL course and the FYC course; what the instructors' learning objectives were for these courses; and to what extent did the students meet these learning objectives. After analyzing the classroom contexts in which these 
students have been learning, as well as the assessment of their work in both the ESL and FYC course, I sought to answer my second overarching research question, which involved the ESL program itself: "How can ESL programs better prepare U.S.-educated multilingual students?" To answer this question, I needed to explore the local context between the ESL program and the FYC curriculum including what types of writing tasks were required of students in the FYC course that were not part of the ESL program curriculum, how those writing tasks were presented to the students, and how the students proceeded in completing those writing tasks. My hope is that in analyzing these areas, I might provide suggestions for curricular augmentation for programs similar to the ESL program at Gridley Community College.

In this chapter, I will provide a short explanation of my position as a researcher in this academic culture; a brief rationale for the study; my research design and justification; the data sources; my experiences in the field; and my analysis.

\section{Researcher's Positionality}

The origins of this study have their roots in my experience as a classroom tutor (teacher's aide) in a community college ESL class. This class, as I will explain in detail in the next chapter, is the final course ESL students at this community college complete before moving on to FYC and mainstreamed content-area courses. My responsibilities, in general, were to provide support to the classroom instructor. Sometimes this meant I would simply sit in the back of the room and observe, watching for signs that a student needed assistance with a classroom task, such as taking notes, finding the correct page, or logging on to a computer. At other times, my responsibilities involved paperwork tasks, such as copying and stapling course materials, grading formative assignments, or taking 
attendance. Especially while students were working individually or collaboratively, I was expected to keenly observe student engagement, making sure that students were on task and making progress toward meeting the objectives of the specific lesson. As I hold an undergraduate degree in English Education and served formerly as a high school English teacher, my supervising instructor gave me extensive freedom to work closely with the students.

During the first few weeks of serving as a teacher's aide in this classroom, I recognized that three students were not quite like the others in their speech and preparedness to approach academic tasks. These three students, I soon learned, were U.S.-educated multilingual students ${ }^{4}$. I will provide detailed information about these students and their backgrounds in the following chapters. As I continued to serve in this classroom, I began thinking about concepts that would eventually become my research questions: How well will these students transition into English 101? How successfully will they complete academic writing tasks in English 101? How well is this ESL curriculum preparing these students? Pondering these questions eventually led to the development of the research questions I'm attempting to answer.

\section{Rationale}

The more I thought about my developing research questions, the more I searched for literature that would help me understand and answer my questions. As I stated and demonstrated in Chapters I and II, scholarship on U.S.-educated multilingual students

4 These three U.S-educated multilingual students were the only three in the program at the time who were one course away from moving on to English 101; therefore, participant selection was not dictated by anything other than the criteria, that the students be U.S.-educated multilingual students in the final course of an ESL program at a community college who planned to enroll in English 101 for the next term. 
transitioning to FYC and other mainstreamed courses is limited. I also began informally observing these three students in the instructional environment of this ESL class. What I informally gathered is that these students' written English literacy skills were not as advanced as their oral English literacy skills. In an attempt to explore this idea further, I began my own case study to determine if the literacy tasks the U.S.-educated multilingual students were completing in the ESL course were preparing them to complete the writing tasks required in the FYC courses at Gridley Community College.

My assumptions in implementing this case study after observing these students for just a few weeks were limited; I did not yet know enough about these students or their written English literacy needs or strengths to make a hypothesis as to how they would perform in mainstreamed credit-bearing composition classes, such as English 101. As the semester progressed, my assumptions became more clarified; I had misgivings about one student's potential of success, for good reason and ones that I will address in Chapter IV. Another student I surmised would transition successfully to English 101 and pass the course and move on to other credit-bearing mainstreamed courses. The third student I predicted would move into English 101 and then be hit with the hard realities of just what was required of college-level writing. These mixed assumptions further underscore the heterogeneous make-up the U.S.-educated multilingual student population. I had already read a wide range of scholarship regarding U.S.-educated multilingual students and their academic literacy challenges as well as what types of literacy strengths are required for college-level writing tasks. In planning my case study, I wanted to discern the "whats:" What was going on in the ESL program? What would happen in the English 101 course? What would these students be successful at? What would challenge them? What 
challenges are unique to U.S.-educated multilingual students? And, finally, What could the ESL program do to better prepare these students? Behind all of these "what" questions were "why" questions, seeking for explanations and reasonings. With these questions in mind, I began planning my study.

\section{Research Design}

Denzin and Lincoln (2000) acknowledge that a basic definition of "qualitative research" is that it is

a situated activity that locates the observer in the world. It consists of a set of interpretive, material practices that make the world visible.... qualitative researchers study things in their natural settings, attempting to make sense of, or to interpret, phenomena in terms of the meanings people bring to them" (p. 3).

As I began planning my research, I realized that I wanted to make sense of how these U.S.-educated multilingual students would perform in a credit-bearing composition course such as English 101. I was still searching for scholarly material on the topic of U.S.-educated multilingual students in academic ESL programs and in FYC. What I found is that most of the research done prior to mine used a case study approach utilizing ethnographic tools of data collection. My qualitative study, then, developed into a case study involving fieldwork techniques such as analysis of field notes and informal observation of the students in the ESL class; semi-structured interviews; analysis of artifacts, such as syllabi, assignment sheets, and student writing; analysis of this data for emergent themes; coding of that thematic data; and analysis of the coded data within its context in order to answer the research questions and to provide pedagogical implications. 
I conducted this study within a constructivist paradigm of research, based on my own assumptions as a researcher. Researchers operating within such a paradigm subscribe to a worldview "in which universal, absolute realities are unknowable, and the objects of inquiry are individual perspectives or constructions of reality" (Hatch, 2002, p. 15). Such a research framework acknowledges that researchers cannot be completely objective, that we bring our own assumptions, knowledge, and experiences in analyzing data: "From this perspective, it is impossible and undesirable for researchers to be distant and objective" (Hatch, 2002, p.15). Additionally, a constructivist paradigm of research requires methods that allow the researcher to "see" the case being studied in its natural environment (Hatch, 2002); this perspective allows the researcher to attempt to construct "reality" as known to the participants. Finally, the rich narrative and contextual detail provided by such a research framework assists the researcher in constructing knowledge as close to the truth (as it is known to the participant) as possible.

Duff (2008) contends that definitions of "case study" abound in works on qualitative research methodology. Recurring themes of a case study, regardless of content area or discipline, include concepts of "boundedness or singularity, in-depth study, multiple perspectives or triangulation, particularity, contextualization, and interpretation" (p. 23). Additionally, Wolcott (2009) defines "case study" as a genre rather than as a method; in designing a tree graphic on which he placed numerous qualitative research strategies, he

had trouble finding a suitable place for case study on the tree. My problem was not that 'case study' did not fit anywhere but that it seemed to fit everywhere. I pondered that perhaps case study is better suited if it, like all other ways of organizing data, is regarded as a genre for reporting than as a strategy for conducting research. (p. 85, Wolcott's italics) 
Wolcott's definition is an appropriate description for the present case study, as my position as a researcher is more to report than to conduct. In the role of reporter, I attempted to "make sense" (as Denzin and Lincoln put it, quoted earlier) of what happened in the field by utilizing appropriate lenses or theoretical frameworks rather than conducting, or directing, the action in the field. The written data samples I analyzed, the interview responses I received, and the observations I recorded all originated with my participants. My field was bounded, which echoes Duff's description of case study research, in that the parameters of my observation and analysis involved one specific community college site and a small group of participants; additionally, instead of focusing on all four components of the Academic English Language Program (reading, writing, listening, speaking), I chose just one facet - writing - on which to focus. While the literacy practice of academic writing is, indeed, intricately interwoven with reading, listening, and speaking, writing served as a foreground for this study, one that we must acknowledge affects and is affected by the other three components or literacy practices. Additionally, Stake (2000) succinctly summarizes the main activities of a case study researcher, and therefore, the activities in which I engaged in the present study. These activities include

1. Bounding the case, conceptualizing the object of study;

2. Selecting phenomena, themes, or issues - that is, the research questions - to emphasize;

3. Seeking patterns of data to develop the issues;

4. Triangulating key observations and bases for interpretation;

5. Selecting alternative interpretations to pursue;

6. Developing assertions or generalizations about the case. (p. 448) 
Again, this case study is bounded, in that I chose a particular population or demographic as a specific learning institution to study. It is in-depth, in that I gathered as much contextual evidence as I could through my research strategies. I have incorporated multiple perspectives with the inclusion of interviews of students, instructors, and directors. The particular unit of analysis upon which I am focusing is the nature of the way the students complete academic writing tasks in their L2s; specifically, I want to measure how successfully these students transition to English 101 and meet the learning objectives of that course. I have included many contextualization details in Chapter IV, and in Chapter V, I have included my interpretation. These elements of a case study genre all collaborate to comprise the method of reporting my research findings and answers to my research questions.

The framework of this case study did not remain as it began. Starting with what Stake (2000) calls a "collective case study" (p. 437), I initially planned to follow all three U.S.-educated multilingual students from their ESL course to their respective English 101 sections. A collective case study Stake defines as a reporting genre in which "a researcher may jointly study a number of cases in order to investigate a phenomenon, population, or general condition" (p. 437). This collective case became more of what Stake calls an “instrumental case study," as two participants did not advance through English 101, for reasons I delve into in Chapter IV, leaving only one participant. In an instrumental case, "the case still is looked at in depth, its contexts scrutinized, its ordinary activities detailed, but all because this helps the researcher to pursue the external interest" (p. 437). My external interest in this study is to ascertain, or to at least approach an understanding, of, how best to prepare U.S.-educated multilingual students for academic writing tasks. 
According to Duff (2008), case study research is not without perceived benefits and limitations. Within the domain of qualitative research, Duff contends that case studies, "when done well...have a high degree of completeness, depth of analysis, and readability" (p. 43). A very thorough analysis that often stems from a case study is one advantage; this "thick description" (Duff, 2008, p. 43) presents more perspectives and origins of data than available from other types of study. As Geertz (1973) states, ...ethnography is thick description. What the ethnographer is in fact faced with - except when (as, of course, he must do) he is pursuing the more automatized routines of data collection - is a multiplicity of complex conceptual structures, many of them superimposed upon or knotted into one another, which are at once strange, irregular, and inexplicit, and which he must contrive somehow first to grasp and then to render. (p. 10)

Any descriptions that we as researchers present, according to Geertz, are "fictions" that we have created based on our interpretation of what we have observed, as we are observing the culture and context of our participants through our own lens (p. 15). In order to as accurately as possible create these interpretations, however, we must gather as much background information as possible about that which we are describing:

In finished anthropological writings ... this fact - that what we call our data are really our own constructions of other people's constructions of what they and their compatriots are up to - is obscured because most of what we need to comprehend a particular event, ritual, custom, idea, or whatever is insinuated as background information before the thing itself is directly examined. (Geertz, 9)

Interpretation involves consideration of as much information - or thick description - as possible in order to as accurately as possible make fine conceptual distinctions (Geertz's uses the example of distinguishing between an eye twitch and an intentional blink). Employing a thick description in case study research allows for a complete story. 
Because so much information is presented, however, case study reporting often can open up new knowledge gaps, according to Duff (2008, p. 44); in striving to answer research questions, researchers may find themselves with additional questions rather than answers. Case study also allows for reporting of "unique or atypical" cases; cases that might be considered outliers in quantitative research or other qualitative genres can be examined in depth through a case study to examine just what characteristics the focus of the study possesses that deems it atypical (p. 45). Additionally, case study, since it usually involves one case or very few cases, can more easily be formatted as a longitudinal study in which change over time can be observed; studies involving many participants or variables often can only feasibly be studied for short periods of time.

Duff (2008) also notes some commonly perceived disadvantages of case study research. Detractors claim that the case study's weaknesses include an inability to generalize results to the larger population in which the case belongs; studying and reporting on abnormal or atypical cases and purporting them as normal; the large amount of space necessitated in reports by thick descriptions and triangulation of research strategies; a lack of objectivity; a lack of a grounding theory or framework for guiding the study; attrition of participants, especially in longitudinal studies; inappropriate use of statistics; and ethical considerations, as case studies involve extensive contexualization of participants that must be kept confidential. Duff goes on to explain that despite the fact that these possible detractions are numerous, case study research is still a valuable tool (2008, p. 48); as in most things, awareness of possible criticisms often leads to conscious action to avoid the situations that invite those criticisms. Therefore, I will assuredly address these potential criticisms as I detail my research strategies. 


\section{Fieldwork Practices}

As my research dealt with just a few particular cases, I sought to have as deep a description as possible of the context of these students' writing spaces. Therefore, I gathered as many artifacts, writing samples, and interview responses as possible. As mentioned earlier in this chapter, my data-gathering tools included observation of the students in the ESL class; semi-structured interviews; analysis of artifacts, such as syllabi, assignment sheets, and student writing; analysis of field notes and informal; analysis of the data for emergent themes; coding of that thematic data; and analysis of the coded data within its context in order to answer the research questions and to provide pedagogical implications.

I first began gathering information about the students and the context of their writing spaces by observing them in the ESL classroom environment. During my observation, I wrote extensive field notes; I kept a running record (Rossman and Rallis, 2012, p. 194) of as many details that occurred in the class as I could. As mentioned earlier, I was also a participant in the ESL class, as a teacher's aide; therefore, I gathered my data as a participant-observer. Alongside the running record, I kept my own comments and perceptions. Frequently, I would review these notes, adding clarification and searching for some emergent themes. I focused my attention in note-taking on the three U.S.-educated multilingual students' academic literacy practices in class. My field notes were kept in notebooks and coded, as I will describe later.

Another data-gathering tool that I used is the interview. As Rossman and Rallis (2012) assert, the interview is crucial to understanding and gaining insight into participants' individual perspectives, to deepen the researcher's understanding of the 
participants and the context, and to elicit descriptive and rich data. I conducted formal interviews with the ESL Director, two of my three participants, and the English 101 instructor. My semi-structured interview questions (Appendices A, B, and C) were grounded in my research questions. Often, my participants would respond in such a way that I would ask for clarification or inquire as to some related matter or issue. Therefore, I did not always proceed linearly through my interview questions, preferring to address them in an order natural to the course of the conversation.

I approached each of the interviews as individual interview studies. As Hatch (2002) explains,

qualitative interviewers create a special kind of speech event during which they ask open-ended questions, encourage informants to explain their unique perspectives on the issues at hand and listen intently for special language and other clues that reveal meaning structures informants use to understand their worlds. (p. 23)

It was in this manner that I approached interviews with my participants, in asking openended and semi-structured questions and asking for clarification. At times, I would have to repeat a question or ask it a bit differently for effective communication.

I conducted a total of six interviews, spanning about six months, from December 2013 to May 2014; I interviewed the ESL Director once; the English 101 instructor once, one participant - Berenice - once, and one participant three times. Each interview was digitally recorded. I transcribed each interview, keeping the digital files on my passwordprotected computer. In addition, I asked clarification questions of both the ESL Director and the English 101 instructor via email; clarification questions and follow-up questions 
were asked more extensively with the main participant at the final interview as a type of debriefing, since that would be our final formal meeting.

Additionally, I collected artifacts, such as syllabi, assignment sheets, and student writing, dating each artifact as to when I received it and the context in which it was utilized in the classroom environment. Therefore, assignment sheets and other materials in the ESL course could be tied to my field notes by date to add a richer context. I attached sticky-notes to these artifacts to record my impressions and perceptions at the time I received them and any other detail I might need to recall. Assignment sheets for the ESL class I collected if the instructor had made enough copies for me to have one; otherwise, I would ask for a copy if the item seemed particularly additive to my research. The English 101 instructor was helpful in providing me with the syllabus for his course and a few other artifacts. Two participants provided me with their student writing from the ESL class, and the one student who transitioned to English 101 provided me with most of his unassessed written work.

In analyzing data based on my observations, interviews, and artifacts, I followed Hatch's (2002) Steps to Interpretive Analysis, which largely echo Stake's (2000) tasks of a qualitative researcher, which I detailed earlier in this chapter:

1. Read the data for a sense of the whole

2. Review impressions previously recorded in research journals and/or bracketed in protocols and record these in memos

3. Read the data, identify impressions, and record impressions in memos

4. Study memos for salient interpretations

5. Reread data, coding places where interpretations are supported or challenged.

6. Write a draft summary

7. Review interpretations with participants

8. Write a revised summary and identify excerpts that support interpretations. (Figure 4.4, p. 181) 
I followed this schematic with my own research, reading through my field notes and artifacts by date, and then reading through my interviews. After doing this several times, I began using colored sticky-notes to identify recurring themes. Through this interpretive analysis, I became cognizant of recurring themes and relationships among the data. I then returned to the data and read through field notes, artifacts, and interviews by thematic category.

During this time, I was also reading and synthesizing scholarly research on the topic of U.S.-educated multilingual students as well as on tangential topics such as multimodal composition, cross-cultural composition, genre analysis, academic literacies, and placement options. I juxtaposed these studies with my data in order to help me clarify issues and inconsistencies.

Through my interpretations of what was going on in the classrooms, what was going on with the student participants, what was going on with the instructors, and what was going on with the focal students' writing, I detailed my findings (Chapter V) and arrived at a pedagogical conclusion (Chapter VI) as to how well these language learners have transitioned from an academic ESL course to a mainstreamed first-year composition course as well as some suggestions as to how the academic ESL program can be augmented to better meet the literacy needs of other U.S.-educated multilingual students who may make this same transition in the future.

\section{Ethical Considerations}

Before I gathered any artifacts from the participants themselves or conduct any interviews, I applied for Institutional Review Board approval at my sponsoring institution 
as well as at Gridley Community College. Both institutions have slightly different protocols for obtaining approval for research with human participants; however, both institutions approved identical procedures as to how I would carry out data collection while limiting unnecessary harm to the participants. All participants signed an informed consent letter for each institution; the letter for the student participants was worded to ensure that the student participants would comprehend exactly what was involved in their participation in the study.

One of the perceived weaknesses Duff (2008) noted regarding case study research, which I addressed earlier, is that often human participants - the focus of many case studies - are put in a precarious position if identity, confidentiality, or other considerations, such as trust between researcher and participant, is breached. Before this case study began, the plans of my study passed institutional review by not only my own educational institution but also that of the case site, the community college; this application process required me to detail ways in which I would protect participants' identities and confidence. Field notes, hard copies of student writing and other artifacts were kept secure, as were any digital artifacts and interview data. It was necessary that I share with the ESL Director who my participants involved, due to the fact that she was responsible for these students, but I did not share that information with the English 101 instructor, as him having that knowledge was not pertinent to my study. Interview times and locations were chosen by the participants, and I ensured that participants were comfortable with specific locations for meetings before commencement of the meetings. All participants were given a comprehensible consent form to read and sign after given time to ask questions or express any concerns; this consent form detailed the 
confidentiality-ensuring measures that I as researcher would implement to protect their identities and information.

Reciprocity is another ethical consideration that warranted awareness during this study. As Hatch (2002) states, "No matter what the anticipated relationships with participants, giving back something of substance needs to be considered as qualitative projects are planned" (p. 66). For example, as I was primarily an employee during the time I was observing my participants in their ESL class, my priority was my job and the classroom culture over my research. Therefore, I took field notes only during times in which I was not asked to do anything else but be available and observe. My second research question specifically addresses another consideration in reciprocity, in that I hope to suggest ways in which academic ESL programs at community colleges can better serve U.S.-educated multilingual students.

Also an ethical consideration in this study was the relationship of the researcher to the participants. First, as an employee within the community college's ESL department, I wanted to avoid breaching any trust or confidence with the ESL Director. Therefore, I include data gathered from her in only a formal interview setting; I did not include information informally obtained from her during staff meetings or casual conversations. Secondly, my relationship with my student participants was one I felt needed to safeguard, as I had built a friendly and trusting relationship with them during their time in the ESL class. As they matriculated, I moved from serving as their teacher's aide to working as a researcher; the former role is one in which I worked to help them succeed in 
the classroom, while in the latter role, my objective was to ascertain how they would fare on their own, drawing on their own resources ${ }^{5}$.

Ending the researcher-participant relationship was another consideration, especially with the student participants. Hatch (2002) asserts that, “...protecting the feelings of those who have given themselves to any project is an ethical imperative" (66). The ESL Director and I remain connected via various professional outlets, while the English 101 instructor and I maintain a professional relationship in which we may collaborate on a project in the future, merging his expertise with FYC and multimodal composition with my knowledge of second language writing. My final meetings with each of the two remaining participants reaffirmed my availability to them for assistance in whatever way I can provide ${ }^{6}$. Hatch considers "leaving the scene" as a time for which to plan carefully when the researcher has a close relationship with participants (p. 66).

Two other ethical considerations in this study include triangulation and member checking. Hatch (2002) defines triangulation of data as "verification or extension of information from other sources" (p. 92). Triangulating data involves juxtaposing various data sources in order to arrive at as accurate a depiction of the research story as possible. However, Hatch (2002) explains that "it should be made clear to gatekeepers and participants on the front end exactly what unobtrusive data the researcher expects to be collecting" (p. 121) that would be involved in the triangulation. One way to ensure that participants are well-informed of the research expectations, according to Hatch, is to

${ }^{5}$ I did not move formally to the role of researcher until I was officially not the teacher's aide for these students, as I was committed to carrying out my responsibilities as a teacher's aide until I was no longer in that position.

${ }^{6}$ One student participant contacted me shortly after the end of the study to ask if I would serve as a job reference for him, something I gladly agreed to do. 
specifically outline these unobtrusive artifacts in the informed consent letter. The informed consent letter that all of my participants signed outlined the artifacts and types of data I wished to gather. For the student participants, this letter of consent also informed the students that I would ask for written artifacts from their classes and that I would be interviewing their instructors about the courses the student participants had been enrolled in.

Member checking was also an ethical consideration, as researchers interpret or construct knowledge out of what they "see." Reviewing interpretations with research participants is a way in which researchers can ensure that the research story written is, indeed, an accurate interpretation of the data provided by the participants. Reviewing and clarifying information with the instructors and the Director of the ESL Program was conducted via email, as this mode was a more efficient one for these busy professionals. Member checking was more intense, conducted during the interviews themselves, with the student participants. It was difficult for one participant to fit subsequent interviews and meetings into her schedule; therefore, the semi-structured interview format allowed me to rephrase and repeat statements she'd made to ensure that I had interpreted them as close to the participant's intent as possible. Likewise, member checking was conducted with the another student participant, only during subsequent interviews and meetings. At the beginning of the second and third interview, I would review with the student participant the items we had discussed at the previous interview, ensuring that there was nothing that he wished to add, change, or delete from my transcribed record and notes. 


\section{Methodological Limitations}

Throughout the course of my data analysis, I discovered several limitations of this study. First, the sample size of participants in this study is small, constrained by a) the number of U.S.-educated multilingual students in the final ESL course and b) the participants' desire and availability to participate. Only three U.S.-educated multilingual students were enrolled in the final ESL course at this community college. Additionally, one participant ceased returning my emails, telephone calls, and texts, while another failed to pass the ESL course. Ideally, I would have gathered a wealth of data from all three students, which would have added more dimensionality to my findings. While my results cannot be generalized, yet they can serve as one more voice in the conversation or piece of the puzzle, as my findings can be transferred and critically and cautiously applied to similar situations.

Another limitation is that the one main participant often did not retain his assessed work, instructor feedback on his written work, or assignment sheets from the English 101 course. As I could not betray his confidentiality to his English 101 instructor, and since guidelines prohibit the instructor from sharing information about student assessments with me without the student's permission, my case study had to rely on artifacts I was able to obtain from the student participant. An additional limitation is that the instructor for the ESL course decided that she did not wish to participate in the study, further reducing the input I gathered on the Academic English Language Program (AELP) Level 4 course. These limitations should be considered in the reading of this case study. 


\section{Conclusion}

In this chapter, I explained how I conducted my research, with rationalization and justification for those choices. I explained the process through which I collected, analyzed, and synthesized data. Additionally, I addressed potential ethics considerations inherent in research involving human participants. And, finally, I acknowledged some limitations of this study, factors that influence the applicability of my findings.

In the next chapter, I provide a deeper context for my data as well as some analysis of minor thematic issues I found within the data. Chapter V addresses several larger recurring themes that arose in my data corpus as well as some theoretical juxtapositions with that data. This analysis leads to Chapter VI, in which I connect my analysis with my research questions in order to delineate my findings. Additionally, in Chapter VI, I suggest some curriculum augmentation to the ESL program derived from my findings 


\section{CHAPTER IV \\ CONTEXTUALIZATION OF THE DATA}

\section{Introduction}

The data contextualized in this chapter is divided into four sections. The first part is a macroanalysis of the community college domain, going back to the Truman Commission report of 1947 , as well as a microanalysis of the particular community college in this study, Gridley Community College, and how its missions and goals are reflected in its ESL program. The second part describes the ESL program at Gridley Community College. In this section, the mission, structure, format, and goals of this program will be unpacked. A discussion of the specific Academic English Language Program (AELP) course observed in this study - and the course in which the studentparticipants were enrolled - will be included in a discussion of the student-participants in a subsequent section of this chapter. The third part of this chapter will portray the firstyear composition program in general as well as the specific English 101 course in which the participant(s) enrolled. The mission and goals, including representative assignments, will be described. The fourth and largest section of this chapter will focus on the participants themselves. This section will not only delve into the students' language backgrounds and writing practices but will also serve as a portrait of these students' academic trajectories: their motivations for enrolling in the community college and their goals for future academic and career paths. This section will also detail the particular 
AELP course in which the student-participants were enrolled as well as the specific English 101 course in order to contextualize the experience of these student-participants.

\section{Part I: U. S. Community Colleges and Gridley Community College}

As mentioned in Chapter I, the U.S. community college, with its open access to higher education, is proving to be a preferred educational domain for many U. S.educated multilingual students. The Truman Commission on Higher Education in 1947 challenged the federal and local governments to increase enrollment in higher education by making higher education accessible to all who would academically qualify by ending financial, racial, religious, and gender discrimination in higher education admissions (Gilbert and Heller, 2013, p. 418 and 420). The community college domain was the intended site of this expansion (p. 430), targeting a student population that might lack the capital necessary to gain entrance to four-year schools:

Today, students who attend the community college are typically those who have insufficient financial capital to attend more expensive schools, insufficient test scores and grades to get into more selective institutions, or insufficient cultural capital to navigate admissions and financial aid processes. Lack of cultural capital may take two forms. One, the student may lack a sense of direction, either in the form of self-motivation or target degree. Second, the student may be first-generation with little family understanding of, and guidance with, higher education. (Treat and Barnard, 2012, p. 696)

U.S.-educated multilingual students often fall into several of these categories. Sometimes, depending on when they immigrated, their K-12 educational experiences, and their own family circumstances, U.S.-educated multilingual students may not have the test scores, financial means, or cultural capital to enter into a four-year university. However, having earned a U.S. high school diploma, these students are no strangers to the U. S. school system, and they are familiar with general U.S. education practices: expectations for 
academic integrity; participation in cooperative learning activities; technology usage, such as basic word-processing software applications; and social roles and norms of teachers and students in classroom environments. Therefore, the community college becomes a viable educational venue.

In response, community colleges are faced with the challenge of appropriately educating these students. While access to the community college domain is relatively open, compared with the more difficult access to four-year educational institutions, incoming students are still assessed for placement. And, as mentioned in Chapter I, the literacy needs of ELLs differ from those of native English speakers. Thus, assessment tools for incoming students at community colleges may identify some ELLs as having needs in some academic literacies that are considered crucial to college success. These students, if they do not indicate their status as second language learners, may be placed in basic English writing programs in preparation for first-year composition. On the other hand, students who identify as second language learners may have the option of enrolling in an academic ESL program in order to gain strength in the necessary academic literacy domains.

The word "community" in the term "community college" denotes a close relationship between the educational institution and the demographics and geographical location - the community - in which the institution resides; thus, each community college should create a missions statement reflective of the needs for this niche of education in their community. Dougherty and Townsend (2006) explain that the missions of a given community college is evident in three areas: its stated missions (statements publicized to the community and in the institutional documents); program offerings (what types of 
programs the community college offers); and the effects of the community college in relation to its geographic and demographic domains. Dougherty and Townsend go on to explain that the missions of community colleges are not static; rather, they change in relation to the changes in the community's needs.

I chose Gridley Community College as a basis for my research due to its proximity and my position as an employee in its ESL department. It is located in the Midwest, near the geographical center of a state with a growing population of ELLs. The community college district serves 230,000 residents and enrolls more than 5000 credit students per year, according to its website. Another large contingent of students comprise the non-credit enrollment. Fiscal Year 2010 realized over 10,000 district residents served by non-credit course opportunities, including community education services.

The main college site is located on the outskirts of the largest community in the district; satellite locations exist throughout the district but are not used for ESL purposes. The geographical location of Gridley Community College within the district is central, and the specific location allows for land and building expansion as enrollment and programs require. Throughout my time of research, and even for years before, new buildings were under construction.

The mission of Gridley Community College states, "[Gridley Community College] inspires lives through accessible and personalized student support, exemplary innovation, and high expectations for success in teaching and learning" (community college website). As Dougherty and Townsend (2006) attest, however, community college missions are also expressed in program development, are reflective of the needs of their respective community, and change as the needs of the community fluctuate. Thus, 
in response to a growing number of second language leaners seeking post-high school education and English instruction in this particular community, Gridley Community College has implemented and then expanded an ESL program.

\section{Part II: Gridley Community College's ESL Program}

Jane $^{7}$, The Coordinator of ESL Programs at Gridley Community College has been teaching for twelve years. Jane earned her undergraduate degrees in French and English and a Master's degree in English with an emphasis in TESOL. English is her first language, but she also speaks French and Spanish. As Coordinator of ESL Programs, she is responsible for all aspects of the program - from curriculum to staffing to securing funding - and she serves as a liaison between the ESL programs and the Adult Education Program within the community college.

The ESL program at Gridley Community College is growing; throughout my research and employment in this program, Jane continuously remarked on record numbers of enrollees, at one point nearing 120 in number. When I asked her about enrollment caps, Jane remarked that, if trends continue, the program will soon be forced to implement a waiting list for students. Housed under the Adult Education Program, the ESL program in this study is composed of two sections: the FESL (functional ESL) program and the AELP (Academic English Language Program). The FESL program has four levels and focuses on equipping students with literacies in English necessary to "survive in their community," according to the Jane (Interview with Jane, December 2013). Students in the FESL program are predominantly immigrant ELLs who moved to the U.S. as adults and enroll in the FESL program to practice such literacies as

${ }^{7}$ All participants are referred to by pseudonyms. 
communicating with doctors or their children's teachers, communicating to find an appropriate residence, or completing forms and applications.

Some students who complete the FESL program remain and enroll in the AELP. The goal of the AELP is to provide opportunities for students to augment their English literacy strengths with the academic literacies necessary for success in college coursework or certificate programs. The AELP is comprised of four levels, all of which include practice in the reading, writing, and oral communication domains. Courses in the AELP are non-credit bearing but also are free of charge to students. Placement in the AELP is determined by a student's score on the CELSA (Combined English Language Skills Assessment), a reading and grammar-based test. Students who identify as nonnative English speakers may first take the college's placement test and then be referred to the ESL Program. Further assessment also includes a small writing excerpt as well as a spoken assessment. If a student is transitioning from the FESL program, teacher feedback is also considered in placement; during my employment in this program, I was frequently asked to comment on the capabilities and potential success of my students who were advancing to the next level. Students, however, have no input on placement and must complete specific levels as indicated by the department to participate in the program.

As it is part of the Adult Education Program, the AELP curriculum is based on and informed by informal research Jane conducts with other departments in the college, specifically the writing and reading programs. In preparing students for credit-bearing courses, the AELP collaborates with the first-year composition program as well as the college's tutoring services, financial aid office, advisement areas, recruitment services, and faculty and administrators in the content areas. After successful completion of the 
fourth level of AELP, students are considered ready for first-year composition and creditbearing content-area courses. The big-picture goal of this course, according to Jane, "is for students to be at or even above the level of native speakers in terms of how to organize a paper, how to work through the writing process,... and to build their vocabulary through a lot of contextualized instruction...." (Interview with Jane, December 2013).

The fourth level of the AELP program includes instruction and practice in oral communication, reading, and writing academic literacies. Throughout the semester-long course, students are asked to read one novel common to the course (the semester of this study, the novel chosen was Lois Lowry's The Giver) and one novel the students would choose from a list composed by Jane and the AELP Level 4 teacher(s) ${ }^{8}$. Reading, writing, and oral communication tasks are then based on these two texts. For example, a standard homework assignment asked students to generate questions based on what they had read in The Giver using question vocabulary from Bloom's Taxonomy; earlier in the study of the novel, students would be required to generate knowledge questions (basic comprehension of characters and events in the novel). As the class progressed through the novel, students would be asked to generate questions based on higher levels of Bloom's, moving through questions of comprehension, application, analysis, synthesis, and evaluation. Students were provided sample questioning vocabulary and examples to help them generate these questions. For example, for one assignment, the students were asked to write five questions that would require an answer that evaluated something in the text using words such as "appraise," "assess," "investigate," and "criticize," to name a few.

${ }^{8}$ The list of novels from which the students could choose is included as Appendix D. 
Other writing tasks based on The Giver included a narrative essay and an oral presentation in which the students were asked to reflect on the themes of the novelconforming to strict regulations, societal norms, and culture - and compose a piece in which they reflected upon a time they were confronted with cultural or societal norms which were different from those to which they were accustomed. The only writing task focused on the students' chosen novel was a book report presentation in which students would relate the book that they read to their own lives; this presentation could be written as a traditional paper or presented as a multimodal composition. Book report presentation modes during the semester of this case study included a traditional written report, a PowerPoint presentation, a Prezi presentation, poetry, and an interpretive dance.

In AELP 4, students also gain experience in research tasks, using the campusbased library and online databases to find and evaluate sources for argumentative assignments. Collaborative learning is encouraged by the ESL program but implemented on a class-by-class basis by the AELP Level 4 instructors.

Writing-specific assignments in the AELP follow a very traditional course. The writing tasks in the AELP Level 4 classes focus on five areas of language and discourse: organization, coherence, unity, grammar and mechanics, and format. The Level 4 syllabus requires students to complete a narrative paper, a research paper, an argumentative paper, and a reflective piece that may or may not include a writing component, depending on the mode each student chooses. Jane projects that, based on what she has heard about the first-year composition courses at this college, students will be asked to complete traditional academic writing tasks, such as research and argumentative papers, extensive responses, and cause-effect compositions, and perhaps 
other genres, depending on the content-area. And, based on reports from credit-bearing course instructors, the students from the ESL program are doing very well in creditbearing courses:

We've had a lot of good feedback lately, because prior to 2008, students would move on based on the assessment, and sometimes the assessment was not... it wasn't a good placer. And so students were struggling when they went to college-level classes. Now, instructors are saying, "Wow. The students are so well prepared. They're doing really well.” Especially the writing department. (Interview of Jane, December 2013)

Thus, Jane's perception is that the students who complete the Academic ESL program are prepared to succeed in credit-bearing mainstream college courses at Gridley Community College.

The students who enroll in Gridley Community College's Academic ESL program are primarily adult immigrants. Most of these students have had no experience in U.S. secondary schools. Very few are ELLs who have attended high school in the U.S. Rather, these students attended high school in their native countries and then placed into the Academic ESL program to prepare to take college courses. A few, however, are U.S.educated multilingual students, students who immigrated to the U.S. before they were 18 years of age and then matriculated into U.S. high schools. Jane, as Director of ESL Programs at Gridley Community College, communicates with ESL programs at the three local public high schools. High school students who are ELLs are identified and are offered a chance to tour the community college and learn how the academic ESL program works and how this program can prepare U.S.-educated multilingual learners for creditbearing college courses. The goal of this on-campus "orientation" for ELLs in local high schools is to identify non-native English speakers and provide them appropriate 
instruction, if necessary, to prepare for credit-bearing courses. The students are encouraged to take the CELSA exam through the community college ESL program in order to determine appropriate placement in the Academic ESL Program.

Students who for some reason do not attend this orientation, who are not "flagged" by the local high school ESL programs, or who do not self-identify as nonnative English speakers may enter the community college on their own. Prospective students who do not enter through the ESL program are required to take a basic skills assessment ${ }^{9}$ in order to determine if he or she is prepared for credit-bearing courses; students can exempt out of this assessment if they have ACT subscores (within the past 29 months) of 21 or higher in reading and writing or 23 and higher in mathematics, or previous college credit, as demonstrated by an official transcript. The basic skills assessment includes sections to measure writing, reading, and mathematics preparedness. If the student's scores on the placement examination place the student into English 101, the student is free to enroll in the credit-bearing FYC course and other content-area courses. If the student does not score appropriately, he or she may be offered an opportunity by the college to enroll in a non-credit bearing mainstream basic English course.

The interesting twist in this matter - what differentiates the possible entrance experience of the adult immigrant student from that of the U.S.-educated multilingual student - is that U.S.-educated multilingual students have several different avenues of entrance into Gridley Community College, whereas adult immigrants are automatically flagged via visa status and referred to the ESL program. First, U.S.-educated multilingual

${ }^{9}$ This basic skills assessment is American College Testing's Compass exam. 
students may choose to self-identify and seek out the ESL Program at the community college. Or, the U.S.-educated multilingual student, having been identified by the high school ESL programs and then referred to the community college ESL program, may choose not to follow that path and instead enter the same way in which a native English speaker might. Or, finally, the student may not be identified by the high school system and thus not be referred to the community college ESL program and proceed as a native English-speaking student might.

The second and third scenarios, where the non-native English speaker is not identified, does not self-identify, and attempts to proceed as a NES does through the higher-education system, is especially possible in the case of U.S-educated multilingual students who immigrated to the U.S. at very young ages and have spent a significant amount of time in U.S. schools. Thus, the paths of the U.S.-educated multilingual students in community colleges are not necessarily homogenous; differentiations exist within this demographic, and those differentiations are often further varied from the entrance experience of recently immigrated adult ELLs. As mentioned in Chapter II, "the picture that emerges...is of a tremendously diverse student population along continua of language proficiency, language affiliation, and academic literacy backgrounds" (Harklau, et al., 1999, p. 5). The common thread these students share is that they have completed secondary education in the United States. However, the type and length of time of education in K-12 schools can vary significantly from student to student, creating a complex situation for higher education institutions. Therefore, it is exceptionally difficult for the community college ESL program to 1) identify U.S.-educated multilingual students at the community college, since not all of them are necessarily in the program, 
and 2) to track their success in credit-bearing courses at the community college. As shown in Chapter II, the literacy needs of U.S.-educated multilingual students are often vastly different than those of native-English speakers as well as adult immigrant students. Tailoring an academic ESL program to meet the needs of U.S.-educated multilingual students specifically becomes difficult if these learners cannot always be identified or choose to not self-identify.

I asked Jane during our interview about Gridley Community College’s U.S.educated multilingual students. When I inquired as to her perceptions of these students' unique challenges, she responded that family expectations seems to be one factor that challenges this group:

I think one major thing is family expectations. And, I don't know if that's something that's ok to talk about, but I think that, um, a lot of times the children are the reason that families come here [to the U.S.], and so there's a very high level of stress, that they have to be successful, and so that's a whole other piece of what's pushing them and sometimes pushing against them and making them so stressed out. (Interview with Jane, December 2013)

Next, I asked Jane about different literacy strengths and needs that U.S.-educated multilingual students might possess, differentiated from those of adult immigrants or international students. Her response echoed Blanton's (2005), Bloch's (2007), and Reid's (2011) findings, that U.S.-educated multilingual students have stronger oral English literacy and more written needs:

Yes, of course their written literacy is far lower. A lot of students may have come at a time when they were learning to read, and so they may have started learning to read in their first language, and then when they came here were forced into ESL classrooms and they were forced to switch how to learn to read in a second language. And so that has caused 
many problems for these types of students. (Interview with Jane, December 2013).

I then asked Jane what kind of feedback she receives from her AELP instructors regarding U.S.-educated multilingual students specifically, and her response echoed Riazantseva's (2012) study that indicates that this group of students tends to capitalize on their oral literacy strengths to offset their written literacy needs:

I think because their oral skills are so high, sometimes they overshadow some of the other students in class and take over. But then on the flip side, if their writing skills aren't as good, it may take longer for the instructors to help them with some of the activities that, for the international students it's a breeze for them .... They may have had more of a focus on reading and writing in their home country, so those skills are more sharp than their oral skills. (Interview with Jane, December 2013)

Jane's responses demonstrate an awareness of the unique strengths and challenges possible with U.S.-educated multilingual students. She understands how they may have different literacy challenges and strengths than their international student or adult immigrant student peers. However, placement options for these students are limited at her institution. U.S.-educated multilingual students at Gridley Community College can skip the ESL courses, providing they have the appropriate ACT scores or score high enough on the college's basic skills assessment. If a student wishes to enroll at Gridley Community College and does not self-identify (or is not identified from the community high school ESL programs by Jane), the student can enroll in the appropriate mainstreamed basic English course (described in the next section). However, the only other placement option for U.S.-educated multilingual students is in the AELP program, contingent upon where they score on the CELSA. And, as of right now, the Gridley 
Community College ESL program does not have the funding or demand for stand-alone U.S.-educated multilingual student sections as described in Allison (2006), Holten (2009), or Murie \& Fitzpatrick (2009); U.S.-educated multilingual students in Gridley Community College's AELP have no choice but to be in hybrid classrooms with international students and adult immigrants. However, programs such as those cited by Allison (2006), Holten (2009), or Murie \& Fitzpatrick (2009) can provide valuable insight and tools into how to structure programs in order to serve the literacy needs of a diverse group of ELLs. In mainstream education, especially K-12 classrooms, teachers must reach a wide variety of student learning styles, backgrounds, and literacy needs; as a former high school English teacher, I can attest to this personally, that teaching to a wide variety of learners is a commonplace challenge. However, from my observations as a classroom tutor/teacher's aide in Gridley Community College's AELP classes, I observed no indication that the instructors ${ }^{10}$ make any accommodation for the unique literacy needs of their U.S.-educated multilingual students other than what they make for their international student population. I will illustrate one of these classes in the next section; and in Chapter VI, I will provide some pedagogical insight based on the placement options and goals cited in Chapter II as to how ESL programs in community colleges can continue to move forward in meeting the unique needs of this population.

${ }^{10}$ Unfortunate for this study, the classroom instructor of the AELP course I illustrate later in this chapter decided to not participate in the present study. Her voice would have been a valuable one, but instead I will rely on my field notes and observations of classroom activities, mindful that I do not know her perspective. 


\section{Part III: Gridley Community College's Mainstreamed English Courses General Mainstreamed English Courses}

The course catalog for introductory English courses lists three basic non-creditbearing courses and two credit-bearing courses. These courses are not part of the ESL program. Placement is determined by the college's placement examination. Students can be placed into English 94 (Writing Skills Review 1) or English 95 (Writing Skills Review

II). Course descriptions for both courses emphasize concurrent registration in the community college's reading support program. The online description for English 94 emphasizes "fundamentals" in English through "an error-analysis approach":

A reading/writing course that uses an error analysis approach to review English fundamentals, including grammar and sentence structure, punctuation, usage, and mechanics. The course introduces students to audience, invention, arrangement and purpose in composing. (Online course description for English 94)

The course description concludes by stating that a final grade is determined by an assessment of the student's portfolio, indicating that revision is a key part of the writing process in this course.

A grade of $\mathrm{C}$ or better in English 94 or an appropriate score on the placement test is a prerequisite for English 95 (also not part of the ESL program). This course appears to be a continuation of English 94, as it focuses on rhetorical conventions in reading and writing. The goal of this course is to prepare students for college-level writing, as "students learn to shape rough preliminary texts into more complex and mature ones" (Online course description for English 95). Again, as in English 94, the final grade in 
English 95 is determined based on an assessment of a final portfolio, indicating emphasis on revision as part of the writing process.

English 99, another basic English course not tied to the ESL program, is titled "Composition I Companion: Writing, Reading, and Reasoning." The prerequisite course for English 99 is a grade of $\mathrm{C}$ or better in English 94 or an appropriate score on the placement test. English 99 is called a "companion" course because concurrent enrollment in English 101 is required. Very little is listed in the course catalog for the learning objectives of this course, but the inference is that it is to be a "help" course for students who may need or desire extra guidance while they are enrolled in English 101.

The English 101 course description reads that placement "presupposes competence in English grammar, mechanics, punctuation and spelling" (Online course description for English 101). This course, as it is at most universities, is to serve the function of an introductory college-level writing course, or first-year composition (FYC), if viewed with the subsequent course, English 102. The remainder of the description outlines what is expected of incoming students and the overall learning objective of the course:

ENGL 101 is an in introduction to college-level writing, with training in the skills needed at each phase of the writing process, including generating ideas about a topic, determining a purpose, forming a controlling idea, analyzing the needs of your audience, organizing and planning your writing, and composing effective sentences, paragraphs, and essays. ENGL 101 is intended to prepare students to write effectively for a variety of audiences and purposes. (online course description for English 101)

Thus, an emphasis appears to be on rhetorical conventions as well as on appropriate English grammatical conventions. A final grade for this course is determined based on a portfolio, which, according to the course description, will include research papers. 
Important to note is that, just like at many colleges and universities, many sections of a particular course exist and many different instructors teach this course. Thus, while instructors adhere to the general course descriptions and objectives, just how they decide to structure the course to meet those objectives is up to the individual instructor; one English 101 course may differ in content from another, yet still maintain the same learning objective goals.

\section{The English 101 Section Specific to this Study}

I chose this particular English 101 section as it is the English 101 section in which one of the participants of this study enrolled. The instructor of this course, Thomas, holds a BA in English from a large university in the same state and earned his MA in English Studies from a local university. He has finished required coursework for his Ph.D. focusing on new media studies through the English studies graduate program at the local university and is currently working on completing his comprehensive exams and writing his dissertation.

This instructor has been teaching mainstreamed English courses for 14 years. English is his first language, although he admits to having minimal competence in speaking Spanish. This instructor has no formal instruction in the TESOL field. His experience with non-native English speakers has been based only his experiences with the students who enroll in his class, and he has not communicated or coordinated with the ESL program. He reports that he has one or two non-native English-speaking students on average in his English 101 sections per semester, although he admits that that number may be higher if students do not self-identify as multilingual students directly to him: 
I wouldn't say "often." But I do [have multilingual students in the classroom]. Um, I would say maybe one or two every semester, on average. But, like this semester, I don't think.... None that I.... You know, the thing is, they may not identify, so, it's um, it's, you know, If they don't, I'm not going to say, “Are you an ESL student?" (interview with Thomas, February 2014)

Thomas's response further exemplifies the difficulty faculty and administrators at community colleges may have in identifying non-native English speakers in the classroom. As this case study is focused on the literacy needs of multilingual students specifically U.S.-educated multilingual students - in credit-bearing English 101 courses, I asked this instructor if he has noticed that multilingual students in his classes face challenges or difficulties in meeting the learning objectives in ways that native-English speakers do not. The instructor's response indicates that he has not previously noticed that multilingual students in his English 101 course sections have more challenges than native-English speakers:

I can't think of anything specific. So, I guess, no? I mean, it's hard to...I can't read a student's mind. All I get to see are the results.... Um, there might be a few cases I've noticed where they might need a little bit of help with certain things. But I've never met a student that was so... where I couldn't understand them. (Interview with Thomas, February 2014)

Additionally, I asked Thomas if multilingual students brought instructional complexities to his classroom, Thomas's response indicates an additive rather than detractive function of the presence of multilingual students in his course sections:

Well, I've had good complexities happen.... Like I have a student from Africa this semester. But, I don't know.... He speaks French. Um. But he speaks English perfectly. He brought in a little bit of, we were talking about, you know, certain words, and their origins and things like that, and we would bring up certain words, and he would say, "That one has a French origin," and "That one has a French origin." So, I think it's good 
for students to see that type, that level, of complexity in someone. I had another student who did a presentation - a Chinese student - who did a presentation on, um, on where they came from, and oppression and things like that. This person was a very big fan of not being in China at that particular time, uh, because he felt that, you know, certain things were going very badly, you know. He was very into the Internet and Internet freedoms and things like that, so. He gave a presentation on his, I forget the exact controversy, um, but, you know, gave a very good international perspective to the rest of the students who, you know, were doing, you know, very domesticated types of controversies and that type of thing.... Yeah, but, I can't think of any, you know, any bad experiences, where it affected instruction. (Interview with Thomas, February 2014)

While this instructor has no formal education or experience in teaching multilingual learners, he appears to welcome multilingual learners to his classroom, and his opinion of their progress and success in his class as multilingual students is not differentiated from his opinion of the progress and success of native English speakers. In his opinion, nonnative English speakers do not present additional complexities that are unwelcomed or insurmountable. Thomas, as a FYC instructor, does not fit the findings of Matsuda, et al.'s 2013 study, discussed in Chapter II, which found that many FYC instructors would like to have additional preparation and support in the instruction of multilingual students in their classrooms.

Thomas's syllabus is grounded on the learning outcomes of Gridley Community College's general English 101 course, but the learning tools and assignments he uses to reach those outcomes have their foundation in the New Media Studies, in which the instructor himself is immersed, and follows a Genre Theory model. As described in Chapter III, a genre theory model for composition emphasizes analysis of genre conventions and then adherence of those conventions in composing texts that "do" what the target genre "does." In Chapter II, I cited Hyland (2004), who asserts that "the 
concept of genre enables teachers to look beyond content, composing processes, and textual forms to see writing as an attempt to communicate with readers - to better understand the ways that language patterns are used to accomplish coherent, purposeful prose" (p. 5). The focus on language within a genre studies model, then, is that language is a tool to accomplish a task or goal.

Thomas described for me the course objectives and how his course assignments fit within those objectives. He described the current course learning objectives as rooted in rhetorical outcomes: students compose written texts based on audience, purpose, and logical consistency. Students also learn how to evaluate sources for support in this course, and so developing an argument based on credible support becomes part of the rhetorical outcomes. Thomas also made an acknowledgement of the importance of grammar - mechanics and conventions - in explaining course objectives. However, he noted that any focus on grammar takes into consideration whether the grammar serves as a detriment or distraction to the message the student is trying to convey to the audience.

The specific writing assignments that Thomas includes in his section's syllabus have as their foundation new media studies and genre theory, as stated earlier. Three main assignments comprise the final portfolio for the course: a Cowbird, a research paper, and a blog. In describing these assignments to students, Thomas focuses on instructing the students in genre analysis:

Um, as far as genres are concerned, I've actually just switched my 101 starting last fall, to incorporate the idea of genre. So, the first project we do is called a Cowbird. I don't know if you've ever heard of what that is. And it's, it's...I purposely chose a genre that's unfamiliar to everyone. Actually, what a Cowbird is, is a website that incorporates imagery, sounds, and writing in order to produce some sort of, ... it can be a creative or reporting piece, and, so there are different ways to create a 
Cowbird or different goals for creating a Cowbird. But, I use that, to, that unfamiliar genre in order to kinda introduce them to the idea of genre itself, and how you might approach an unfamiliar genre. How you might say, “Ok, I don't know how to do this kind of writing or this kind of communication, you know, what criteria can I apply to that?" (Interview with Thomas, February 2014)

In other words, instead of telling the students what a Cowbird text looks like - its function, intended audience, and purpose - Thomas leads the students through an analysis of the genre. He used the Cowbird as an introductory assignment in order to teach the students how to approach writing an unfamiliar text. And, instead of telling students the components and conventions of the text, he created a formative assignment that leads the students through an analysis of the genre. The assignment description reads:

For this project, you will create a Cowbird. I'm not going to tell you what a Cowbird is, or how to make one. I will, however, point you in certain directions and provide activities, instruction, and workshops to help you along.

You as a class, through research, investigation, and experience, will define what a Cowbird is, what elements are included in a Cowbird, and what a successful/effective Cowbird entails, contains, etc. You will also define how this project will be assessed by me.

You as an individual, through work, creativity, and thinking, will create your own Cowbird. You will then connect your Cowbird to other Cowbirds through the category systems on the website, and to others through social media. You will also add your Cowbird to your blog (when we get to that unit). (Thomas's course syllabus, received February 2014)

Thus, the students are required to research the genre themselves in order to reach a conceptualization of how to create the genre. Researching texts in order to determine how the genre is comprised is at the core of the Genre Studies approach.

Thomas assessed the Cowbird assignment using a rubric. The rubric focused on the presence of traditional rhetorical conventions in the piece - purpose, audience, genre, 
voice, and mechanics - and spelled out the outcomes or goals of each of those categories. Therefore, students knew how their Cowbird texts would be assessed.

The second major written assignment in this course is a research-based paper, titled on the syllabus as a "Rhetoric, Subcultures, and Media paper/argument." This paper follows from the Cowbird in that after learning how to analyze a genre, students approach the research paper by analyzing it in the same way. Thomas explained the assignment and the purpose to me during our interview:

Then of course, we have to do, uh, an academic essay. And so, I use that as the second project, where we say, "Ok, now I know some stuff about genre, let's focus a little bit more on rhetoric on this one," but also use what we've learned about genre, and say, "OK, an academic essay is a specific, has a specific set of production and representation rules, and has a specific type, you know, type of audience that has a, you know, it also is something, it's a genre that is, some people say is not utilized a lot out in Nature," Right? But it is a very important genre that students encounter all the time. Um, so if you run into these, you know, an academic essay in your college career or whatever, what do you need, what are some good strategies and approaches to take when you first encounter that in a classroom or whatever. (Interview with Thomas, February 2014)

Questions the instructor wants the students to consider with the research paper are the same as for the Cowbird: What does this text do? Who is the audience? What is my purpose? The guidelines for this assignment ask students to consider the rhetorical situation, just as it did in the Cowbird assignment, in order to produce a text consistently adhering to that genre. For this assignment, students were to consider how mass media portrays a subculture and write a five-page paper analyzing how the chosen subculture is portrayed in the media. Students are required to gather sources and analyze them for credibility before synthesizing them into the paper. An annotated bibliography is required in the final draft but is also used as a formative assessment to ensure that students are 
proceeding appropriately. During the timeframe of this assignment, students are required to meet one-on-one with the instructor for a writing conference regarding the assignment.

The third written text for the portfolio is what the instructor calls "The Translation Project." This project requires students to analyze the genre of the blog and then "translate" what they wrote for the research paper into a blog. As the genre of a blog is very different from that of an academic research paper, the translation requires students to consider the requisite changes in the rhetorical situation and rewrite their text accordingly. Thomas explained this final project to me in this way:

The final project we do is a blog. And I call it "The Translation Project," where we take the academic essay and translate it into a new genre. So, we take that type of, the type of material that you would produce for an academic essay and we say, "Ok, now how do we take that content and put it into a new genre?" And, of course, you know, the content has to change in some significant ways. And then, the approach of a blog is very different, you know, it's different kinds of audiences and a completely different purpose. So, it's, it's...I've only done this once, last semester, and it worked out pretty good, it was pretty rough, but we got through it. (Interview with Thomas, February 2014)

In describing this assignment to me, Thomas referred to the concept of translation, a new media concept in which texts are not simply copied from one mode to another but translated; the writer must determine the rhetorical purpose and audience differences between the former mode (in this case, a discursive mode, as the research paper is written with words on a screen or paper) and the new mode (in this case a blog). Blogging, as shown in Bloch's 2007 case study described in Chapter II, requires a more informal register than typical academic writing. What Thomas was essentially asking students to do was to analyze the genre of a blog, determining how it is different in rhetoric than a 
research paper, and translate the information and argument in their research papers to their own blogs.

The syllabus and other course materials complete the picture of the design of the course. Scattered throughout the semester are various formative assignments such as the annotated bibliography that the instructor reports are intended to help the students learn and practice in order to reach the course objectives. For example, students learn how to write a rhetorical coversheet, which students include for each of the major writing assignments in the course. The rhetorical coversheet includes the student's name, the course, the date, and the title of the text, but it also requires the student to write a paragraph describing the target audience, the purpose, and the design of the assignment itself. Another example of a formative assignment in this course is the paragraph analysis assignment, in which students must analyze their own writing, paragraph by paragraph, to ensure that each paragraph has one main focus with supporting details and that each paragraph proceeds from the former and into the subsequent paragraphs with appropriate transitions and logical reasoning. Cooperative learning is also incorporated into formative assignments, as it was in the Cowbird genre research assignment. Peer review is utilized with the research paper as part of the global revision process.

Course objectives themselves are detailed in the syllabus, with particular general education outcomes ${ }^{11}$ cited to link the two. Course objectives for Thomas's English 101 course are as follows:

11 "General education outcomes" are those instituted in general education courses at Gridley Community College. Thomas's syllabus connects each of his learning objectives to one or more of the college's general education outcomes. These outcomes "help 
- Establish and maintain a voice that is appropriate to the selected rhetorical context.

- Demonstrated theoretical and practical understanding of the relationship between audience and purpose, and produce texts that address a variety of audiences effectively.

- Engage inquiry in evaluating difference in perspectives and opinions - including critical self-assessment of one's own perspective and its relationship to the perspectives of others.

- Develop an essay that demonstrates effectively organized and presented reasoning and supporting evidence.

- Interact effectively with multiple sources, subordinating them to the writer's purpose; creating confidence that they have been represented fairly; and documenting them in MLA style.

- Develop an effective writing process that includes successful strategies for inventing, choosing, and narrowing a topic; exploring and developing ideas through research and critical readings; and employs global and local revision and editing strategies. (Thomas's English 101 syllabus, received February 2014)

I will return to these learning objectives in Chapters V and VI, as I use my data to help answer my research questions; these learning objectives will help illuminate just how successful my participant(s) was in transitioning from the AELP course to English 101, as they illustrate the measures of success in the English 101 course.

The "logistical" parts of the course - attendance, how to communicate with the instructor, course information, etc. - is clearly detailed in the syllabus. Noteworthy in this instructor's syllabus is the emphasis on the course as student-centered rather than instructor-focused:

Think of me [the instructor] as a guide in your explorations of writing, rhetoric, and critical thinking. I will ask you questions and give you suggestions to help you in YOUR writing and learning. I am not a sage or an infallible genius that can transform you into an expert writer. And I cannot show you the "one true way" because there is no "one true way." There are many strategies and a range of perspectives for any given task. I

students develop proficiency in Communication, Diversity, Problem Solving, and Critical Thinking" (Thomas's English 101 syllabus, received February 2014). 
will provide materials, lessons, and assignments designed to help you learn (if you decide to) and achieve the course objectives. And I will provide honest and helpful evaluations of your work. I will also make myself adequately available for your questions and ideas. (Thomas's course syllabus, received February 2014)

Throughout the syllabus, the idea of "you are responsible for your own learning" is reiterated. Additionally, the instructor reminds students that academic discipline requires students to have an awareness of course objectives and then work to a high level in order to achieve these course objectives. The concept of a student-centered classroom is important, since the AELP course was predominantly instructor-focused, as I will detail in the next section. I will return to this differentiation later in this chapter and again in my discussion.

\section{Part IV: The Fall 2013 AELP Level 4 Course and the Participants}

\section{The AELP}

The Academic English Language Program Level 4 class in the fall of 2013 is the first site of learning that I observed in this study. As I mentioned earlier in this chapter, the AELP is part of the ESL Program at this particular community college. The AELP program has four levels; upon successful completion of the fourth level, students are considered ready for credit-bearing college coursework.

I observed the AELP Level 4 class in this study in the fall of 2013, as I was hired as a classroom tutor (or teacher's aide) by Jane. The AELP instructor had been in the field of education for a number of years and had, at this point, taught many levels of the ESL program at Gridley Community College. As I explained earlier, the course emphasized traditional writing genres, such as narrative writing, a research paper, an argumentative paper, and a reflective piece. These four genres comprise the four basic 
units of the course and serve as a foundation for writing, speaking, reading, and listening summative and formative assignments. The course description outlines the learning outcomes:

ESL 081 [AELP Level 4] covers advanced instruction in writing, reading, listening, and speaking for academic purposes. Course objectives include improved awareness of audience and purpose, application of research in the academic essay and in oral presentations, and introduction into academic integrity and plagiarism. This course prepares students for success in the U.S. academic environment. (Course syllabus, received August 2013)

According to Jane, this course - as well as the other courses in the AELP - was designed based upon projection of and research into the language tasks students would potentially be asked to complete in credit-bearing courses.

As I previously described, assignments in this class involved reading, writing, speaking, and listening. Students were required to perform all in-class tasks in English. The topics for some writing tasks involved students reflecting on or using their knowledge of their "native culture" as a foundation for the written content. For example, a first writing sample prompt required students to compare writing in English to writing in their "native culture:"

Do you like to write??? Do you like to write in English? In your native language? What are some of the similarities and differences when you write in English and when you write in your native language? How does writing in English make you feel? What are the most difficult parts of writing in English? (Assignment sheet, received August 2013)

This writing prompt was given to students as a way for the AELP instructor to initially diagnose the students' writing strengths and needs. Students were given thirty minutes in class to complete the writing, which was to be written on the computer, printed, and submitted. Students were instructed, as they were for all subsequent assignments in the 
course, to use a twelve-point font, and to double-space their writing, checking for appropriate grammar, format, and spelling.

Another writing assignment, the narrative essay, required students to examine the concepts of culture and cultural values:

For this writing assignment, you will think about your own experience of entering a new culture and dealing with the new cultural norms. Write a narrative essay about A PARTICULAR SITUATION when you were in a new culture and you witnessed someone doing something that goes against your own cultural values. How did you react to your new culture's norms despite your core values from your home culture? Did you act in a way that goes against your personal core values in order to follow the culture's norms or did you follow your core values and beliefs? Were you able to do so easily? How did you feel after that incident? Did this incident alter your beliefs? If so, how? (Assignment sheet for AELP Level 4, received September 2013, bold print and all-caps as shown in the course syllabus)

Likewise, the argumentative essay required students to draw on knowledge and values from their "home culture:"

For this writing assignment, you will ponder an issue in your home community that you would like to see changed. Write an argumentative essay about that particular issue. You will inform your audience, your home country ambassador, of your opinion in an effort to convince them to adopt that point of view. You will convince your audience of what will happen if the issue is not faced. (Assignment sheet for AELP Level 4, received October 2013)

Other writing assignments in the course centered upon a common text, The Giver. As mentioned earlier, students were asked to compose questions about this novel that followed Bloom's Taxonomy. The instructor would then evaluate these assignments and return them to the students, but nothing was every said or done with them. Students were also given assignments to practice paraphrasing texts, specifically before work on the research paper began. And, as noted earlier, students were asked to compose a report 
based on a novel they chose individually from a given list; the list was comprised of novels that narrated the experience of the author or of a character in moving to a new country or culture.

The traditional writing process was stressed in this course, with the five-paragraph essay as an initial foundation. Students would brainstorm and then take notes. From the notes, students would compose an outline and then a draft. The draft would then be required for a peer-review day. Students would be given prompts for the peer review. After a specified time for revision, students were required to submit a final copy online to the instructor. The instructor would also then require that students grant her permission to check their final drafts with SafeAssign, an online software that compares student texts to all other online texts in order to identify possible plagiarism.

As evident in the assignments cited above, the concept of culture seemed to be a common theme in this AELP class, one that served as a basis for class assignments. Moran (2001), in Teaching Culture: Perspectives and Practice, asserts that culture is multidimensional and dynamic; many factors make up culture, and the extent to which those factors make up what an individual claims as "culture" is highly individualized and not necessarily tied - or tied strongly or specifically - to an individual's native country of birth. Matsuda and Atkinson (2008), in their academic discussion, acknowledged that the concept of culture is a complex one that cannot be pinned down exactly. As I will soon illustrate, this class - like every other ESL class (Matsuda 2006) - was extremely diverse and not homogenous. As the AELP instructor was reviewing the narrative assignment with the students, students began asking clarifying questions that expressed concern over the concept of culture. For example, one student who immigrated from China as an adult 
but had resided in the U.S. for several years remarked that she considered her culture to be the same as U.S. culture. Yet, the assignment equated "culture" with "country of birth," and did not allow for acknowledgment of the individualization of culture or its multidimensional or dynamic nature. Additionally, the AELP instructor met some resistance with two of the U.S.-educated multilingual students in the class when they were given the narrative assignment. These two students, who had been in school in the U.S. since approximately the third or fourth grades, remarked that they did not remember entering a new culture (see the assignment description above). A compromise between the instructor and the students involved the three U.S.-educated multilingual students in the class to just trying to remember what they could.

The same issue arose again when the instructor was explaining the argumentative paper assignment (see above description). The three U.S.-educated multilingual students had very little recollection of the country of their birth, having immigrated to the U.S. at young ages. This assignment became, for them, a task in learning about a conflict in the country of their birth and then choosing a position for or against it. Having been adopted from Russia at the age of ten years, one student argued for resuming open adoptions in Russia. Another, after doing some research on his birth country - the Democratic Republic of the Congo - realized that children were being used to fight in civil wars; thus, he argued against the use of child fighters.

The experience of these U.S.-educated multilingual students in this class was one that echoes Harklau's (1999) case study in which U.S.-educated multilingual students were placed in an ESL classroom alongside international students; the students in Harklau's study exhibited resistance at assignments focused on assumed cultural and 
native knowledge when, in their opinion, they had been residents in the U.S. for long enough that they considered the U.S. "their" country. Inherent in such assignments is a view of culture as unidimensional, defined by characteristics strongly linked to stereotypes of language and national borders (Moran, 2001). Such a simplistic, essentializing view fails to take into consideration the multidimensional and constantly shifting characteristics of more fluid definitions of culture. The AELP 4 assignments that centered on culture, like those in Harklau's study, created some tension in the classroom for the U.S.-educated multilingual students. Perhaps students in both this study and Harklau's would have benefited from the agency of determining for themselves how and with what country they wished to identify and which cultural characteristics they wished to highlight.

\section{The AELP Level 4 Class}

Approximately twelve students were in the fourth level AELP course. Three students I identified were U.S.-educated multilingual students; I first became aware of their possible situation in my observation of their resistance to culture-based assignments described in the previous section. The program, as I mentioned earlier in this chapter, does not distinguish between students who arrived to the U.S. as adults (international students or adult immigrants) and those who arrived in the U.S. during the years of K-12 schooling (U.S.-educated language learners). The nine adult immigrants in the course moved to the U.S. from various countries: Mexico, Pakistan, South Korea, China, and India. All of the adult immigrants had completed high school in their native country; some had attended graduate school or held graduate school degrees from universities in their native country. 


\section{Early Participation of the U.S.-Educated Multilingual Students}

The three U.S.-educated multilingual students became the participants for my study toward the end of the AELP Level 4 course. Their backgrounds vary in that they immigrated to the U.S. from different countries: Jack immigrated from the Democratic Republic of the Congo with his family at age 10; Berenice immigrated from Mexico with her family around the age of 10; and Natalya immigrated from Russia at the age of 10, having been adopted by a family in the U.S. All three attended public school and graduated from high schools in the community.

In the initial stages of this study, all three students were willing participants. All three agreed - as did the instructor - that I would attend the students' final debriefing for the course. A grade of a $\mathrm{C}$ was required in AELP Level 4 to continue on to credit classes, and one of the three participants - Berenice - received a grade lower than a $\mathrm{C}$. We agreed that I would still include her in the study, noting that she would be retaking AELP Level 4 in the spring. Jack and Natalya passed AELP Level 4 and planned to enroll in English 101 for the spring semester; Jack earned a C in the course and Natalya earned a B.

After the semester break and after giving the students a chance to settle into their credit-bearing course schedules, I reached out to all three to schedule the first interviews. Berenice responded that she had forgotten to re-enroll in AELP Level 4, but that she would be willing to talk to me about her language background and AELP Level 4 experience anyway. Jack and I scheduled and completed the first interview. Meanwhile, after many attempts at scheduling an interview with Natalya, only to have her cancel or not attend, she informed me via text that she was not enrolled in English 101. Eventually, she ceased responding to my texts and telephone calls, and I determined that she wished 
no further participation in the study. Therefore, I was left with two participants, and only one - Jack - was currently enrolled in English 101.

\section{Berenice}

My observations of Berenice throughout the AELP Level 4 course revealed a polite yet shy student who was frequently late to class and often did not have homework completed. What work she managed to submit was usually completed to the teacher's satisfaction. Often, work from Berenice was handwritten, whereas other students would choose to use computer word processing to type assignments. When I observed Francine speaking to Berenice about her late assignments or late arrival to class, Berenice always took complete responsibility, citing home and family responsibilities.

Now a young mother at the age of 21 years, Berenice moved to the U.S. from Mexico with her family when she was in fifth grade, at around the age of 10 . Her first language (L1) is Spanish, which she learned in Mexico. She does not remember learning Spanish, as she learned Spanish when she was "really little...when I was small, since birth" (Interview with Berenice, April 2014). She still communicates with her family and friends in Spanish - both orally and in writing - but for schoolwork she reported that she uses only English; she reports that she does not speak or write in any other language but Spanish and English.

Berenice learned a little English in school in Mexico before immigrating to the U.S., but says that she did not remember what she learned there and did not believe that learning English as a foreign language in Mexico helped her out at all with communicating in English after immigrating to the U.S. Once she was in a U.S. elementary school, she began learning English with the help of teachers who also spoke 
Spanish. The school system, Berenice reported, grouped her in class with other Spanish speakers in elementary school, yet she does not remember being part of an actual ESL program until she moved into a different school district in the eighth grade.

In elementary school, Berenice would begin by composing in Spanish and then translate the composition to English; however, she says that she moved away from that practice when she entered high school. In high school, Berenice was placed into an ESL program. This program consisted of specific ESL classes as well as mainstreamed classes, in which the ESL students would have an ESL teacher assist them. Berenice recalls that her Business, Biology, and History classes in high school were mainstreamed; students would have an ESL teacher as a resource. Berenice's English class, on the other hand, was for ESL students only.

In addition to using her L1 - Spanish - to communicate with her family and friends via Facebook and texting, Berenice commented on a culture course she completed in high school as part of the ESL curriculum. This course, which Berenice called Spanish Heritage, was intended to assist native-Spanish speakers with Spanish grammar and vocabulary. Berenice told me that she knows how to spell a lot of words in Spanish, but that her Spanish grammar needs a lot of work. The Spanish Berenice uses to communicate with family and friends tends to be a slang-Spanish, she admits.

When I asked her what types of writing she was expected to do in high school, Berenice reported that the writing assignments depended on the class. All of her academic writing, with the exception of writing for the Spanish Heritage course, was expected to be composed in English. For the English class, she remembers writing essays and book reports. "But they were not really big. They were just really short," she 
remarked (Interview with Berenice, April 2014). I asked her if she had to write in English on Science and Social Studies tests. She answered that the multilingual students in the ESL program were expected to use English on tests, but

They [the ESL teachers] made our work much easier in a way, so we really didn't write big papers. And, it was good and bad, 'cause we didn't learn like how to.... I learned basically when I was in AELP [Level] 3 how to really write a good essay and all the things. But in high school, like they would make it easier, our classes, so we didn't have to write really big papers, or ... on our tests, we kind of, um like in Business class? We, uh, all the ESL would go in a different room and she [the teacher] would read our tests. So, it was easier. (Interview with Berenice, April 2014)

According to Berenice's account, at least one school district in the area, then, makes accommodations for multilingual learners. And Berenice seems to be very much aware that the ESL program at her high school made the work easier for her because she was a second-language student.

But Berenice enjoys writing in English, she said, even though Spanish is her first language and comes easier to her. She identifies punctuation, using the past tense, knowing when to end and start a new sentence, and spelling as her challenges in writing in English. From my observations of her writing in the AELP course, I would agree with her regarding her challenges with writing in English.

I chose to retain Berenice in this study, as her background and performance in AELP Level 4 as a U.S.-educated language learner serves to reiterate the lack of clear boundaries the fields of TESOL or second language writing can impose upon this demographic. She heard about the community college's Academic ESL program from the visit the high school ESL programs make to the community college, organized by Jane, as I mentioned earlier in this chapter. She recalls being told that the Academic ESL 
program can help multilingual students prepare for college courses. Berenice has an older sister in the community college's AELP, and her mother is in the Pre-AELP course, which is a preparation course for the four AELP courses; thus, Berenice has family support for continuing her education, as her sister and mother are both invested as well in the ESL program at Gridley Community College. Berenice, after taking the CELSA, placed directly into AELP Level 3. She finished that course in one semester and moved on to AELP Level 4, which she did not pass the semester I served as a tutor in her class.

During my interview with Berenice, I asked her what she perceived her challenges were with the AELP 4 class. Her response reveals that she takes full responsibility for not passing the course, as she responded that she constantly chose to put her young son and her job security ahead of academic responsibilities:

I think that probably being on time to my class. I should be, like, doing my work. Like, I would do it, but then, like...I don't want to make a lot of excuses, like "My kid...." But like, it was kinda, I don't know, complicated in a way, like focusing on my schoolwork and my kid and work and all this stuff.... Like, I kinda like, I wanna like work on school, but then work, like...If I had to be there on time, I'd have like problems at work. (Interview with Berenice, April 2014)

In addition, as already mentioned, work from Berenice turned in for the AELP 4 class was often not typed and often late (or not completed at all). When Francine would ask Berenice about her handwritten work, Berenice would respond that her family did not own a computer and she would have to visit the library or Gridley Community College's computer lab to put her assignments into her online student folder. Also, Berenice was also often late to class (more than fifteen minutes late for a class that met for one hour and fifty minutes three mornings a week) or totally absent. As I was given the task of 
taking attendance in the class, I once asked Berenice if there was any way she could be on time to class; her response was that often she had to wait to leave for class until her mother had returned from her night-shift job so that she had someone to watch her son and could drive the family vehicle. Often, too, she remarked to me, her child was ill, and she needed to care for him.

Family and financial responsibilities such as these that Berenice reported to mechallenges that proved insurmountable to her during the semester I was tutoring in her AELP class - are echoed in Song's (2006) case study of instructor and student perceptions of why ESL students fail ESL courses. Berenice might have faced other factors that Song (2006) claims often contributes to ESL students' failure of the ESL courses, such as insufficient target-language use and/or deficient first-language literacy; however, it is my opinion from my observation and conversations with her that family and financial responsibilities, as well as a lack of support for educational and personal needs from the institution, were heavy factors involved with her failure to transition to English 101.

In closing our final interview, we discussed some plans she could make to help ensure that she would enroll in and complete successfully AELP Level 4, such as working with her employers and other family members for scheduling and daycare. Despite these hurdles that she will have to overcome, Berenice remains committed to returning to the classroom and eventually moving on to credit-classes in order to fulfill her goal of becoming a preschool teacher. 


\section{Jack}

Like Natalya and Berenice, Jack immigrated to the U.S. at a young age. Jack's first language is French, which is typical for people native to the Democratic Republic of the Congo. Jack spent his early years with his family in the city of Kinshasa, DRC. He doesn't remember learning French, as like Berenice, he learned it at a very young age: "It's always been the language I've known since I was born, since I was a little kid" (Interview with Jack, February 2014). He began learning English in the DRC when he was eight years old, right before he immigrated with his family to the U.S. According to Jack, his English as a foreign language instruction involved the teacher saying something in English and requiring the students to repeat what was said. He did not learn to read and write in English in the DRC, he said; rather, he learned how to read and write English once he immigrated to the U.S. He does not believe that his English instruction in the DRC helped him take part in conversations in the U.S. once he arrived. He reported that prior to coming to the U.S., he knew only a few phrases, such as "please," "thank you," and "one second, please." Arriving in the U.S. at the age of 9, speaking very little English, Jack reported that he felt "left out" because he did not know English as well as everyone else. He spent the summer before school began that particular August watching many television programs in English and paying attention to the spoken English at the church he and his family joined.

Now, at Gridley Community College, Jack reports that he is here because, "I've had really good references to this community college, and um, it's also really close to home. It's like being away from home without actually being away from home" (Interview with Jack, February 2014). Jack hopes to eventually enter into a business 
program, specifically into marketing or advertising; transferring to a four-year university is one of his academic goals.

Jack utilizes various languages, depending on the literacy practice he's engaged in. For instance, at his church, he is responsible for cueing the correct worship song for the overhead projector or PowerPoint; these worship songs are in various languages, Jack told me, but often they are in French or Lingala. To do this, he has to type the number of the song into a computer, and the song appears on the screen. Jack's parents speak Lingala at home, and they write, read, and speak Lingala, French, and English. He says that he can now understand Lingala and actually speak it a bit, just from listening to his parents. Jack surprised his mother recently by translating English dialog from a television program into Lingala for his grandmother to understand; Jack's mother had no idea he had picked up Lingala and could speak it so well:

Well, I was, um, my grandmother and I were watching a movie, so I had to translate what was happening. So, my mom. My mom didn't recognize my voice, because I changed it a little bit. And, um, she thought that somebody else, that someone else came home and was translating what we were watching.... She thought, um, well, last time she heard me speak Lingala, I spoke it really badly, so she automatically had that in mind.... it's been like, uh, seven years? since the last time she heard me. So I've gotten better. (Interview with Jack, February 2014)

When I asked Jack how he improved speaking in Lingala, he responded that he had practiced. His reasoning in practicing Lingala centers on a fear of language loss:

Well, um, because I, because I'm losing French a lot, and because my parents speak Lingala around me all the time, so I'm trying to, uh, if I'm at least losing French, I've gotta keep one native language from the Congo. (Interview with Jack, February 2014)

Jack continued to explain that he still has family members in Kinchasa with whom he communicates via Skype and telephone, and this communication - and the 
communication at home - is predominantly in Lingala, even though until recently he didn't speak it often himself.

Jack enjoys free-writing, and utilizes both French and English. He remembers a teacher in high school remarking how unique it is for a student to have the ability to write in two languages:

Well, my teacher thought it was pretty unique, that, um, that somebody, that he had a student who could do that, because not too many students could, like, write in English and then could write, could translate it into another language. (Interview with Jack, February 2014)

Jack enjoys writing autobiographical texts when he free-writes, choosing to write about his life experiences in either French or English. He also texts and sends out emails utilizing both languages. His preference, though, if asked to sit down and write about his life experiences, would be to use English. During our interview, he told me that he is very comfortable with English - more comfortable than he is with French - after living in the U.S. for the past ten years: "Well, because, as you said, I'm very comfortable with English. And then in French, well, I've forgotten, um, how to like, uh, start up a conversation. I mean, how to start up a writing sample” (Interview with Jack, February 2014). When I asked him to rank the languages he likes to write in, he responded that English is his preference.

When I asked Jack about writing for school - engaging in academic literacy practices - Jack reported that he still prefers writing in English. He remembers most of the punctuation and spelling of French, but he also remarked that he's forgotten a lot of French: 
It's been a while since I've been in a school that speaks French and, uh, sometimes you forget things. There are a lot of things in French that I've forgotten. (Interview with Jack, February 2014)

He also noted what he feels are his strengths in using English for academic literacy practices:

Well, um, I'm really good at brainstorming. That's one of my, that's one of the big things I'm really good at. And then, uh, I'm also really good at, um, spelling, and those are the two main things that pop into mind: brainstorming and spelling. (Interview with Jack, February 2014)

His reported challenges in writing in English echo those of Berenice, especially in knowing when to end a sentence and begin another one:

Well, I really need to think about when to end a conversation. What to, uh, I mean, when to end a sentence, because there are some times I don't mean to write a run-on sentence, but it just happens.... I also need to learn where to put a comma. Those commas! (Inteview with Jack, February 2014)

That both of these students demonstrate awareness of their literacy needs with grammar and punctuation illustrates that the focus on mechanics in the AELP classes and their previous K-12 courses has had an impact on them and that they think reflectively about their writing and can speak about it using metalinguistic language.

Jack's approach to composing in English for school assignments follows the writing process described in the AELP Level 4 class: he brainstorms ("I think about things") and then tries to "put it on paper." I asked him how he puts his information on paper, and he answered

Well, bullets and then write down what I know about a certain bullet, what's on a certain bullet. From there, I usually try to use the Internet and look up some more things and, uh, write down everything that I learn from the Internet.... And then I write my paper.... I usually proofread it. I usually proofread through it and make sure I didn't miss anything. And 
then I usually give credits to sites that I used. (Interview with Jack, February 2014)

As evident in this interview passage, Jack has awareness of the writing process as he learned it in the AELP course and his K-12 courses and is able to discuss what it means to him and how he applies it. In discussing giving "credits to sites that I used," Jack remarked that he really enjoys researching, but most of his research is completed on the Internet; he rarely consults books or library resources when he's searching for information on a topic. When I worked with him in the AELP class, he was quite reluctant to access academic databases on Gridley Community College's website, preferring to use as sources websites he would find on his topic with shorter passages with less-academic vocabulary. However, it is evident that Jack is aware of the issues such as intellectual property and plagiarism, two issues that serve as instructional objectives in the AELP Level 4 course and are also typical U.S. academic literacy objectives.

When I asked him if he ever revises his writing, Jack acknowledged that he does, after a teacher has made comments on his draft: "Usually I look through, um, through the teacher's comments, and then, um, try to see where you went wrong" (Interview with Jack, February 2014). Jack also told me that he appreciates the peer-review process often utilized by his instructors during class time: "Because there could be some things that you might have missed that they can catch, and there might be something that they might have missed that you can catch" (Interview with Jack, February 2014). But Jack reports that he does not seek help from the college writing center or from anyone outside of his class. 
My initial interview with Jack was in February. I met with him at the end of his semester, after his grades in English 101 had been finalized, and he happily reported to me that he had been very successful in English 101, earning an 88\%. He is enrolled in Math 92 (a basic Mathematics course at Gridley Community College) and English 102 -Oral Communication - this summer (the second semester of FYC at Gridley). He will try again to tackle a Psychology class in the fall, having dropped the class earlier this semester because of the heavy reading load. His long-range educational plans are to transfer to a four-year university in the community and major in Business.

When I asked Jack about how helpful he perceived the AELP program to be for him personally, he remarked that it was helpful, in his opinion. Because of his high school courses, he already knew how to find sources, he reported, and he felt that - by the time he reached English 101 - he knew "everything I needed to know" (Interview with Jack, May 2014). When I asked him if he found English 101 difficult, he replied, "It had its moments" (Interview with Jack, May 2014). He elaborated on that comment by explaining that concepts discussed in class were often confusing, but that the textbook would help him clarify what the instructor had been saying ${ }^{12}$. Also, contrary to what he told me in our February interview about not asking other classmates for help, by the end of the English 101 course, Jack was relying on a NES friend to help him with his writing. This friend, Jack told me, would point out to him when his written statements were too broad, a chronic challenge for him with writing, he told me in this later interview. And, as

12 The textbook for the course was Faigley, Lester and Jack Selzer. Good Reasons: Designing and Writing Effective Arguments. Fifth Edition. New York: Pearson. 
Jack has always asserted and continues to assert, mandatory peer reviews in the English 101 class as well as in the AELP class have always proven helpful to him.

While I was excited for Jack and celebrated with him his excellent semester grade in English 101, I was also intrigued as to how he could have managed so well; his assessment of his challenges with writing are ones I agree with. Additionally, I recall from the AELP class that Francine and I had to continually discuss with him appropriate sentence structure, the necessity of elaboration of main points, and using an academic register rather than an informal, speechlike tone in his writing. I will address the speechlike register in Jack's academic written texts and his need to elaborate and support his argument more in-depth in the next chapter; however, here I do want to touch upon two points that I believe had influence upon his success in Thomas's English 101 course (and his lack of success in the Psychology course).

First, Jack was able to adjust adequately to the academic rigors of a credit-bearing FYC course. The progression of Jack's graded work in English 101 reflects a possible adjustment period to credit-bearing classes. For example, on quizzes early in the semester, Jack missed more points than he did on quizzes later in the semester. Jack himself expressed to me that he had to adjust to the course expectations. More than likely, Jack's success at adjusting is due to his prior experience in U.S. educational institutions (his K-12 schooling in the U.S.). What Jack was prepared to do in an academic class and the reality of the requirements of that class were at odds, demonstrating the three discrepancies Allison (2006) found in her case study of U.S.educated multilingual students in community college classes (see Chapter II). Additionally, Riazantseva's (2012) study of successful U.S.-educated multilingual 
students from Russia suggests how students like Jack can be successful with academic writing classes at the college level despite producing writing that often does not demonstrate an academic register or structure (Riazantseva calls it "at times simply poor" 2006, p. 189). Jack shares several qualities related to success with Riazantseva's participants. First, like Riazantseva's participants, his oral literacy is high. Thomas, Jack's instructor, actually remarked about Jack's oral strengths without realizing he was remarking upon my participant:

Like I have a student from Africa this semester. But, I don't know.... He speaks French. Um. But he speaks English perfectly. He brought in a little bit of, we were talking about, you know, certain words, and their origins and things like that, and we would bring up certain words, and he would say, "That one has a French origin," and "That one has a French origin." (Interview with Thomas, February 2014).

It is evident from these remarks that Thomas is not totally sure of Jack's background as an ESL student in his class, but that he feels Jack's oral skills are quite good. When I asked Jack if he was the student about whom Thomas made these remarks, Jack proudly took credit and elaborated more upon the context of the class discussion on word origins.

Jack's classroom participation, as evidenced here and by the points he earned for participation in the English 101 class (150 out of 160 points for participation and attendance) illustrate a second shared quality between Jack and the participants in Riazantseva's study: they participate regularly in class discussion and are more often than not engaged in the class, as they are meta-aware of their written challenges. Like the U.S.-educated multilingual students in Riazantseva's study, Jack - due in part to his experience in the U.S. K-12 educational system and also to his family's support of his 
educational goals - possessed the cultural capital he needed to succeed in Thomas's FYC course.

However, while Jack quickly adjusted in English 101, he did not in the Psychology class, due to what he perceived as a heavy course reading load ${ }^{13}$. The reading load in English 101, according to Jack, was much lighter. It is evident from these facts that academic reading, while it was not a focus of this study, is an academic literacy task that may prove difficult for Jack in the future. Jack's challenges in this area may be due in part to his arrested literacy development in French and Lingala when he immigrated to the U.S. At the time of immigration, his French was not fully developed and then ceased to advance (see the discussion of Blanton's 2005 case study in Chapter II); and, his English capabilities, as he reported, were not helpful once he arrived in the U.S., requiring him to learn quickly in order to succeed in the academic environments. While reading is not a focus of this study, reading and writing, along with speaking and listening, are key academic literacy areas, as Singhal (2004) contends. Success in academic contexts, according to Singhal (2004) have strong communicative skills in all four areas, in addition to highly-developed critical thinking skills and strong research skills (p. 10). Further study is warranted, in my opinion, on the impact on success in credit-classes for U.S.-educated multilingual students in the other literacy areas in addition to writing.

${ }^{13}$ While this study did not encompass Jack's experience in his other credit-bearing courses and instead focused on FYC, it is still worth noting that Jack did not complete a content-area course in which he had enrolled as well as his reason for that noncompletion. 


\section{Chapter Summary}

In this chapter, I provided information relevant to the context of this study: the community college; the ESL Program at this community college and the Director of ESL Programs; the introductory mainstreamed English classes as well as the English 101 section and instructor specific to this study; and a portrait of each of the studentparticipants. While only one of the three original participants in this study actually transitioned to English 101, it is important to acknowledge that one - Berenice - plans to continue along her academic trajectory and will hopefully transition to credit-bearing courses. Therefore, while Chapter V will include an analysis and discussion of predominantly Jack's writing in both the AELP Level 4 and English 101 classes, I will also include what little of Berenice's writing from AELP Level 4 she provided me. From an analysis and discussion of both students' writing at this community college, and from an evaluation of Jack's success and challenges in English 101, Chapter VI will then address the original research questions as well as pedagogical implications and suggestions for both the ESL Program and the English Department. 


\section{CHAPTER V}

\section{DATA ANALYSIS AND FINDINGS}

\section{Introduction}

In the previous section, I provided a context for the present study. More specifically, I described the community college venue as an accessible site for U.S.educated multilingual students. I also demonstrated how Gridley Community College specifically is serving the ESL population in the community. The ESL program at Gridley works to serve not only adult immigrant students who desire to learn and improve their English literacies but also adult immigrant students, international students, and U.S.-educated multilingual students who wish to continue along an academic trajectory, whether that involves completing an associate's degree or eventually transferring to a four-year university to earn an undergraduate degree. In short, the previous chapter served to provide a picture of the context in which I sought to answer my research questions:

(i) What are the experiences of U.S.-educated multilingual students in mainstream composition courses in community colleges?

(ii) How can ESL programs better prepare U.S.-educated multilingual students?

As my research questions are focused on the experiences of U.S.-educated multilingual students in mainstream community college composition courses, I described in depth the Director of ESL Programs, Jane; the AELP class in which my participants were enrolled; 
the English 101 course into which Jack transitioned; and the instructor and instructional climate of that course: the assignments, expectations, and Jack's success in that course. Additionally, I provided some analysis of some secondary themes of my research. I explained that, because of a lack of demand and resources for more focus on U.S.educated multilingual students as distinct from other ESL students at Gridley Community College, the former are grouped into courses with the latter. I also provided some thoughts, based on current research on U.S.-educated multilingual students who do not pass ESL courses, on why and how Berenice did not pass the fourth level of AELP. I also provided some insight, based on literature, on why and how Jack might have been so successful in English 101, despite my initial reservations.

In this chapter, I will closely examine the academic literacy practices of these two participants as students, seeking to answer the two research questions driving my study. Specifically, I will show and discuss similarities and differences in these students' academic literacy strengths and weaknesses. As U.S.-educated multilingual students, both Jack and Berenice report an adherence to the traditional process approach to writing, as that is what they have learned in their U.S. K-12 schooling and also in the AELP courses. Additionally, as the findings will illustrate, Jack's and Berenice's academic writings demonstrate much "speechlike" discourse as well as often a lack of elaboration or use of support. Finally, the findings will show that these two participants share similar perceived writing challenges as well, reporting that they often are challenged to know just how to employ appropriate sentence structure.

In the previous chapter, I also discussed a difference between these two students: Berenice has challenges in "being a student," so to speak, that Jack does not, in that she 
often has to prioritize her employment and family responsibilities over her schoolwork and course attendance. Jack's situation, however, was much different, and he transitioned to English 101. Because of this, Jack met a new kind of challenge, that of adapting to forcredit courses and a slightly different instructional style. Therefore, I wish also to discuss in this chapter Jack's challenges in utilizing secondary sources appropriately, as well as his adaptation to learning about different types of texts - specifically, multimodal ones and his challenges with reading longer academic texts, which inevitably affects his academic writing.

The academic literacy practices that I will analyze in this chapter, and that I analyzed in Chapter IV, are part of what is traditionally considered "the language of schooling" (Schleppegrell, 2001). Schleppegrell states that "in academic contexts...there are clearly recognized text types that are characteristic, and these text types are instantiated through grammatical features that are common to school-based uses of language and that reflect the purposes for which language is typically used in schooling" (p. 432). These "text types" are genres; as I discussed in Chapter II, Hyland (2004) defines genre as "a term for grouping texts together, representing how writers typically use language to respond to recurring situations" (p. 4). Often, how writers use language in writing a particular genre - or the register - depends upon the writing context of that genre. Schleppegrell (2001) defines and discusses the term "register" concisely:

A register is the constellation of lexical and grammatical features that characterizes particular uses of language.... Registers vary because what we do with language varies from context to context. The choice of different lexical and grammatical options is related to the functional purposes that are foregrounded by speakers/writers in responding to the demands of various tasks. Texts produced for different purposes in different contexts have different features. (pp. 431-432) 
Therefore, when I discuss the academic genres my student-participants are required to compose in their AELP program or in the English 101 course, I refer to these genres as academic texts or writing tasks. In my discussion, I will show how, often, Jack does not utilize the standard register for the given academic assignment.

\section{Similarities Between Jack and Berenice: Using a Process Approach to Composition}

Jack and Berenice both fit into the nebulous grouping of U.S.-educated multilingual students, in that they both arrived in the U.S. as children and completed U.S. high school education. As they learned English writing, they learned to write using a conventional process approach; this approach was the main approach to writing instruction in the AELP at Gridley Community College as well. The instructor of the course spent much instructional time reviewing and emphasizing the process approach; she had many hand-outs, including a section from The ESL Writer's Handbook, that she reviewed with students regarding the writing process. Much of that material detailed the stages of the writing process as including understanding the assignment; thinking about audience; generating ideas; organizing and outlining ideas; drafting; revising; and editing (AELP hand-out, received September 2014). Writing assignments also reflected this process-centered approach by often requiring students to demonstrate the various steps of the approach; for example, for almost every assignment, students would be required to have a draft ready by a certain day of class, to have it reviewed by a peer (and to review a peer's writing as well), and then to show evidence of revision. Sometimes students would be given direction, either verbally or in the form of a hand-out, on just what to look for during the peer review time. A few times, students were given a grade for how 
thoroughly they reviewed a peer's writing. Thus, a process-centered approach drove the composing process in the AELP Level 4 course.

Both Jack and Berenice reported in their interviews with me that they used the process approach in composing an academic text. I asked both of them how they began writing a text in English, either as an assignment for AELP or for English 101. My exchange ${ }^{14}$ with Berenice regarding her composing process proceeded like this:

M: So, when the teacher in AELP 4 would give you a writing assignment, like the narrative paper or the research paper, what would be the first thing you would do to do that writing assignment? How did you go about completing the assignment?

B: I usually like writing it on paper first, and then, like, I'll write it and then I'll check again if it sounds right or not. Like, my brother, he knows more English than me and my sister, so like I will ask for help from him? And then I'll correct it and then I'll type it on the computer.

M: Do you brainstorm first?

B: Yeah.

M: And then what do you do?

B: I come up with and I try to make sense and I try to, not in sentences, but whatever I brainstorm and I try to put it together into a paragraph or paper or whatever.

M: You use phrases.

B: Yeah. Phrases.

M: We often brainstorm with phrases. So in that class, there was a lot of peer-review. Do you like your classmates reviewing your writing?

B: Uh, yes, 'cause it helps me, like, know where I'm making a mistake, like if I'm spelling something wrong or my grammar or something.

M: And, you mentioned about asking your brother for help?

14 This was my only formal interview with Berenice. 


\section{B: Mm-Hmm.}

M: Do you ask anybody else for help with your writing?

B: Um, not really. It's him or my sister. We tend to ask more my brother, because he knows. (Interview with Berenice, April 2014)

This interchange between Berenice and me reveals several things about her personal composing process. First, she mentions that she initially puts her ideas into writing on paper, and then she checks it and also has her brother check it before she types it into the computer. What she is describing is a recursive writing process, where her writing goes through several stages in the composing process. In asking her brother for help, Berenice is also implementing a peer review process, of sorts, in her composing. She also knows the value of peer review, but she implements this for predominantly surface errors: "Uh, yes, 'cause it helps me like know where I'm making a mistake, like if I'm spelling something wrong or my grammar or something” (Interview with Berenice, April 2014). Later in the interview, I returned to questions regarding the writing process:

M: How do you revise your writing? You said you go back and check to see if it's right.

B: Yeah, I read it out loud.

M: Oh. That's a good strategy.

B: And then I try to like, like, repeat it once or twice to see if it actually sounds like it's supposed to sound. And that's pretty much it. (Interview with Berenice, April 2014)

These two sections of my interview with Berenice, in which we discussed the writing process, demonstrate that she is aware that composing is a process and that she should return to what she has written to ensure that she has used appropriate grammar, sentence 
structure, and spelling. At no time, however, does Berenice make mention of rhetorical concerns, as in using a logical pattern of presenting information, supporting her points with examples, or making certain she has an introduction and a conclusion. Her revision process, and what she hopes her peers and brother will help her with in reviewing her writing, is isolated to surface errors. Her process - centered on surface errors - echoes what Silva (1997) contends is often an imbalance in the composing process of an ELL: “The ESL writers' composing processes seemed constrained in some salient and important ways. Compared with NES subjects, they planned and reread their writing less, wrote with more difficulty because of a lack of lexical resources, and exhibited less ability to revise intuitively by ear" (p. 215). Berenice might have reread her writing several times, but as evidenced by the interview transcripts above, she spends little time in the planning stage of the writing process. Additionally, as I will show later, she is not often successful in revising by using her auditory intuition.

My exchanges with Jack regarding how he approaches writing assignments followed a similar path. I asked Jack essentially the same question that I asked Berenice: How do you approach a writing assignment? We were discussing how he began the research paper in the AELP class the previous fall:

M: So, when the teacher last semester gave the research paper assignment, and said, "You have to write a research paper," what is the first thing that you did?

J: What's the first thing that I did? I usually, um, think about what I know about, um,... I usually think through things.

M: And then what do you do?

J: Well, I try to put it on paper, so... 
M: Ok. How do you put it on paper?

J: Well, bullets and then write down what I know about a certain bullet, what's on a certain bullet. From there, I usually try to use the Internet and look up some more things and uh write down everything that I learn from the Internet. (Interview with Jack, February 2014)

The above excerpt from Jack indicates traditional prewriting strategies, strategies instructors focusing on a process-approach to writing typically instruct students to complete first. Jack utilizes all of the appropriate prewriting concepts in detailing his steps: "think about things," "put it on paper," using "bullet" points to outline. He continues using typical writing process concepts as he tells me about how he composes a piece of writing in English:

M: Ok. Do you then write your paper?

$\mathrm{J}$ : And then from ,.. yeah, and then I write my paper.

M: Ok. And then what do you do with the paper? Do you hand it in?

J: I usually proofread it, I usually proofread through it and make sure I didn't miss anything. And then I usually give credits to site that I used.

M: Right, you cite your sources. You learned about that last semester I remember.

J: Right.

M: Do you ever revise anything that you write?

J: Yes, I do.

M: How do you do that?

J: Usually I look through, um, through the teacher's comments, and then um try to see where you went wrong.

M: Ok, so the teacher looks at your draft? 
$\mathrm{J}$ : Yes.

M: And so that's how you revise. Do you ever have peer comments, like classmates who look at your paper and tell you stuff about it?

J: Yeah. We do.

M: Do you like that?

J: Yes, I do. Because there could be some things that you might have missed that they can catch, and there might be something that they might have missed that you can catch.

M: So, you think it's very helpful to peer review.

J: Right. (Interview with Jack, February 2014)

In this excerpt, Jack details what he does with his writing after he makes his outline: he writes his paper, he proofreads it, and he provides citations for his secondary information. In Jack's narrative, a teacher evaluates his paper, provides feedback, and then he revises. He also mentions peer-review, which he says he likes because "there could be some things that you might have missed that they can catch."

Like Berenice's responses, Jack's responses indicate that he knows that writing is a process; he knows that he begins by thinking about what he knows and then writing what he knows on paper using bullets. The "bullets" Jack invoked coincides with the "phrases" that Berenice mentioned. The instruction in the AELP course seems to have encouraged the students to brainstorm their ideas in phrases or using bullet-points, rather than writing out complete sentences. As evidenced in Jack's responses, he may spend a bit more time in the planning stages of writing than Berenice does. Jack's responses also show that he, like Berenice, values the peer-review activities as a way to help him revise and improve his writing and for him to help others do the same. 
Jack did not elaborate on just what it is that he revises in these responses, but I recall from working with him in the AELP class that his revision process would focus on surface errors only. Jack would ask me about spelling and punctuation, and especially about sentence structure. But, always, Jack's writing would have rhetorical gaps in which he would not have fully explained a point that he had made, requiring his reader to try to fill in that gap in the thought process. After advising Jack to revise such issues, I would return to look at a subsequent draft and realize that he had not revised the rhetorical structure of the text but only the surface, mechanical structure. This lack of elaboration and explicitness is something that I will return to later in this section, but it bears mentioning here, as both students' ideas of proofreading and revising involve checking for minor surface-level errors only rather than on logic or more complex rhetorical features.

The concept of rhetoric is one that is central to this study, as it is a main focus of the learning objectives of the English 101 course as well as a concept repeatedly discussed in case studies on academic literacies (See my discussion of academic literacies in Chapter II, especially Jeffries and Yi, 2008; Silva, 1997; Singhal, 2004; and Thonus, 2003). Tardy (2005) discusses the importance of rhetorical knowledge to academic literacy in a case study involving second-language writers at the graduate school level. In her case study, she makes the argument for the necessity of rhetorical knowledge as part of academic literacy learning and acquisition. As Tardy states, "expert writers... see texts rhetorically, existing within a social activity, created by and for real people; rhetorical knowledge is therefore a crucial part of advanced academic literacy, which demands writing for and within a social group" (p. 327). If the goal of instructors is to support 
students in developing their academic literacies, then applying rhetorical constructs to academic writing needs to be stressed in courses such as the AELP class; students need to realize that there is more to the composition and revision process than correcting mechanical, surface-level errors. In this same context, Thonus's (2003) teacherresearcher case study (discussed in Chapter II) on how writing centers can help ESL students with academic writing tasks can be applied to the AELP classroom, as well as FYC classrooms with ESL writers. Thonus's third principle explicitly addresses this issue: Focus on rhetorical concerns with writing rather than just grammatical or sentencelevel concerns. While the AELP curriculum in this study discussed rhetorical factors in writing, more explicit discussion of these factors may need to happen at the reviewing stage, demonstrating to students just how to make changes in their texts to enhance the rhetorical outcome, rather than just completing surface-level editing.

\section{Similarities Between Jack and Berenice: Imbalance Between Oral and Written}

\section{English}

Arriving in the U.S. during their elementary school years, Jack's and Berenice's study and usage (in other words, their academic literacy) of their L1s (for Jack, French; for Berenice, Spanish) ceased to develop, and they were forced to learn English as an additional language. As Blanton (2005) explains, students such as Jack and Berenice are caught between their first language and their second language, with still-underdeveloped academic literacy in their L1 and very basic literacies in English. To revisit Blanton's 2005 study, which I detailed in Chapter II, Blanton conducted a teacher-researcher case study in which she sought to ascertain how two of her U.S.-educated multilingual students could better be served by a four-year university. According to Blanton, U.S.- 
educated multilingual students have different literacy needs in writing in academic English. These needs have their roots, Blanton claims, in having their L1 written literacy "arrested" (Blanton, 2005) before it was fully developed; these students then learn to compose in English by springboarding from their literacy strengths in English: speaking. As Schleppegrell (2013) explains, "school children [as opposed to international students] often quickly develop informal registers of the new language that serve them well in interaction with peers and teachers about everyday things" (p. 154). The students in the present study moved to the United States as young school children, at around the age of ten years, as discussed in Chapter IV. In Schleppegrell's view, young children use language interactionally, and so when they learn a second language - especially when they are immersed in that language - they will acquire that language in informal, interactional registers first. Schleppegrell goes on to explain that this informal, interactional register is more commonly used than academic ones, because "many of these children have few opportunities outside of school to learn or use the academic language needed for success in school contexts" (p. 153).

Berenice and Jack, similar to the two students in Blanton's study and also similar to the "young children" about which Schleppegrell speaks, also moved to the U.S. before their L1 writing competencies were fully realized. Berenice reported to me that, when she first arrived in the U.S., she had classmates and a teacher who spoke Spanish, serving as a support-system in making the transition to speaking English:

M: And you didn't feel like you were prepared to speak English?

B: Not really. But there were, like, some more Hispanic kids, it was like... M: Oh. So you had classmates that you could talk to. 
B: Yes, most of them was Hispanics, I remember.

M: And that was at your elementary school?

B: Yeah, and the teacher actually spoke Spanish, too. (Interview with Berenice, April 2014)

As the interview excerpt above illustrates, while Berenice had no formal instruction in her L1 - Spanish - after she moved to the U.S., she had a support system, in that some of her classmates and even her teacher spoke Spanish in the schooling context. Berenice reported to me that it was not until her junior year of high school that she had additional formal instruction in her L1; however, that experience was not ongoing instruction:

I think it was my junior year in high school, I took a Spanish Heritage class. It was for people who actually, like, spoke Spanish, it was to teach us our grammar and such, so we wrote in Spanish.... Yes, and it help us remember our grammar.... I actually want to, like, have a certificate that I actually, like, speak or write Spanish, you know? (Interview with Berenice, April 2014)

In my talks with Berenice, she told me that she uses Spanish for personal communication, as in talking and texting with her friends and family. But, she calls this Spanish "slang Spanish." Thus, she has appropriated her L1 for personal and informal purposes, rather than for academic purposes.

Jack's L1 development could also be said to have been arrested. Jack's first language is French. This is the language he began learning from birth, he says: "Yeah. It's always been the language I've known since I was born, since I was a little kid" (Interview with Jack, February 2014). Unlike Berenice, Jack does not report any peers or teachers in his early school-year classes in the U.S. who also spoke French. His uses for his L1 - French - since he moved to the U.S. have remained, like Berenice's uses of 
Spanish, primarily personal, as French is the language spoken in his home. Additionally, while Jack is currently in the process of trying to "pick up" Lingala from listening to his parents and others from his birth country, the Democratic Republic of the Congo, he has no formal instruction in using it for academic purposes. Thus, both Jack and Berenice use English for public literacy practices (or non-academic practices), as well as academic ones.

As I presented in Chapter II, much research points to U.S.-educated multilingual students having advanced oral literacy in English over their written literacy in English. Again, Schleppegrell (2013) explains that this is because they learn English by practicing it interactionally, in informal social contexts, rather than in school contexts. Blanton (2005) reiterates this concept, as she asserts that U.S.-educated multilingual students are those "whose written English proficiency lags far behind their spoken fluency, but whose L2 writing, however deficient it is considered to be, may actually be more developed than their L1 writing" (p. 110). As already mentioned in this chapter, students' L1 literacy development ceases when they immigrate. Students' spoken English literacies then become much more developed than their written oral English literacies as they usually learn English first through spoken discourse due to the increased necessary input and output necessary in the oral domain. Bloch (2007) mentions this literacy imbalance in describing the results of a case study on a U.S.-educated multilingual student's academic literacy growth from blogging. His case study examined the use of blogging by U.S.educated multilingual students as a way to bridge their more-developed oral English literacy with their less-developed written English literacy. Underscoring both Bloch's (2007) and Blanton's (2005) assertions of an imbalance between oral English literacy and 
written English literacy for U.S.-educated multilingual students, Reid (2011) describes U.S.-educated multilingual students as “'ear' learners," having acquired English predominantly through listening and speaking" (p. 83). Likewise, Jane, the Director of ESL Programs at Gridley Community College, reports her own awareness of this characteristic:

Yes, of course their written literacy is far lower. A lot of students may have come at a time when they were learning to read, and so they may have started learning to read in their first language, and then when they came her were forced into ESL classrooms and they were forced to switch how to learn to read in a second language. And so that has caused many problems for these types of students. (Interview with Jane, December 2013).

These remarks from Jane acknowledge an imbalance between oral and written literacy and are consistent with what has been said in the published literature about U.S.-educated multilingual students' literacies. In Chapter IV, additionally I reported on my interview with Thomas, Jack's English 101 instructor, who commented on a student from Africa in his current English 101 course whose English was near perfect: "Like I have a student from Africa this semester. But, I don’t know...He speaks French. Um. But he speaks English perfectly" (Interview with Thomas, February 2014). As I mentioned in that chapter, Jack readily acknowledged being that "student from Africa."

Several studies have also found that U.S.-educated multilingual students tend to apply their oral literacy processes to their written literacies. As I cited earlier, Reid (2011) makes the connection between U.S.-educated multilingual leaners' strong oral literacy and their oftentimes "speechlike" writing: "These learners' writing "displays the conversational, phonetic qualities of their 'ear-based' language learning, as well as the 
use of their self-developed language 'rules' that may, upon examination, prove to be overgeneralized or false" (p. 83). Similarly, Jeffries and Yi (2008) sought to determine if there was a connection between U.S.-educated multilingual students' strong oral literacy and their writing, finding that their participant's written academic texts resembled in register her oral, and relatively informal, presentations. Additionally, Schleppegrell's (1996) study, a close analysis of how U.S.-educated multilingual students often operationalize lexicon in written discourse in much the same way that native speakers operationalize the same lexicon in oral discourse, demonstrates how U.S.-educated multilingual students in her study used the conjunction "because" in written texts in ways that were non-standard for a spoken register.

While I did not conduct a focused linguistic analysis of specific spoken discourse markers used in written texts like Schleppegrell (1996) did, I gathered many examples of written texts from both Berenice and Jack that demonstrate that they often write like they speak. However, these two students apply their oral literacy knowledge to written texts in ways different from each other, as will be further explained below.

Berenice, in my interview with her, remarked several times that, to check her writing, she would often read it to herself to see if it sounded correct:

B: I usually like writing it on paper first, and then, like, I'll write it and then I'll check again if it sounds right or not.

and:

M: How do you revise your writing? You said you go back and check to see if it's right.

B: Yeah, I read it out loud.

M: Oh. That's a good strategy. 
B: And then I try to, like, like, repeat it once or twice to see if it actually sounds like it's supposed to sound. And that's pretty much it. (Interview with Berenice, April 2014)

In both excerpts, Berenice reported that she relies on "sound": She wants to make certain that her writing "sounds like it's supposed to sound." Interestingly, Berenice often resorts to phonetic spelling or to using words that sound similar to those she intends to use. The following passage is from Berenice's AELP argumentative paper in which she argued for no-cost birth control ${ }^{15}$ :

I'm going to talk about free birth control. By having birth control we will have more teenagers taking them and encoring them to protect them selfs..... think is a way of protecting their future so that they can have a carrier and when they are grown in off they can became parents.

(Berenice's proposal excerpt, received December 2013)

In this passage, it is evident that either Berenice's spelling is often phonetic and that the word-processing system changed her misspelled words to words that sounded like what she wanted to use, or that she relied on her ear - on how the text sounded - when she revised. For example, her use of the word "encoring" instead of "encouraging" more than likely stems from her inability to spell the root of "encouraging," misspelling it as the root of "encoring." The same situation more than likely happened with "carrier" when Berenice intended the word "career." "Them self"s" also sounds similar to "themselves," and so Berenice did not realize that her usage was nonstandard. She uses the correct

\footnotetext{
${ }^{15}$ I have transcribed interviews and reproduced the participants' writing as closely as possible to their actual spoken and written compositions. Additionally, while these students might demonstrate numerous complexities and nonstandard usages, I will focus on just the themes that are relevant to this chapter, instead of addressing every surfacelevel error, such as punctuation or grammar errors.
} 
collocation of "become parents;" however, she employs the past-tense of "become" and instead writes "became."

Similar non-standard usages occur in Berenice's book report:

At the begging of this book we see the family always traveling in two cars where Lala's uncle drives one while her father drives the other one and all the things they see while getting to Mexico City and living with her grandparents.... Lala is a young girl who has always remembering of going to Mexico for the summer to see her grandparents....Probably something that affects her is getting back to the idea that every summer she is in Mexico and has to get used to the idea way her grandparents living. (Berenice's book report, received December 2013)

In this book report passage, we see that Berenice used the word "begging" when she obviously meant "beginning." "Remembering" is also used as a noun here: "Lala is a young girl who has always remembering..." Berenice perhaps intended the word "memories," instead. She also, in a non-standard sentence structure, uses "idea" appropriately once, and then uses it again when she probably meant "ideal." Also, Berenice skips words, such as the auxiliary verb "are" between "grandparents" and "living." Her ear does not notice these mistakes when she reads her writing to herself, and so, to her, her usages are correct.

While unlike Berenice Jack does overly rely on spoken discourse and, as a result, spell words phonetically or use inappropriate words that sound like the word he intended to use, Jack uses an inappropriately informal register for his academic writing tasks.

Francine (the instructor for the AELP Level 4 class), during a final one-on-one conference with Jack mentioned to Jack that he writes like he speaks; she cautioned him to take a more formal tone in his academic writing in English 101. 
Jack's academic writing task register did not vary significantly from the AELP course to English 101. In the AELP Level 4 class, as described in Chapter IV, Jack and his classmates were assigned an argumentative paper. An excerpt of the writing assignment gives an overarching picture of the academic task, which required students to draw on knowledge and values from their "home culture:"

For this writing assignment, you will ponder an issue in your home community that you would like to see changed. Write an argumentative essay about that particular issue. You will inform your audience, your home country ambassador, of your opinion in an effort to convince them to adopt that point of view. You will convince your audience of what will happen if the issue is not faced. (Assignment sheet, received October 2013)

Jack's argumentative paper for AELP 4 contains many examples of his speechlike writing. The following excerpt is taken from a paragraph in Jack's paper in which he is describing one reason why children in the Democratic Republic of the Congo are fighting in wars:

Some Congolese say that kids go to war because they usually have families to take care of and earn respect. I'm not going to lie; this is a good reason to go to war, but you have to remember that we are talking about kids who are five years old carrying muskets.... Is this our way of going to serve our country? By kidnapping innocent kids?... Why do we drag them into hard situations like going off to wars? I mean, it's bad enough that these kids are struggling at home. Now you want to put more stress in the lives of these kids.... Is the money really worth putting the kid's life in danger? Even if my family was struggling, do you honestly think that I would allow my kid's to risk their lives for me? If you do than you are definitely crazy, because no amount of money is worth life. I don't care how much money it is.... Is this the kind of country we want to live in? I didn't think it was, because who would be crazy enough to let their kids live in a community like this. (Jack's paper, Child Soldiers in the DRC, received December 2013).

The first feature to note is that Jack uses the first person "I" to refer to himself as the writer and "you" to refer to his reader. While using the first person "I" is used 
occasionally in academic writing, he also refers to his reader with "you" and employs the first-person plural - to include himself and the reader - with the use of "we".

The next feature of Jack's writing to note with this excerpt is the repetitive use of rhetorical questions to support his main point. Some of these questions he answers himself (“... do you honestly think that I would allow my kid's to risk their lives for me? If you do than you are definitely crazy...."), and others he relies on his reader to answer (I will address the lack of explicitness and support in a subsequent section). Asking many rhetorical questions such as these could be seen as more acceptable for an oral presentation. Additionally, Jack employs word choice and phrases that are discourse markers for spoken discourse rather than academic written discourse: "I'm not going to lie...”, “I mean, it's bad enough...”, “...do you honestly think...?”, “I don’t care...”, and “...who would be crazy enough..." are all examples of phrases that are more appropriate for a casual spoken register than for a written academic task.

Excerpts from Jack's academic writing in English 101 also reveal his inappropriate application of an informal register to an academic writing task. The following excerpt is from an argumentative paper on media portrayal of African stereotypes that Jack wrote for English 101, approximately five months after he wrote the child soldiers paper (excerpted above) for the AELP course:

If you get your sources from Google, you might think that African women walk around with if not 1; both of their fully exposed breasts. Another thing you get when you search African people on Google is, a pictures of people wearing animal skin around their necks. But the stereotypes that are most disappointing are the UNICEF commercials. We have all seen those commercials; I admit they are sad, and true.... When I lived in Africa I've have never seen snow in my life. I just thought that snow was a friendly weather that kids usually play with, but boy was I wrong.... 
We African's do believe in education a lot, just like in the United States. We don't have the same type of educational technologies that we have in the U.S. Why is that you ask? Well if you're thinking it's because we are poor that is not the reason why.... Anyone would get out of their country to come to the United States, if the Economy in their country isn't doing too well. It's just reasonable thinking that's all. Anybody with a brainstem would pull something like this.

The bad thing about Africa is that some African countries have Child Soldiers. In case you don't know what Child Soldiers are, they are kids who go to fight in wars. (Jack's argumentative paper, "African Stereotypes," for English 101, received May 2014).

Again, in these excerpts we see that Jack is using the first person narration, using "I", as well as referring to his reader(s) as "you." In the third paragraph, he also uses the firstperson plural "we" to refer both to himself and other African people as well as himself and the reader ("We don't have the same type of educational technologies that we have in the U.S."). With his choice of narration and pronouns, Jack invokes a closer relationship with the reader than what is usually expected from an academic written task.

Jack also again employs phrases that are much more conversational in register than is appropriate for academic written texts: "I admit they are sad, and true...", "but boy was I wrong", "It's just reasonable thinking that's all”, "Anybody with a brainstem would pull something like this", and "In case you don't know...." These examples all demonstrate that Jack, even in English 101, is continuing to write in a conversational manner.

Schleppegrell (1996) explains why writing in a speechlike manner is problematic in academic writing tasks: "Registers used in conversational genres reflect the interaction of the interlocutors and the joint construction of discourse. Writing, on the other hand, typically reflects the fact that the writer and reader do not interact directly, and that the 
writer has time for revision of a written text" (p. 280). With his oral English literacy strengths outweighing his written English literacy strengths at this particular time, Jack is relying on the former to produce the latter. However, he does not realize that written academic tasks have a different purpose, a different type of audience, and require a different register than the spoken literacy he is proficient and comfortable with. Important for this study, a study in which students from an academic ESL program are transitioning to English 101 and content area courses in which they will be required to complete academic writing tasks, is that these students need to understand and have the written literacy strengths to compose in registers appropriate to the tasks. Schleppegrell (1996) states, "Language learners who want to succeed in academic contexts need to acquire competence in registers typical of written language genres. This means acquiring a different understanding of how language is structured when it is written rather than spoken" (p. 279). Both Berenice and Jack - as well as any student transitioning from the ESL program to for-credit college classes - need to acquire this competency.

\section{Theme \#1: Lack of Support and Explicitness}

Interesting to note with Berenice's and Jack's written texts is that they adhere to a strict overall structure when they compose academic essays or reports in English. Berenice's and Jack's proposals for the AELP argumentative papers (Berenice's was on free birth control; Jack's addressed the conflict of child soldiers in the Democratic Republic of the Congo) followed the writing prompt exactly. Francine, the AELP instructor, had given the students an assignment sheet that included questions the students should address in their written proposal; students were asked to explicitly state their topic, their position on the topic, their audience, their intended message for the audience, 
and what they wanted their audience to do as a result of reading their argument. Both students explicitly answered all of the questions, often repeating words or a phrase from the question. For example, in response to the query as to audience action after reading their arguments, Berenice and Jack both answered in their written proposals as follows:

B: I want readers to support the idea of free birth control and more knowledge about what effect these does by not having birth control. (Berenice's argumentative paper proposal, received December 2013)

J: I want the readers to think that something has to be done about these kids. (Jack's argumentative paper on child soldiers, received December 2013)

The book report assignment for AELP also had a list of specific questions or issues to discuss in relation to the students' chosen book. Berenice, like she did in her proposal, addressed each area; however, instead of writing her text as flowing, cohesive report answering the questions on the assignment sheet with paragraphs and transitional phrases, she numbered her answers, with numbers corresponding to the questions students should consider in writing their reports. For example, the first question of the assignment asked students to explain what their book was about, and the second question asked students to write about some of the main points of the book; Berenice's responses to these two queries are below:

1. This book is about a Hispanic family who always has travel to from Chicago to Mexico for the summer to see Ceyala's grandparents more known as Lala. at the begging of this book we see the family always traveling in two cars where Lala's uncle drives one while her father drives the other one and all the things they see while getting to Mexico City and living with her grandparents. The author of this book is Sandra Cisneros.

2. Some of the main point of writing this novel is that people can know some history about Mexico and that you can feel the love and the joy of a family. (Berenice's AELP book report, received December 2013). 
In these written excerpts, we see that Berenice answered the questions explicitly; as long as the question was asked directly, she answered it directly.

Jack completed his book report as a PowerPoint text. His slides, like Berenice's written report in which questions are answered explicitly, are organized according to the discussion points suggested on the assignment sheet. His second slide is titled, "Author \& Reason for writing this book," and his third slide is titled, "Where is he from?" The fourth slide addresses characters of the novel he chose, as he titled this slide, “Characters” (Slides from Jack’s PowerPoint book report, received December 2013). These students understand that, to be successful students in an academic context, they need to adhere to instructions on the assignment sheet given to them.

Also interesting to note is that Jack's essays and argumentative papers for the AELP class follow a very strict structure ${ }^{16}$. His compositions all begin with an introduction that includes a thesis statement. Each paragraph has a topic sentence with a transition. He has a conclusion that restates his thesis. The overall structure of Jack's written academic texts for narrative and argumentative genresadhere to traditional conventions of structure ${ }^{17}$.

However, neither Berenice nor Jack habitually provides adequate or appropriate support for their points. Silva (1997) asserts that lack of development and explicitness is one of the key differences that is often evident when comparing the writing of ELLs and

\footnotetext{
16 I have less written text to use as data from Berenice due to her absences in AELP Level 4 course. Additionally, she had no computer files to share with me, having either typed and printed her work in a library computer lab or written her work by hand.

${ }^{17}$ I specify "narrative and argumentative genres" here, as I will later show how Jack did not adhere to an standard genre conventions in completing multimodal compositions.
} 
NESs: In Silva's review of studies comparing the writing of ELLs to that of NESs, he found that these studies largely concurred that the writing of ESL undergraduates was "less effective" than writing by NES undergraduates (1997, p. 210). The texts of ESL writers were also found to be less cohesive, employing a much lesser degree of support and detail for posited claims than the texts of NESs. It is in this way that Berenice's writing and Jack's writing both exhibit characteristics of writing by ELLs.

Berenice's writing is devoid of explicit elaboration. Her book report, for example, lacks developed concrete details; Berenice relies instead on abstract, lofty statements:

Some of the main point of writing this novel is that people can know some history about Mexico and that you can feel the love and joy of family. (Berenice's book report, received December 2013)

This excerpt was Berenice's short response to the book report assignment prompt that asked students to illustrate main points of the novel they read. What Berenice might have considered doing in this paragraph is explaining what she meant by "history about Mexico": Two questions that she could have considered in writing this paragraph in order to support her point more explicitly are, What types of historical facts would a reader learn by reading the novel? and, What were the main characters' perceptions of these historical details? She also should have elaborated upon her phrase, "that you can feel the love and joy of family." Providing explicit details here would have required Berenice to connect the concepts of love, joy, and family to the novel and explain how the narrative illustrated these concepts through the storytelling.

Another place in this book report where Berenice fails to provide explicit support and details is in discussing the action of the novel. Berenice writes, "Probably something that affects her [the main character] is getting back to the idea that every summer she is in 
Mexico and has to get used to the idea way her grandparents living" (Berenice's book report, received December 2013). Here, Berenice might have considered illustrating, using concrete examples from the novel, how the main character's life was different from that of her grandparents. Instead, however, Berenice moves on to the next idea in her book report. While Berenice explicitly answers the questions that are asked, she does not elaborate upon them or answer them fully.

Jack's writing, like Berenice's, often lacks support and elaboration for his main points. Frequently, he either restates one thought in several differently-worded sentences (or rhetorical questions, as we examined earlier), or else he chooses personal accounts and opinions or non-credible sources for his support. One example of a lack of support or explicit details is in Jack's argumentative paper on child soldiers for the AELP course. Jack's thesis statement at the end of his introduction reads, "But the biggest problem in the DRC is the child soldiers that we have roaming around the streets" (received December 2013). This thesis statement is not specific or explicit enough, as Jack's first point (which he placed at the beginning of his first body paragraph) refers to why children serve as soldiers in the DRC: "Some Congolese say that kids go to war because they usually have families to take care of and to earn respect." This point was not explicitly asked for with the thesis statement. The rest of the sentences in Jack's first paragraph further illustrate a lack of rhetorical connection and explicitness in its lack of adequate support:

Some Congolese say that kids go to war because they usually have families to take care of and to earn respect. I'm not going to lie; this is a good reason to go to war, but you have to remember that we are talking about kids who are five years old carrying muskets. Imagine what the world would be like if we have 5 years old soldiers roaming around with a 
gun Kids would have to be alert at all times, and there would be a lot of deaths out in the streets. I don't think that this is the kind of things that people want in the community. (Jack's AELP argumentative paper, received December 2013)

If Jack adhered to the rhetorical purpose of his topic sentence for this paragraph, he would use the rest of the paragraph to explain with concrete details exactly why child soldiers are utilized in the DRC. He would also, ideally, choose to introduce some of his outside or secondary sources at this point. Instead, his subsequent sentences discuss the negative outcome of having five-year olds carrying guns in the street; he also includes his opinion on the matter.

Jack's second body paragraph begins with information from a secondary source: "According to Weary from War, there are some kids who get kidnapped in the streets." This seems to be a second point as to why there are child soldiers in the DRC. However, as in the previous paragraph, Jack fails to adequately support this point and, instead, issues his opinion and several rhetorical questions for the reader to consider:

According to Weary from War, there are some kids who get kidnapped out in the streets. Is this our way of going to serve our country? By kidnapping innocent kids? They barely know what's right and what's wrong. Why do we drag them into hard situations like going off to wars? I mean, it's bad enough that these kids are struggling at home. Now you want to put more stress in the lives of these kids. Think about their families; they have to worry about their kid's at all times, not knowing if your sons or daughters are alive or not. Now imagine if the kid dies on your watch, how are you going to go break the news to the kid's families? (Jack's AELP argumentative paper, received December 2013)

One way in which Jack could adhere to the expected convention of standard academic writing could be to explain more about his secondary sources concerning child kidnappings and why they are occurring. Instead, Jack's explication involves rhetorical 
questions invoking the children's young age, their innocence, and the emotional suffering they and their families endure.

Jack's third body paragraph again has as a topic sentence a reason as to why there are child soldiers in the DRC: "Weary from War, also said that kids are paid to fight." However, instead of expanding upon this point from his secondary source, Jack issues his opinion that it is wrong for families to trade their children for money:

Weary from War, also said that kids are paid to fight. Is the money really worth putting the kid's life in danger? Even if my family was struggling, do you honestly think that I would allow my kid's to risk their lives for me? If you do than you are definitely crazy, because no amount of money is worth life. I don't care how much money it is. No money on earth can buy life. Money doesn't give life; god is the only one who gives us life. (Jack's AELP argumentative paper on child soldiers, received December 2013)

By the time Jack wrote his argumentative paper for English 101 in April, Jack had begun supporting his topic sentences and main points with specific examples. In Jack's English 101 argumentative paper, which discussed portrayal of African stereotypes in the media, Jack asserts in his introductory paragraph that many of the ways in which African people are portrayed in the media are not true. His main points, according to his body paragraphs, address the following, as I have loosely outlined:

- media sources that portray Africans inappropriately

- the stereotype that animals run loose everywhere and there is a lot of war in Africa

- the stereotype that every African is in a tribe and every tribe has items with symbolic meaning ascribed to them

- the stereotype that African people are all good runners

- the stereotype that African people speak only by clicking

- the stereotype that Africans do not value education

- the stereotype that Africans physically abuse their children

- the stereotype that all Africans are impoverished

- the fact (and here Jack pulls in material from his AELP argumentative paper) that some African countries condone child soldiers 
Jack's paper was five and one-half pages long (his AELP argumentative paper was only three pages long) ${ }^{18}$ Unlike his AELP written texts, the structure for the argumentative paper for English 101 is not as strong toward the end of the paper, especially when Jack introduces a fact about Africa, that some African countries utilize children as soldiers. Jack does not appropriately transition from his discussion of stereotypes of Africa to the fact that he presents.

Jack's inclusion of appropriate details to explicitly support his main ideas are a bit more prevalent in this paper than in the AELP paper, however. Jack's first body paragraph begins with the topic sentence, "According to the Daily News Article, it is said that there are so many places in the media that have African Stereotypes; it just depends on where you get your sources from" (Jack's argumentative paper for English 101, received May 2014). Using first- and second-person pronouns, just as he did in his AELP papers, Jack builds upon his main point by pointing out two media sources in which one might encounter stereotypes of African people: Google and television commercials. After discussing these two sources, Jack digresses by discussing human nature in making judgments based on individual knowledge sources; he then gives an example of his misunderstanding of how dangerous to people snow and a cold winter can be - he'd never experienced such weather in the DRC.

His second body paragraph - the paragraph in which he argues against the stereotypes that animals run loose everywhere in Africa and that there are many wars in

18 Jack's paper did not include a Works Cited or Bibliography page. And, as was evident in the AELP argumentative paper, Jack does not yet have a firm grasp on citing secondary sources, nor does he demonstrate an understanding of the correct MLA format that he was required to use in both papers. 
Africa- begins with a quotation from his secondary source before he discusses civil wars, tongue clicking, and the television program South Park:

The Daily News article also said, the media portrays Africa as "the continent where animals run loose everywhere, or where there is a lot of war." Well it is true the audience usually take things the other way. What I'm trying to say is that animals do run loose, but they don't run loose on the streets. We also have cities in Africa, and we don't have animals run loose in the cities. The civil wars in Africa happen because we don't really know how to settle our differences. That is one area where I admit, we need to work on. There is also a language problem that goes along with this. Most people get the idea that some countries when they speak, they sometimes use tongue clicking. Like on south park when they did an episode about Africa and they had a kid from Africa named Starvin Marvin. He had a really skinny body and a really big head and, as did the other Africans in the show. Marvin and the other Africans were supposed to talk by clicking. Another stereotype I've heard is that all Africans are fast runners, because they use their speed to hunt animals and run from animals when they feel threatened. (Jack's English 101 research paper, received May 2014)

Jack combines two totally different stereotypes into on paragraph, as his source - The Daily News - groups the two together in one statement. However, rhetorically, this would have been much more cohesive and logically organized had Jack used one paragraph to address the animals thoroughly and another to address war, instead of addressing two different stereotypes in one paragraph. Additionally, his topic sentence does not make mention of the stereotype that everyone in Africa uses click-languages. Jack initiates this discussion in this second body paragraph and then returns to it in a later body paragraph:

Well we don't use tongue clicking; we speak normally, but the 3 most popular languages are English, French, and Portuguese. So our languages aren't that different, they are actually pretty similar. Along with our alphabets, although they do sound different; but they are actually written a lot alike. Another common thing that they have in common is some of the words that we use. They sound the same but they usually have 1 or 2 letters that are different, and the pronunciation is different but it almost sounds the same as the way you would say it in a different language. So 
we don't use tongue clicking when we speak. (Jack's English 101 research paper, received May 2014)

For rhetorical purposes, the coherence of Jack's paper might have been easier for the reader to follow had he used the South Park tongue-clicking example and discussion in this later body paragraph to augment his personal explication, rather than address language stereotypes such as tongue-clicking in the animal and war paragraph earlier in the paper.

Throughout these U.S.-educated multilingual students' compositions - in both the AELP course and in English 101 - it is evident that they attempt to follow a structure for organizing their writing. Berenice seems to compose lofty, abstract statements and then does not support those statements with evidence. And, while Jack attempts to have a thesis statement, main points as topic sentences, and an appropriate conclusion for each of his assigned written texts, one of his challenges (besides appropriately using secondary sources and citation conventions ${ }^{19}$ ) is that he does not grasp that his writing also needs to have a rhetorical structure, a structure that logically flows from one idea to the next without leaving gaps for his reader or digressing to another topic. He also has not fully demonstrated that he understands what types of details are appropriate supporting details, instead using numerous rhetorical questions (as discussed in the previous section) and lofty personal opinion statements instead of hard evidence from secondary sources or explicit personal examples.

${ }^{19}$ Singhal (2004) asserts, as I discussed in Chapter II, that appropriate use and synthesis of secondary sources is a goal in academic writing, as does Murie and Fitzpatrick (2009). Likewise, Thomas's English 101 syllabus includes appropriate use of secondary sources as a learning objective. I will return to this matter in more depth later in this chapter. 
As I discussed in Chapter II, Singhal (2004), in describing components of academic English, explains that these elements outline key concepts that writers need to grasp to be effective academic writers. The linguistic component requires students to use "discourse devices, transitions and transitional expressions" to "create logical relationships" in writing that will lead to cohesive texts (p. 4). Likewise, Murie and Fitzpatrick (2009), as discussed in Chapter II, assert that academic literacies have several components:

- analyzing content, making meaning, developing a stance;

- writing from source material, knowing when and how to cite;

- developing a thesis and coherence, using the language of coherence;

- supporting main points with specific information and discussion;

- organizing ideas effectively;

- drafting, reviewing, and revising (p. 159)

Murie and Fitzpatrick's concepts echo those of Singhal (2004). As demonstrated by the illustrative student-writing excerpts in this chapter, however, neither Berenice nor Jack has a firm grasp on creating relationships between concepts in their writing, relying instead on simply making abstract statements without support (Berenice) or providing irrelevant support (Jack). The absence of elaboration or essential explicit support in both students' written texts indicates that the writing process for these students is still one fraught with difficulty.

\section{Theme \#2: Perceived Literacy Needs}

Interesting to note are the students' perceived difficulties with writing in English. I asked both students about their challenges in writing in English, and here is what they had to say: 
B: I think there is a lot of challenges. Like probably, like the past and then the, and like the, well maybe that, but like, I don't know, like punctuation and like, where to start a new sentence. Like the beginning of a new paragraph. Probably that.

M: Spelling. You mentioned spelling earlier. That's a challenge.

B: Uh-huh. (Interview with Berenice, April 2014)

Here, Berenice admits to having challenges with sentence structure and punctuation.

Earlier in the interview, she had shared with me that her spelling is one challenge she has in writing in English. As shown in the excerpts throughout this chapter, spelling and punctuation, as well as sentence structure, do seem to be challenges for Berenice.

Jack's answers regarding his perceived challenges in writing in English echoed Berenice's:

J: Well, I really need to think about when to end a conversation. What to, uh, I mean, when to end a sentence, because there are sometimes I don't mean to write a run-on sentence, but it just happens.

$\mathrm{M}: \mathrm{OK}$

J: And I also need to learn where to put a comma. Those commas.

While the focus I chose for this chapter was on the students' rhetorical control and oral literacy strengths as compared to written literacy strengths, Jack is correct in that he also has challenges with sentence structure and punctuation, as evidenced in the textual excerpts provided. The fact that both of these students can articulate their challenges, however, means that they can speak metalinguistically about their own writing, that they are reflective of how they write, even if they are still using inappropriate constructions. From my observations, the AELP Level 4 class can be credited with helping students acquire this metalinguistic knowledge. The instructor of the course used terms for 
language use in her explanations of grammar and writing as well as in her feedback to the students. For example, the students in the AELP Level 4 course were required to keep a mechanics $\log$ on which they recorded their grammatical "mistakes" on written assignments. Francine, the instructor, was consistent in her use of terminology or markings on student papers; "S-V" always meant "subject-verb agreement," for example. Another example is that transitional phrases were almost always called "hooks." Students would then know exactly what Francine meant when she wrote "hook" as feedback on their writing. Through the instructor's consistent use and reiteration of language about grammar and writing, the students began using this language themselves. Having necessary metalinguistic knowledge and vocabulary is an essential tool for U.S.-educated multilingual writers, according to Thonus (2003). This ability to speak about their own linguistic characteristics will aid these U.S.-educated multilingual students in the future as they continue to develop their written English literacies, especially in light of the assertion by Blanton (2005), discussed earlier, that the L1 literacies of U.S.-educated multilingual students often stagnate before the students can develop this same metalinguistic knowledge about their first language.

\section{Jack: Reading Academic Texts}

As I discussed in Chapter II, Singhal (2004) suggests that academic literacy has three components: linguistic, cognitive, and usage of rhetorical components of language in order to analyze and synthesize. Singhal's second component, in encompassing critical thinking, suggests that critical thinking involves

numerous types of activities such as determining the credibility of evidence, reading between the lines and inferring information, determining how claims and evidence in readings can be accounted for in different 
ways, analyzing issues and information to decide what constitutes valid and logical evidence and arguments, and recognizing relevant information and research and synthesizing and arranging it effectively to create a cohesive and coherent whole" (6)

In other words, students must be able to critically read texts with discernment of argument in order to comprehend and gather information. Critical reading skills, then, according to Singhal (2004) is a crucial element in academic literacies.

Singhal's (2004) third component - language discovery - requires students to be able to analyze and synthesize outside sources in order to then apply them to the student's own argumentative writing, according to Singhal. Singhal asserts that effective use of secondary sources entails students analyzing and synthesizing those texts in such as way that they can then apply them as evidence for their own argument; avoiding plagiarism and ensuring proper citation are two additional objectives of utilizing outside sources to support an author's argument. The academic writing learning objectives stated by Murie and Fitzpatrick (2009) also emphasize "writing from source material, knowing how and when to cite" (p. 159).

The learning objectives of the AELP course as well as those for the English 101 course also stress students' effective use of outside sources in their argumentative writing. The AELP syllabus states includes "analyze credibility of sources," "utiliz[e] academic writing format," and "synthesize information from various sources" as learning outcomes (AELP Level 4 syllabus, received August 2013). Additionally, the AELP Level 4 argumentative assignment sheet lists the following as learning objectives: "you will find appropriate sources (Research)" "you will use sources correctly to provide background information on your topic (Paraphrasing and Citing)," and "you will learn 
how to produce a logical argument that includes evidence such as facts, statistics or opinions (Support)" (Assignment sheet for Unit 3: The Argument for AELP Level 4, received November 2013). As detailed in Chapter IV, the English 101 learning outcomes also place emphasis on effective use and citation of sources:

- Develop an essay that demonstrates effectively organized and presented reasoning and supporting evidence.

- Interact effectively with multiple sources, subordinating them to the writer's purpose; creating confidence that they have been represented fairly; and documenting them in MLA style.

- Develop an effective writing process that includes successful strategies for inventing, choosing, and narrowing a topic; exploring and developing ideas through research and critical readings; and employs global and local revision and editing strategies. (Thomas's English 101 syllabus, received February 2014)

Thus, the learning objectives of both courses - the AELP Level 4 and the English 101 courses - stress appropriate use of outside sources in creating a logical and wellsupported argument. These learning objectives are consistent with Singhal's (2004) and Murie and Fitzpatrick's (2009) necessary academic literacy repertoire for students.

Even though effective use of sources and supporting an argument with those sources is an emphasized objective in these courses, it appears that Jack still has not mastered effectively using outside sources to support his writing. As evidenced in the written excerpts in the previous section, Jack supports his main points with primarily his own opinion or else the opinion he hopes to elicit from his reader from his rhetorical questions. Throughout his argumentative paper on child soldiers in the DRC for the AELP class, he referenced an article, "Weary from War" twice when listing reasons children in the DRC might be fighting in wars; neither time did he provide a citation or reference, and his paper did not include an MLA bibliography page. 
Likewise in the English 101 course, Jack used outside sources very sparingly, relying more on his personal opinion and experience as evidence. In his argumentative paper on African stereotypes, Jack references one article by the Daily News (which he refers to as "the Daily News Article") and UNICEF commercials. He also references the popular Disney television show "That's So Raven" as well as the television show "South Park" to provide examples of stereotypes of the African culture in the media. While he uses a bit more evidence from secondary sources in the English 101 paper than he did in the AELP paper, he still needs to address proper citation conventions as well as usage of a bibliography or works cited page, which are conventions that are stressed along with synthesis of these outside sources.

If effective use of secondary sources - including analysis of credibility, synthesis, and citation conventions - is a crucial part of academic writing, then Jack's mastery of this objective appears to me to be still at a low level. He has not yet met this objective, from what I have viewed in his work for both classes. Additionally, while second language reading is not a focus of this study, I anticipate that there is a link between Jack's literacy challenge of reading academic texts in English and his reticence to utilizing more academic sources into both argumentative papers. During our final interview, I asked Jack about a Psychology course that he was also taking this semester. He reported to me that he dropped the course early in the semester due to the course's very heavy reading load. The reading load in a Psychology course would, more than likely, be highly scientific. I recall working with Jack in the AELP course; he asked for assistance in finding sources for his paper on child soldiers. I would repeatedly steer him toward academic journals and longer news articles on the topic; the end result is that Jack 
used one source for that paper, an article titled "Weary of War." Likewise, he reported to me during an interview that finding sources for his English 101 paper was also proving difficult; I reminded him again of the journal database that he could access through Gridley's online library system. The resulting argumentative paper regarding African stereotypes included one source - The Daily News - in addition to two television program sources (two situation-comedies). A quick search of the school's library database reveals numerous articles on stereotypes of the African culture, leading me to believe that Jack either did not do the search or was overwhelmed with the academic nature of the reading required to fully understand articles that are more credible and valid.

This possibility - if the idea of reading more complicated texts is overwhelming to a student like Jack, who passed the fourth level of AELP is correct - is problematic. One of the literacies that Singhal (2004) lists as key to academic success is critical reading strength. And, credit-bearing courses, such as the Psychology course Jack hopes to complete and courses in Business in which he plans to enroll later, will require that Jack possess critical reading skills. The AELP program, as I'll reiterate in Chapter 6, should consider adding an academic reading component to its curriculum, similar to what Holten (2009) and Murie and Fitzpatrick (2009) incorporated in their programs for U.S.educated multilingual students, discussed in Chapter II. Furthermore, NCTE's statement on multimodal composition states, "We affirm, in our theory and practice of teaching English language arts, that reading and writing are ultimately different but inherently related aspects of the same process of meaning making" (NCTE, 2003). Therefore, U.S.educated multilingual students preparing for college-level courses should have instruction 
to help them improve their academic reading comprehension, in addition to instruction to assist them in augmenting their academic writing literacies.

\section{Jack in English 101: Multimodal Compositions and Genre Analysis}

As I explained in my discussion of multimodal composition theory in Chapter II, in addition to the research paper, Jack was also required to create two multimodal texts in English 101. The first was a Cowbird, as described in Chapter IV. As a reminder, a Cowbird is a website that incorporates sound, visual elements, and linguistic writing to create one unified message. Instead of telling students what the elements of the genre of a Cowbird included, Thomas - the instructor - required the students to analyze the genre themselves in order to determine what elements to combine to create their own version of the genre.

The other multimodal text that Jack was required to complete for English 101 was a blog entry. The Cowbird, the research paper (already described in depth in this chapter and in Chapter IV), and the blog comprised the main writing components of the class. Other assignments included quizzes over lecture and reading material and formative assessments, such as proposals, peer reviews, and a conference.

The reason that these two multimodal assignments are so important to this case study is that these two assignments together were weighted approximately equal to the research paper. His approach to teaching the first-year composition course, as detailed in Chapter IV, is to organize the course in such a way that students are conducting genre analyses and composing multimodal texts. Thus, a large portion of the class was devoted to multimodal composition. 
Outside of completing PowerPoint presentations for the AELP class, Jack had no experience with multimodal texts; all of his compositions up to entering English 101 were traditional and discursive. And, as explained in both Chapters 2 and 4, the AELP class curriculum did not take a genre analysis approach, instead relying on telling students what elements were required for each composition.

One of my interviews with Jack was shortly after he had completed the Cowbird (see Appendix E). We talked about his perception of the project in general:

Cowbird Transcript \#1:

1. M: Now, what I'm going to do right now is I'm going to pull up your Cowbird. Ok?

2. J: OK. Uh, I forgot to put a picture with my Cowbird project.

3. M: So, yours doesn't have a picture. It just has words?

4. J: Yep.

5. M: So, this was a piece of writing that you had to do. Now, what is a Cowbird? Because I still don't understand it.

6. J: Well, it's like a sort of, website source where people can write down their life experiences, and feelings, yeah. So it's kind of like a Facebook or a Twitter.

7. M: Ok. So you can update it? It's social media?

8. J: Yeah.

9. M: So, this was all about ten years ago in Kinchasa, in the DRC. When the instructor said that you were going to do a Cowbird, how did you figure out, I mean, Did you know what a Cowbird was?

10. J: Did I know what a Cowbird was? At first, no. I thought it was a bird. 
11. M: When your instructor told me your class would create a Cowbird, I didn't know what it was, either. And I had to look it up. Did he explain a lot about what a Cowbird is?

12. $\mathrm{J}$ : No, he had us do research on what it is.

13. M: And so that's what you decided it was, it is an online source where you can do your own life-writing - which you like to do and you chose to write this in English, right?

14. J: Right.

15. M: Ok. Was this - I see there's a conversation with your mom and your dad -

16. J: Yep. It's more of a narrative.

17. M: Ok. And, at the time, were you speaking in French?

18. J: Yes, I was. I just translated it into English.

19. M: That's ok. And so tell me what the idea of this story is.

20. J: Yeah, yeah, this story is to show, um, how I felt before my first plane ride.

21. M: Why did you decide to write about this story?

22. J: Because this is where it all began.

23. M: Where "what" all began?

24. J: Where my first plane ride began. So.

25. M: If you were to write more, to do another Cowbird, would you extend this story?

26. J: Yes, I would.

27. M: And what would the next Cowbird be?

28. J: The next Cowbird would be about me coming to the United States and then the difficulties that I had to face. 
29. M: And I read a bit about those [in the narrative from the AELP class].

30. J: Yes.

31. M: You might put that narrative from last semester and put it into a Cowbird. Were you supposed to use pictures?

32. J: Oh, yes, but I forgot. I forgot to put the picture in it on there. I didn't actually have a picture of me on my first plane ride, but...

33. M: What did the instructor say about your Cowbird?

34. J: He thought it was really creative, that it was, um, nobody thought of writing a narrative beside me.

35. M: Really? Oh. And so it's supposed to be something you can use for life-writing, but no one else thought of using a narrative.

36. J: Yeah, nobody else thought of doing that. (Interview with Jack, May 2014)

Interview \#1, in which Jack and I discuss his Cowbird, demonstrates several points about the multimodal component of this English 101 course. First, genre analysis is indeed part of the assignment, as I discussed in Chapter IV. In Lines 10 and 12, Jack explains that he did not know at first what a Cowbird was; in order to create his own Cowbird, he had to research the genre. Researching the genre was an assignment created by Thomas in order for the students to conduct their own genre analysis; I will discuss more about this genre analysis later in this section. As I pointed out in Chapter IV, the students researched Cowbirds in small groups and then presented as groups their findings to the rest of their classmates. Jack was apparently successful at meeting the learning expectations of that formative genre analysis assignment, earning twenty points out of twenty on the assignment. 
Second, as I pointed out in Chapter II, often mainstream composition classes with a mix of ESL students and NES students can create what Pratt (1991) calls "contact zones" (p. 38). To not acknowledge the diversity in a mainstream classroom - ignoring the heterogeneity in composition classrooms -- can result in diminished student motivation, according to Harklau (1999). Harklau (1999), Peirce (1995), and Johns (2009) all discuss the value of encouraging students to write about their lived experiences, employing students' prior knowledge to practice their English literacy. This Cowbird assignment did just that: it provided students a genre in which to write about their lived experiences.

Jack enjoys sharing his life story. As I reported in Chapter IV, Jack writes autobiographical pieces in French, his L1, and English, his L2, for his own enjoyment; this would be considered a private literacy of his. In researching the Cowbird genre, Jack concludes that a Cowbird is "well, it's like a sort of, website source where people can write down their life experiences, and feelings, yeah (1. 6 from Transcript \#1: Cowbird). Jack explains that he chose to write about his first time on an airplane, because "this is where it all began" (1. 22, Transcript \#1: Cowbird). During the interview, I recalled that Jack had written a life-writing piece for the AELP narrative essay, and so I asked him about that:

25. M: If you were to write more, to do another Cowbird, would you extend this story?

Jack's response indicates that he views narrative as an ongoing story, that the Cowbird is an effective tool for life-writing:

26. J: Yes, I would. 
27. M: And what would the next Cowbird be?

28. J: The next Cowbird would be about me coming to the United States and then the difficulties that I had to face.

This multimodal assignment provided Jack a context for sharing his story. As discussed above, Harklau (1999), Peirce (1995), and Johns (2009) all purport that second language students sharing their story can provide them a sense of agency in the classroom, in that they are allowed to define themselves in their own writing. Additionally, assignments such as the Cowbird, which encourages life-writing, serves to provide a springboard between what Courage (1993) calls private literacy (Jack's life-writing that he does for himself) and a public one (the Cowbird he completed for the English 101 course). As Bloch (2007) demonstrates in his study in which he measures how well blogging can help U.S.-educated multilingual students with their academic literacies, composing in a genre such as a Cowbird can serve as a bridge or springboard between a student's daily, informal speech or writing and academic tasks.

The Cowbird assignment was a multimodal one, and also a genre that required the students in the class - Jack included - to analyze before beginning. Jack had never completed this type of multimodal assignment before, and I wondered if he had been successful in composing a Cowbird text, especially after his comment in Line 2 in which he told me that he forgot to include one component. I inquired about the Cowbird again, focusing on Jack's assessment of how he performed the task:

Cowbird Transcript \#2:

1. M: Do you think you got a good grade on it [the Cowbird]?

2. J: No, because um, I forgot to put the picture in it... 
3. M: Did you know how to put the picture in it?

4. J: Uh, yeah, I do.... I know how to put a picture in it. I just forgot to.

5. M: Did you feel prepared to do this Cowbird project?

6. J: Yes, I did.

7. M: It sounds like it wasn't a big deal for you.

8. J: No, it wasn't.

9. M: Would you do a Cowbird again?

10. J: Yes, I would.

11. M: What do you like about it?

12. J: Well, just the idea of getting my story out there so that all of the people can see it.

13. M: Mm-hmm. Your story about moving to the United States? Or your story in general?

14. J: My story in general.

15. M: You like, uh, life-writing. So, this was an unfamiliar kind of writing, but you think you did ok. Except for the picture. Did he [the instructor] take off a lot for the picture?

16. J: I believe so. You were also supposed to have sound, and I didn't know how to put sound on it.

17. M: Oh. Hmm. So, a Cowbird is also supposed to have sound. What sound would you have used if you could have?

18. J: Well, I would have used a sound of an airplane taking off as a sound. The sound of an airplane taking off.

19. M: Anything else? 
20. J: Yeah, and the sound of a, well, you know how you're in airports and they usually tell you which planes are taking off or are arrived and landing?

21. M: Mmhmm.

22. J: I would have used one of those.

23. M: Oh! The voice over the loudspeaker at airports?

24. J: Yes.

25. M: So, you forgot the sound and you didn't include the picture. But you had the narrative. So he took off quite a bit on that you think?

26. J: Yeah.

27. M: Do you feel that the academic ESL class last semester prepared you to do this?

28. J: Yes, it did.

29. M: Do you think they [the students in AELP] should try to do a Cowbird?

30. J: Yeah, they should.

31. M: Why?

32. J: Well, because it's a good way to try to get stories out there.

33. M: Was this a more difficult assignment, do you think, than a research paper?

34. J: This was a lot easier than a research paper. (Interview with Jack, May 2014)

Again, we see in this excerpt that Jack appreciated the chance to write about his lived experiences, as he refers in Lines 12 and 32 that he believes the genre allows students an opportunity to share their stories, which he enjoys doing. Not only did Jack enjoy this 
assignment, he feels as if it was easier than writing a research paper (1. 34, Transcript \#2: Cowbird).

What is troubling, however, is that Jack did not incorporate two elements - visual elements and sound - into his Cowbird project. He realizes this and admits it (lines 2 and 16); he forgot to add a picture and sound. Visual and sound elements were two modes of text that Jack explained in lines 2 and 16 were supposed to be included in the Cowbird genre, according to his genre analysis. But yet he "forgot" to add the visual element (lines 2 and 4), and he did not know how to add the sound element (1. 16).

While Jack's self-assessment is that composing a Cowbird is easier than writing a research paper (1.34), he was also correct in his perception that he did not score well on this project (1. 26); he earned 38 out of 50 possible points on the Cowbird - 76\%. Jack shared with me the written assessment ${ }^{20}$ of his Cowbird project, with Thomas's feedback: "I only saw text here, with no picture and no sound. The goal was to have 2 out of 3. [D]id you post the correct link? Talk to me about this when you can" (Written feedback from Thomas on Jack's Cowbird project, received May 2014). This was far below the $87 \%$ he earned on his argumentative research paper, and Thomas's comments indicate that Jack did not meet some of the expectations of the project.

As I discussed in Chapter II, writing a multimodal or non-discursive text is much different than composing a discursive or linguistic one. Writers need to have a firm grasp on how various elements rhetorically combine to create one unified composition.

${ }^{20}$ Unfortunately, this was the only written assessment Jack could find to share with me from the English 101 course. For obvious reasons, this type of written feedback for Jack's argumentative paper and, later, for the blog entry, would have provided rich data for analysis. 
Although the NCTE has adopted a policy encouraging English teachers at all levels to incorporate multimodal composition in their classrooms (see Chapter II's discussion), the AELP class still has not implemented multimodality beyond Prezi or PowerPoint. All texts in the course were to be written discursively or presented orally; students could choose to compose their final project multimodally, but multimodality was not required. Jack had no experience in the AELP course in composing multimodally besides incorporating discursive text into a PowerPoint or Prezi program.

As Shin and Cimasko (2008, discussed in Chapter II) found, sometimes ESL students are reluctant to incorporate multiple modes of text into their compositions, even if they are required to. In Jack's case, he forgot to include the visual element; and he did not know how to incorporate sound, although he knows he would have chosen the sounds of a plane taking off and of the airport intercom system. In their study, Shin and Cimasko attempt to determine if students' reluctance to incorporate non-linguistic elements in compositions is due lack of knowledge in how to incorporate those elements; Shin and Cimasko conclude that the ESL students in their study were reluctant to incorporate audio text in their compositions, because "audio design represents a strong departure from, and thus a potential breach of, traditional academic discourse norms" (2008, p. 385). They reach this conclusion through analysis of the students' self-reflections as well as narrative from the instructor. In Jack's situation, he admits not knowing how to incorporate the sound element, and this composition task was not one he had an opportunity to learn in the AELP Level 4 course, as it was not required.

As I insinuated above, another task Jack was asked to complete in the English 101 course that he had not practiced in the past was genre analysis. The first genre analysis of 
the English 101 course was of the Cowbird genre, described above; this analysis was completed by the students through a collaborative assignment designed by the instructor entitled, "Cowbird, or Not a Cowbird." With this assignment, students - within their groups - would determine what they thought a Cowbird was and then the groups were to report back to the class. Jack earned 20 points out of 20 on this genre analysis assignment ${ }^{21}$. However, the next text that he had to analyze was a blog. This was the final project of the semester; students were asked to translate their academic argumentative research papers into a blog. Thomas described this project to me in some detail, which I discussed in Chapter IV:

The final project we do is a blog. And I call it "The Translation Project," where we take the academic essay and translate it into a new genre. So, we take that type of, the type of material that you would produce for an academic essay and we say, "Ok, now how do we take that content and put it into a new genre?" And, of course, you know, the content has to change in some significant ways. And then, the approach of a blog is very different, you know, it's different kinds of audiences and a completely different purpose. So, it's, it's...I've only done this once, last semester, and it worked out pretty good, it was pretty rough, but we got through it. (Interview with Thomas, February 2014)

I do not know Jack's score for this individual assignment, but he said that he did very well on it. The online list of his assignments and scores (this list does not include any written feedback) indicates that the blog entry was grouped with his final portfolio for a grade; the two combined totaled 682 points, and Jack earned 594 points (this equates to $88 \%$ for a grade of B). When I asked to see his blog, Jack provided me a Word document copy; he did not have a link to share with me of the blog posted online. I compared his

${ }^{21}$ The genre analysis collaborative task was a different assignment than actually producing the Cowbird project, on which Jack earned 38 out of 50 points. 
blog (the Word document of what he posted to the blog site) to his argumentative paper. The two were exactly the same discursive text. Nothing had been altered or changed, except that he typed the text of argumentative paper into an online blogging site. Nothing had been translated. Yet, Thomas remarked to me during the interview that the students' information from the research paper would need to be changed: "And, of course, you know, the content has to change in some significant ways. And then, the approach of a blog is very different, you know, it's different kinds of audiences and a completely different purpose" (Interview with Thomas, February 2014). The content of Jack's research paper did not change in becoming a blog.

As Bloch (2007) demonstrated, blogging is an excellent way in which U.S.educated multilingual writers can practice written English literacy by applying their oral literacy strengths to writing. I was both surprised and not surprised that Jack felt he had performed well on this assignment. First, since blogging requires a more informal register than academic writing, Jack's speechlike writing would be appropriate for the genre. On the other hand, I wondered how Jack could have copied and pasted the text from his academic paper to an online blog site and not demonstrated any translation strategies to account for a different genre, audience, and purpose. Unfortunately, I have no access to Thomas's comments on Jack's argumentative paper or his blog, so I cannot say for certain.

However, the fact that a FYC course requires students to conduct genre analyses and also to compose multimodal texts is enlightening for those developing curriculum for the final AELP course. I will expand on this further in Chapter VI, but perhaps this is an indication that the AELP should investigate just what types of assignments students in the 
English 101 courses are being asked to complete. Additionally, if NCTE is encouraging composition instructors to teach multimodal composition, than this should be reflected in the AELP curriculum as well.

\section{Conclusion}

What I have shown in this chapter is an analysis of written and spoken data I gathered from the two U.S.-educated multilingual students studying at a community college in the Midwest. The writing of both Berenice and Jack illustrated characteristics of what has been described in research as unique to either ESL students in general or U.S.-educated multilingual students studying at a community college in the Midwest. Both students reported adhering to a traditional version of the writing process. However, I demonstrated that both Jack and Berenice avoid developing main points in their writing, which is a common feature of writing by ESL students, according to Silva (1997). Both students employ characteristics of spoken communication in their writing. Berenice spells phonetically and often chooses an inappropriate word that sounds like her target word. Jack, on the other hand, utilizes an informal register, a register that is more standard for spoken literacies than an academic written literacy. Furthermore, I suggested that perhaps Jack's academic reading skills presents a challenge for him, and that this challenge may deter him from meeting the learning objectives of finding, critically reading, and appropriately utilizing credible secondary sources in his argumentative writing. Additionally, I also made a brief mention of the multimodal assignments and genre analyses required of Jack in English 101. While he seems to have succeeded in both of these areas, incorporating elements of both into the AELP curriculum would be 
responsible pedagogy, especially in light of NCTE's encouragement of English teachers' use of multimodal composition assignments in the classroom.

The purpose of the next chapter - the final chapter - is to discuss the pedagogical aspects of this data analysis in detail. I begin by providing a summary of information and data presented in the thesis thus far. Then, I comment on pedagogical implications and possible augmentations to the AELP curriculum. I also make suggestions for areas of future research in order to add to the existing scholarly conversation regarding U.S.educated multilingual students transitioning from community college ESL programs to community college writing programs. 


\section{CHAPTER VI}

\section{CONCLUSION}

\section{Overview}

The present study analyzed data from U.S.-educated multilingual students in a community college ESL program transitioning to first-year composition. My goal with this study was to answer two questions: first, how successful were these students in making the transition to first-year composition? and second, how can similar ESL programs better prepare U.S.-educated multilingual students for first-year composition?

The studies focused on U.S.-educated multilingual students that frame and support the present study exemplify not only the infancy and interdisciplinarity of scholarship in this area, but also the (as yet) unfocused research subfields, such as U.S.educated multilingual students' academic literacy experiences in community colleges. Studies like this one - a small case study in which only a few U.S.-educated multilingual students are studied, in a Midwestern community college's relatively small ESL program, as they transition to English 101 - add to the growing body of research on this demographic in this particular U.S. institutional space.

\section{Part I: Research Question \#1, Revisited}

Even small studies like this one often come to complicated conclusions. My first research question - "What are the experiences of U.S.-educated multilingual students in mainstream composition courses in community colleges?" - is itself broad with an 
answer that cannot be generalized. While my findings are not generalizable, the case study of Jack demonstrates that, at this particular community college, if a U.S.-educated multilingual student succeeds in the AELP Level 4 course, he can succeed in English 101. As discussed in Chapters IV and V, Jack earned a C in AELP Level 4; he earned a high B in English 101. He has enrolled in the next course, English 102, as well as a Math class.

There is more to Jack's story of success than just a grade; it is more complicated than a grade on a transcript. The analyses of the data in Chapters IV and V pointed out some challenges Jack met in the English 101 course as he attempted to meet the objectives of the course. First, he often used a casual, conversational, informal register that was not standard for the academic texts he was asked to compose, especially in the case of the research paper. Establishing and maintaining a voice that is appropriate for the selected rhetorical context was one of the learning objectives for the English 101 course. Another challenge Jack encountered was using appropriate secondary sources to support his rhetorical argument or point for the given genre he was composing; this corresponds to the learning objective for the English 101 course that states, "[students will] interact effectively with multiple sources, subordinating them to the writer's purpose; creating confidence that they have been represented fairly; and documenting them in MLA style" (Thomas's English 101 syllabus, received February 2014). I also discussed that, based on the data, Jack was challenged in supporting his main points in the academic texts he was asked to compose; this learning objective is stated in Thomas's syllabus: "Develop an essay that demonstrates effectively organized and presented reasoning and supporting evidence" (Thomas's English 101 syllabus, received February 2014). Thomas's research 
paper for English 101 lacked strong supporting evidence and reasoning, as discussed in Chapter V.

\section{Part II: Implications and Research Question \#2, Revisited}

The fact that Jack transitioned successfully from the AELP Level 4 class to and through English 101 demonstrates that, according to the instructors and administrators, Jack possesses the academic literacy tools to succeed in first-year composition. Jack also met some challenges in the English 101 course, and Berenice encountered obstacles within her own situation that inhibited her successful transition. A few pedagogical enhancements to the curriculum could improve the potential and likelihood of success for U.S.-educated multilingual students like Jack, Berenice who are in programs similar to Gridley Community College's. As many of the students in the AELP Program at Gridley Community College are adult immigrants and not U.S.-educated multilingual students, it is understandable that major changes may not be feasible or supported; certainly, programs specific to U.S.-educated multilingual students, as presented in Miele (2003), Allison (2006), Holten (2009), and Murie \& Fitzpatrick (2009), are not feasible at Gridley Community College, due to the small enrollment of this demographic and funding, as discussed in Chapter IV. Augmentation or minor changes, then, are more appropriate for programs like this one. In this section, I answer my second research question - "How can ESL programs better prepare U.S.-educated multilingual students?"

In answering this question, I present several research-based pedagogical implications for community college ESL program as well as community college English departments; these implications would benefit not only the U.S.-educated multilingual students in the academic ESL programs but also the international students and adult 
immigrants in those programs. And, where collaboration and minor changes are suggested for the campus's writing instructors and departments, non-identifying ESL students as well as native English speakers may benefit as well.

\section{Pedagogical Implications for Community College ESL Programs}

One suggestion for consideration is that community college ESL programs consider revising their ESL curricula to include writing tasks assigned in their college's first-year composition courses. As shown in Chapters IV and V, the English 101 section in which Jack enrolled at Gridley Community College required writing tasks focused on elements of genre analysis and multimodal composition. For example, the AELP administrators at Gridley Community College might consider adding some elements of genre analysis to the curriculum. In Chapter II, I cited Hyland (2004), who asserts that "The concept of genre enables teachers to look beyond content, composing processes, and textual forms to see writing as an attempt to communicate with readers - to better understand the ways that language patterns are used to accomplish coherent, purposeful prose" (p. 5). Looking beyond content and form to see precisely how the language of the text is used to accomplish a specified goal is a pedagogical framework Thomas uses in his English 101 course. In the AELP Level 4 course, however, four traditional genres serve as the core of the course, and students are told by the instructor how to compose those texts. Using a genre studies approach in a multilingual composition classroom, such as the AELP Level 4 and the English 101 course, enables students to see the L2 as a tool to accomplish communication. Analyzing conventions of a specific genre also enables students to determine the most appropriate register and lexicon for a particular type of text. Jack, for example, did not modify his text from its use in the English 101 research 
paper to the English 101 blog, despite the vast difference in genre (audience, purpose, mode, and register). Practice in analyzing different genres, however, might have allowed Jack the tools to create both of those genres more effectively.

In addition to adding elements and instruction in genre analysis, community college ESL programs could also consider adding more multimodal composition projects to its curriculum. As explained in Chapter II, the "NCTE Position Statement: Resolution on Composing with Non-Print Media" (2003) charges language instructors and program administrators to work toward incorporating more non-print composition in curricula. With obvious advancements in technology, and, as the NCTE Statement acknowledges, the proliferation of non-print texts in everyday life, exposing students to these various literacies and usages in the language classroom is a pedagogical best practice.

Thomas built multimodal composition opportunities into his curriculum, adjoining it with genre analysis (as discussed in Chapters IV and V). While the AELP Level 4 course invited students to use variable modes of expression for the final project, the book report, the assignment did not required the use of multiple modes of composition. As discussed in Chapter V, Jack's Cowbird project for English 101 did not incorporate two multimodal elements (he forgot to include a visual element, and he did not know how to incorporate the audio one), resulting in less success (again, if a level of success equates to assessment) than the one assignment that was purely discursive in nature: the research paper. Additionally, non-discursive modes, as they may not be based in linguistic composition (cf. visual imagery), allows multilingual students a tool of communication not bounded by linguistic conventions of the L2. Exposure and instruction in composing in various and concurrently multiple modes, in addition to genre 
analysis to determine the most effective mode(s) for a particular type of text, equips students for not only courses like Thomas's English 101 but also courses in other academic disciplines.

Community college ESL curricula could offer opportunities for students to utilize their private literacies and/or literacy strengths as bridges to the academic literacy goals of the course. As I detailed in my literature reviews, Courage (1993) discusses the differences between students' private and public literacies and how building on private literacies or "customary uses of language" (p. 488) can serve as a springboard toward composing texts that fit the purpose, audience, and rhetorical pattern of the academic texts required in the composition course. These "customary uses of language" also often coincide with students' lived experiences, a concept discussed by Johns (2009) and Peirce (1995). Allowing students to incorporate their lived experiences in the classroom, within their chosen literacy practices (and, here, multimodal composition may play a role as well), can serve as a starting point toward learning academic literacies as well as increase student motivation (Harklau, 1999) in the multilingual composition classroom.

This adjustment to the AELP curriculum might have benefited all of the students in the course, not just the U.S.-educated multilingual students, in that students' private literacies could have been utilized as a foundation on which to build in order to present the academic research paper genre. While certainly there are several ways to construct a curriculum to accommodate this adjustment, one way to do this in Gridley Community College's AELP Level 4 course, for example, would be to ask students to complete the book report assignment before the research paper assignment. Students could choose their own mode of completing the book report assignment, using a literacy practice that they 
feel comfortable and confident in. In describing elements of their chosen books, some students may compose a texting exchange or a Facebook or Twitter post-thread. Others may choose to present an oral report or even write a skit, while others may prefer to present the material as a PowerPoint or as a written report. The goal would be for the students to utilize a mode and style with which they are comfortable.

Following this book report assignment, students could be asked to locate one social issue associated with their book on which they would like to focus with a research assignment. Then, the instructor could guide the students through discovering elements of the literacy practice they utilized to share information about their chosen book and compare those elements to elements of the genre of the research paper, noting similarities and differences in vocabulary, register, format, etc. Students could then move forward with researching their chosen social issue and forming an argumentative research paper focused on that issue. In this way, students would analyze the genres of their preferred literacy practices and apply that knowledge toward composition of the research paper. Jack, for instance, might have chosen to blog or give an oral report about his chosen book as his book report assignment. He could then evaluate the similarities and differences between his preferred mode for the book report and examples of research papers the instructor provided. In this way, Jack could have analyzed different genres, making connections between literacy practices he was comfortable with (oral literacy or freewriting, perhaps) and those involving the academic paper genre.

Locating these private literacies requires students to become self-ethnographers in which they investigate their own literacy practices and language use. Such a curricular model would be more effective in a learner-centered classroom such as Thomas's English 
101 course. Thomas's English 101 syllabus, as detailed in Chapters IV and V, describes a learner-centered classroom in that students are given agency and are responsible for their own choices and learning experience. Incorporating a genre-studies approach is consistent with this type of classroom, in that students analyze genres for the purpose and audience of the language and the desired goal of the communication to determine how to construct a text belonging to that particular genre. Analyzing their own frequent literacy practices or genres allows students to ascertain how they are using language and then to apply that knowledge to less-known or practiced literacies, which may include school literacies. Thus, community college ESL programs might consider making the advanced levels more learner-centered since putting students in a more active role, responsible for their own literacy investigation and achievement of the course outcomes with the instructor as a guide, provides students agency and, therefore, investment in their own education.

One practice in community college ESL curricula that may detract from learner motivation and agency is that of the "your country" assignments. As explained in Chapter IV, the AELP Level 4 syllabus outlines several assignments requiring students to narrate, explain, or argue for or against practices or issues in their native country. In the community college context, in which most of the ESL students are either adult immigrants or U.S.-educated multilingual students, this type of assignment may serve to “other" students. As I illustrated in Chapter IV, the students in the AELP Level 4 course often exhibited resistance to these culturally-based assignments. Jack, for example, decided to write about child soldiers in his native country only after being told that he had to find a topic from his native country - not his current country, the U.S. - to write about. 
While some students may not resist these types of assignments, others may see them as othering or marginalizing, as they may inadvertently imply that the students are illegitimate members of the community. Therefore, community college ESL programs may choose to eliminate these types of assignments, substituting instead assignments that require students to investigate their own identities. This pedagogical concept was discussed in Chapter II, when I detailed Harklau's (1999) study on U.S.-educated multilingual students in a FYC classroom. The U.S.-educated multilingual students still felt "the sense of discomfit, perplexity, and frustration" (p. 113) due to the culturally polarizing effects of some classroom literacy tasks. These culturally polarizing assignments, or assignments that impose an identity upon students to which they may or may not subscribe, can decrease student motivation, as Harklau (1999) contends. Instead, academic ESL programs may consider generating literacy tasks for genre analysis and multimodal composition that require students to investigate and define their own identities as individuals and students.

Finally, community college ESL curricula may decide to incorporate more challenging reading into the curriculum. Paltridge, et al. (2009) asserts that reading is interdependent with writing: "Academic writing involves considerable reading: writers need to read the instructions for the writing task; they frequently need to read resources, such as books, articles, and digital resources; and they need to (re)read their own texts" (22). According to Paltridge, et al., students' challenges with reading in academic contexts include students not accurately reading instructions to tasks and not effectively reading other academic texts, such as secondary sources. As I discussed in Chapter IV, Jack appeared challenged by some reading tasks, specifically those traditionally 
considered more academic. Instead of incorporating more scholarly and credible sources as secondary support for his argument in both his AELP argumentative paper and his English 101 research paper, he utilized his own experiences and his knowledge of certain television programs to illustrate his theses. Jack did not include a bibliography for either of these papers; as far as I can ascertain, Jack used one online news source, "The Daily News," for the English 101 research paper, and I cannot determine what credible source Jack utilized for his AELP child soldiers paper. As I also mentioned in Chapter IV, while I was serving as a teacher's aide in the AELP class, I encouraged Jack to find more credible, scholarly sources; he continuously returned to online news sources whose articles were shorter and less lexically sophisticated than the sources we helped him find in the community college's online database. When students resist more challenging reading tasks in ESL programs, it may be advantageous to the curriculum and the student to investigate the impetus for this resistance by the student.

My observations are that Jack's reluctance in incorporating more scholarly appropriate texts as secondary sources, as required by these two research paper literacy tasks, perhaps lie with reading challenges that he may have in English; these suspicions are reinforced in light of Jack's comments regarding the Psychology course he dropped early in the spring semester. When I asked Jack in one of our interviews why he dropped the course, he responded that he dropped it because of the heavy reading load. The Psychology course was an introductory one for which English 101 was not a prerequisite; Jack's entrance into for-credit courses based on the community colleges standards (as described in Chapter IV) should have meant that he was prepared for such academic tasks. Yet, he for some reason was unconfident in his ability to manage the reading. 
These clues - Jack's reluctance to read more lexically advanced sources and to utilize more appropriate secondary sources into his academic research writing, as well as his lack of confidence in handling a reading load in an introductory social sciences course - lead me to believe that Jack has literacy needs in the area of L2 reading. While the English 101 course did not assess or emphasize reading, the AELP curriculum includes reading as one of the four main literacy areas, along with speaking, listening, and writing. As Singhal (2004) argues, students who succeed in academic contexts have strong communicative skills in reading, writing, speaking and listening, highly-developed critical thinking skills, and strong research skills. After analyzing the data I have gathered, I suspect that Jack, despite successfully transitioning from the AELP curriculum to and through English 101, is still challenged in the areas of reading and writing. As he continues along his academic trajectory, he may encounter literacy hurdles that he will need to negotiate.

To better prepare students like Jack - whose oral literacy competencies are relatively more advanced than their written or reading competencies but whose L1 writing and reading development was either ceased or temporarily arrested (see Chapter IV and my discussion of Blanton, 2005, in Chapter II) - for the communicative skills necessary for academic writing tasks, community college ESL programs may wish to explore adding in samples of the types of academic genres students may encounter in their for-credit coursework. Academic texts such as journal articles could also serve as models in how to incorporate secondary texts in composing a well-supported argument. 


\section{Administrative Implications: Increase Collaboration Among Academic Departments}

In my discussion with Jane, the Director of ESL Programs, I learned that she often communicated with the English Department to informally research what types of literacy tasks students transitioning to English 101 would be asked to complete. The goal of such research is to make certain that the learning objectives of the AELP are preparing students to successfully meet the learning objectives in the English 101 program as well as content-area courses.

In my discussion with Thomas, Jack’s English 101 instructor, I ascertained that the ESL Program's informal research is basically "a one-way street." The ESL Program administrators survey the English Department, but it does not appear that the English Department takes responsibility for also communicating with the ESL program. Thomas admitted to me to that he had no prior training in second language writing instruction nor did he collaborate with the ESL program at Gridley Community College.

Additionally, it appears that Jane may not be receiving comprehensive information about exactly what types of literacy tasks are incorporated into the English 101 courses. As I discussed in Chapter IV, Thomas asserted that the overriding learning objectives are the same for all of the English 101 sections but that each instructor tailors the course in his or her own way. Thus, Thomas developed a syllabus that ensured that he covered the learning objectives for the English 101 course but in his own way: by incorporating genre research and multimodal composition.

Thus, there may be a discrepancy between the AELP curriculum and certain English 101 section curricula. As I discussed earlier in this chapter, Jack seems to have 
succeeded - actually exceeded - the learning objectives for the English 101 course, as evidenced by his grade of B in the course. I discussed in Chapter V a few of the challenges Jack faced with the multimodal assignments (incorporating the visual and audio elements into the Cowbird project) and appropriate genre analysis (translating his research paper into a blog post). And, as I discussed in the prior section, community college ESL programs may better serve their students by addressing these two areas in their preparatory curriculum, especially considering the respective charges by NCTE and CCCC. Above all, though, the English Department and the ESL Program, as well as other content areas, should communicate frequently so that the ESL Program is continually preparing its students for the types of literacy tasks they might encounter in for-credit courses; an informal survey modeled after that of Carroll and Dunkelblau (2011; described in Chapter II) could provide insight to the ESL Program in designing the AELP curriculum.

Community college English departments could also consider cross-training FYC instructors in both ESL pedagogy and composition pedagogy. This cross-training may serve all students, as Matsuda points out that homogeneity in the composition classroom is "a myth" (2006). Students in today's college composition classroom are going to bring a myriad of backgrounds, experiences, and languages, as shown throughout previous chapters. Success among such a variety of students requires what Matsuda (1999) calls, "a division of labor," dependent upon composition instructors who are cross-trained experienced in not only mainstream FYC pedagogy but also in ESL instruction. This type of collaboration between the two sub-disciplines happens rarely, if at all, according to Matsuda (1999). As he asserts, "To work effectively with the student population in the 
twenty-first century, all writing teachers need to reimagine the composition classroom as the multilingual space that it is, where the presence of language differences is the default" (p. 649). The heterogeneous and multilinguistic nature of the composition classroom is echoed by the CCCC's Statement on Second Language Writing and Writers, which also contends that language instructors should have training and experience in working with second language learners (2009). Additionally, Matsuda, Saenkhum, and Accardi’s (2013) study on teacher perceptions of multilingual students in the classroom, discussed in Chapter II, found that many FYC instructors would like to have additional preparation and support in the instruction of multilingual students in their classrooms.

Developing a program to inform and then implementing that program with mainstream FYC instructors may be a long-term goal for smaller community colleges like Gridley Community College rather than a short-term solution. An alternative to cross-training every FYC instructor would be for the college to offer a hybrid ESL/FYC course taught by a FYC instructor who also has formal college preparation in teaching and background experience in working with multilingual students. Models for different types of placement were described in Chapter II. Three of these models focus on courses that would include only U.S.-educated multilingual students. Holten's (2009) study described a hybrid ESL/FYC course for U.S.-educated multilingual students only; Miele's (2003) study on the three-year pilot Language Minority Crossover Project in New Jersey also focused solely on U.S.-educated multilingual students; and Murie and Fitzpatrick's (2009) study presented a year-long interdisciplinary program at a four-year university for, again, only U.S.-educated multilingual students. These three options may 
not be viable for an institution like Gridley Community College, which has very few U.S.-educated multilingual students enroll in its ESL program.

Two common concepts prompted the development of the programs described above: first, that U.S-educated multilingual students often bring characteristic but also varying literacy experiences and backgrounds to the FYC classroom, and second, that sometimes hybrid mainstream/multilingual writing classrooms can serve as cultural “contact zones" (Pratt, 1991, p. 38; see also in Chapter II my discussion of Harklau, 1999). While courses designed only for U.S.-educated multilingual students such as those illustrated in Holten (2009), Miele (2003), and Murie and Fitzpatrick (2009) may not be viable for Gridley Community College, and while training all mainstream FYC instructors in the various literacy needs of multilingual students (U.S.-educated multilingual students specifically) may be a long-term rather than short-term goal, implementing a FYC course for both NESs and multilingual students may be an option. Ideally, the course would be led by an instructor with experience in teaching FYC as well as education in TESOL and experience working with multilingual students. Such an instructor would be versed in not only FYC curriculum design but also in the specific but varying literacy needs and challenges of all types of multilingual students. In response to Ortmeier-Hooper's (2008) study of the sociocultural considerations of multilingual students transitioning to mainstream FYC courses, and in light of findings by Salas, et al. (2011) in which multilingual students were often marginalized into remedial tracks in a community college in Georgia, a TESOL-trained FYC instructor ideally would have the pedagogical tools to create a curriculum that allows students agency in their own self- 
identification as individuals and that also employs cross-cultural considerations of all students in the course, NESs and multilingual students alike.

Accompanying such a hybrid FYC curriculum, and further adhering to Matsuda's (1999) concept of the "division of labor" between ESL areas and writing programs, community college writing centers should also be prepared to help meet the academic literacy needs of second language writers, U.S.-educated multilingual students, specifically. As I discussed in Chapter II, Thonus's (2003) teacher-researcher case study of student-tutor interactions demonstrates that writing center staff should be trained in how to meet a variety of student literacy needs. Thonus researched how writing tutors can best assist U.S.-educated multilingual students specifically, by recognizing not only their heterogenous backgrounds and literacy experiences but also by directing feedback and suggestions in the most appropriate areas of a writing project. The writing center at Gridley Community College is available to students in the ESL program; Jack, however, admits to not knowing that a writing center was available to him. More collaboration between the ESL area and the college's writing center, as well as specific instruction for tutors on some common challenges in second language writing and outreach to those students, could make the writing center a more beneficial resource for students in the ESL program. This program also may need to be advertised more emphatically as a beneficial resource for ESL students.

\section{Part III: Limitations of the Present Study and Areas for Further Research}

In my attempt to answer my research questions, I felt I uncovered more questions than answers. Primarily, it appears that the ESL program at Gridley Community College prepares students to succeed in English 101, if I generalize my findings that are based on 
Jack's performance and experience. Additionally, the literature I reviewed reveals some pedagogical concepts that could be implemented into the community college ESL curricula in order to better serve U.S.-educated multilingual students like Jack. The end result of my case study, however, is that I now have additional questions, questions specific to this case - primarily Jack's further progress - as well as questions relating to U.S.-educated multilingual students in community colleges.

One limitation of this study is that the length of this study inhibited me from observing and analyzing how Jack transitioned further than the English 101 course. Ideally, such a project should follow Jack as he moves through the community college's courses, applies to a business program (or whatever program he may decide upon at that time) at a four-year university, and proceeds through credit-courses in the upperundergraduate levels. Analysis from additional data as to how Jack adjusted to various writing tasks in composition courses as well as content-area courses would shed more light on how well the AELP curriculum prepared Jack for literacy tasks in other credit courses.

My awareness of this limitation - and the knowledge of the additional insight that longer-term research could add - provides one area of further research in regards to community college ESL programs and U.S.-educated multilingual students in those programs: more longitudinal research needs to be conducted on U.S.-educated multilingual students' writing experiences in community college institutions. Additionally, more research into ESL program curricula as well as how those programs collaborate with mainstream course departments should also be considered. Finally, individual community colleges should conduct their own action research to determine the 
needs of their own student population and possible augmentation to current programming in order to meet those students' needs.

Additionally, two factors in providing specialized instruction for U.S.-educated multilingual students at a venue such as Gridley Community College include the relatively small size of the ESL program and the small number of U.S.-educated multilingual students who enroll in the AELP courses. The cases I described in Chapter II all involved larger community colleges with enough U.S.-educated multlingual students to justify stand-alone courses for that demographic. More research should focus on smaller programs in which the numbers of U.S.-educated multilingual students in the ESL program are small, such as the program at Gridley Community College. The very fact that these students represent so few of the students moving through the AELP Level 4 course (three students out of twelve were U.S.-educated multilingual students; the rest were adult immigrants) could result in a lack of focus on the unique literacy needs of U.S.-educated multilingual students in the program.

One issue not addressed in this case study, as it was not only outside the scope of the study but also because data from the participants was not available to me, is assessment of the student participants' work. While Jack shared with me the breakdown of his scores for English 101, I was not able to see just how Thomas assessed Jack's writing. Obviously, Thomas felt that Jack had exceeded his expectations in English 101; Jack earned a B (88\%) in the course, while Thomas's syllabus indicates that earning a C would demonstrate success ${ }^{22}$. The grade of a B, however, for Jack signifies that he not

\footnotetext{
22 Thomas's syllabus states, "Your success (meaning a grade of a " $\mathrm{C}$ ") will require success in the written and verbal aspects of the course, in classroom and online activities and exercises, as well in demonstrations of your understanding and application of the course objectives." The syllabus also
} 
only met but exceeded Thomas's expectations and learning objectives for the course.

When viewing Jack's grade in the English 101 course, based on Thomas's assessment of Jack's work, I feel that Jack was very successful and exceeded course expectations.

Finally, in terms of teacher-training, more research should be conducted into the benefits and drawbacks of requiring all English language teachers, not just ESL instructors and bilingual education majors, to complete coursework in teaching multilingual students, specifically in the area of cross-cultural composition. As explained in Chapter I, the heterogeneous classroom is becoming more the default than the exception. College students studying to teach in primary and secondary schools in some states are required to complete coursework in meeting the educational needs of students who have learning challenges, as special education students are, as a general rule, mainstreamed as often as possible, placed into the least-restrictive environment. As multilingual students, too, are mainstreamed into primary, secondary, and post-secondary institutions in the U.S., those responsible for their instruction should also have to complete coursework in order to raise awareness and provide tools in developing appropriate curriculum and instruction.

\section{Concluding Comments}

In this case study, I attempted to ascertain how successfully U.S.-educated multilingual students in a small, Midwestern community college would transition to

states the department's explanation of the letter grade of 'B', Jack's earned grade: “This grade represents performance significantly beyond the level necessary to achieve the course objectives. Work is of high quality but not consistently at an outstanding level. Performance at this level signifies that the student is well prepared to continue with more advanced study of the subject" (Gridley Community College's English Department website, accessed June 2014). 
English 101 courses. Through gathering and analyzing data about my studentparticipants' experiences and the nature of the community college ESL program, juxtaposed with current scholarly research, I ascertained that students who successfully pass through the AELP courses at Gridley Community College will likely succeed in English 101. This study was small, however, and these results are not generalizable to other students and other institutions and programs.

However, while students like Jack may successfully negotiate their way through the AELP courses as well as English 101, they may still encounter literacy challenges in future academic courses, just as NESs might. My analysis of data gathered from Jack throughout the course of this study suggests that he may in the future find that he is challenged by academic literacy tasks with which he is not familiar, especially in the areas of writing and reading. Therefore, I also sought to provide suggestions, based on my research of current scholarly literature and of the program and the studentparticipants, as to how programs could be enhanced to better equip U.S.-educated multilingual students like Jack for English 101 and other for-credit courses. Most of my suggestions, including increasing collaboration between the English Department and the ESL program, as well as cross-training FYC instructors and writing center tutors, could provide benefits to not only the U.S.-educated multilingual students in the program but also to the international students and adult immigrants who enroll in the ESL program and/or for-credit courses at Gridley Community College.

While research on U.S.-educated multilingual students at the college level is growing, research on this demographic in the community college setting - especially in relatively small community college venues such as Gridley Community College - is still 
scarce, especially in the area of students transitioning from community college ESL programs to FYC and other content-area courses. It is my hope that this present study can serve to augment this important area of second language writing instruction. Best practices grounded in current research on genre analysis, multimodal composition, academic literacies, cross-cultural composition, academic literacy strengths and needs, and placement options are necessary to ensure that students transitioning from an ESL program to FYC are prepared for the required academic literacy tasks. Through such analysis and reflection, community college ESL support programs can better tailor their academic preparatory curricula to meet the literacy needs of U.S.-educated multilingual students transitioning to mainstream courses. 


\section{REFERENCES}

Allison, H. A. (2006). Immigration + new literacy studies + digital technologies $=\mathrm{ESL}$ for a new South. In M. Spaventa (Ed.), Perspectives on Community College ESL: Volume 1, Pedagogy, Programs, Curricula, and Assessment (Vol. 1, pp. 47-60). Alexandria, Virginia: TESOL, Inc.

Barton, D., Hamilton, M., \& Ivanič, R. (2000). Introduction. Situated Literacies: Reading and Writing in Context (pp. 1-6). London, U.K.: Routledge.

Benesch, S. (2008). "Generation 1.5" and its discourse of partiality: A critical analysis. Journal of Language, Identity, and Education, 2008(7), 294-311.

Blanton, L. L. (2005). Student, interrupted: A tale of two would-be writers. Journal of Second Language Writing, 14, 105-121.

Bloch, J. (2007). Abdullah's blogging: A generation 1.5 student enters the blagosphere. Language Learning \& Technology, 11(2), 128-141.

Blumenthal, A. J. (2002). English as a second language at the community college: An exploration of contexts and concerns. New Directions for Community Colleges, 117(Spring 2002), 45-53.

Carroll, J. \& Dunkelblau, H. (2011). Preparing ESL students for "real" college writing: A glimpse of common writing tasks ESL students encounter at one community college. Teaching English in the Two-Year College, March, 271-281.

Casanave, C. P. (2004). Controversies in second language writing: Dilemmas and decisions in research and instruction. Ann Arbor, Michigan: The University of Michigan Press.

Case, R. E., Williams, G. M., \& Xu, W. (2013). Instructors' feedback among Generation 1.5 students, international students, and basic writers. Journal of Excellence in College Teaching, 24(1), 85-103.

Conference on College Composition and Communication Committee on Second Language Writing. (2009). CCCC Statement on Second Language Writing and Writers. College Composition and Communication, 52(4), 669-674.

Connor, U. (2003). Changing currents in contrastive rhetoric: Implications for teaching 
and research. In B. Kroll (Ed.), Exploring the Dynamics of Second Language Writing (pp. 218-241). Cambridge, U.K.: Cambridge University Press.

Connor, U. (2004). Intercultural rhetoric research: Beyond texts. Journal of English for Academic Purposes, 2004(3), 291-304.

Courage, R. (1993). The intersection of public and private literacies. College Composition and Communication, 44(4), 484-496.

Denzin, N. K. \& Lincoln, Y. S. (2000). Introduction. In N. K. Denzin \& Y. S. Lincoln (Eds.), Handbook of Qualitative Research (2nd ed., pp. 1-28). 2000: Sage Publications, Inc.

di Gennaro, K. (2008). Assessment of Generation 1.5 learners for placement into college writing courses. Journal of Basic Writing, 27(1), 61-79.

di Gennaro, K. (2012). The heterogeneous second-language population in US colleges and the impact on writing program design. Teaching English in the Two-Year College, September 2012, 57-67.

Doolan, S. (2010/2011). A language-related comparison of Generation 1.5 and L1 student writing. The CATESOL Journal, 22(1), 87-112.

Dougherty, K. J. \& Townsend, B. K. (2006) Community college missions: A theoretical and historical perspective. New Directions for Community Colleges, 136(Winter 2006), 5-13.

Duff, P. A. (2008). Case Study Research in Applied Linguistics. New York, New York: Routledge.

Fix, M. \& Passel, J. S. (January 2003). U.S. immigration -- Trends and implications for schools. Paper presented at the NCLB Implementation Institute, National Association for Bilingual Education. New Orleans, Louisiana.

Geertz, C. (1973). The Interpretation of Cultures. New York, New York: Basic Books, Inc.

Gilbert, C. K. \& Heller, D. E. (2013). Access, equity, and community colleges: The Truman Commission and federal higher education policy from 1947 to 2011. The Journal of Higher Education, 84(3), 417-443.

Harklau, L. (1999). Representing culture in the ESL writing classroom. In E. Hinkel (Ed.), Culture in Second Language Teaching and Learning (pp. 109-130). Cambridge, U.K.: Cambridge University Press. 
Harklau, L., Siegal, M., \& Losey, K. (1999). Linguistically diverse students and college writing: What is equitable and appropriate? In L. Harklau, M. Siegal, and K. Losey (Eds.), Generation 1.5 Meets College Composition: Issues in the teaching of writing to U.S.-educated learners of ESL (pp. 1-14). Mahwah, New Jersey: Lawrence Erlbaum Associates, Inc.

Hatch, J. A. (2002). Doing Qualitative Research in Education Settings. Albany, New York: State University of New York Press.

Holten, C. (2009). Creating an inter-departmental course for Generation 1.5 ESL writers. In M. Roberge, M. Siegal \& L. Harklau (Eds.), Generation 1.5 in College Composition (pp. 170-184). New York: Routledge.

Hyland, K. (1996). Second Language Writing. Cambridge, U.K.: Cambridge University Press.

Hyland, K. (2004). Genre and second language writing. Ann Arbor, Michigan: The University of Michigan Press.

Jeffries, M. \& Yi, Y. (2008). Relationship between spoken and written discourse of a Generation 1.5 ESL student: A study of a German student in college ESL composition class. The CATESOL Journal, 20(1), 65-81.

Johns, A. M. (2009). Situated invention and genres: Assisting Generation 1.5 students in developing rhetorical flexibility. In M. Roberge, M. Siegal \& L. Harklau (Eds.), Generation 1.5 in College Composition (pp. 203-220). New York: Routledge.

Kachru, Y. (1999). Culture, context, and writing. In E. Hinkel (Ed.), Culture in Second Language Teaching and Learning (pp. 75-89). Cambridge, U.K.: Cambridge University Press.

Kress, G. (2010). Multimodality: A social semiotic approach to contemporary communication. New York, New York: Routledge.

Kroll, B., Matsuda, P. K., Polio, C., Cumming, A. H., Silva, T. J., Ferris, D., . . Leki, I. (2003). Exploring the dynamics of second language writing. Cambridge, U.K. ; New York: Cambridge University Press.

Kubota, R. \& Lehner, A. (2004). Toward critical contrastive rhetoric. Journal of Second Language Writing, 13, 7-27.

Louie, V. (2005). Immigrant newcomer populations, ESEA, and the pipeline to college: Current considerations and future lines of inquiry. Review of Research in Education, 29(1), 69-105. 
Louie, V. (2009). The education of the 1.5 generation from an international migration framework: Demographics, diversity, and difference. In M. Roberge, M. Siegal \& L. Harklau (Eds.), Generation 1.5 in College Composition (pp. 35-49). New York: Routledge.

Matsuda, P. K. (1999). Composition studies and ESL writing: A disciplinary division of labor. College Composition and Communication, 50(4), 699-721.

Matsuda, P. K. \& Silva, T. (1999). Cross-cultural composition: Mediated integration of U.S. and international students. In P. K. Matsuda, M. Cox, J. Jordan \& C. Ortmeier-Hooper (Eds.), Second-Language Writing in the Composition Classroom: A critical sourcebook (pp. 252-265). Urbana, Illinois: National Council of Teachers of English.

Matsuda, P. K. (2006). The myth of linguistic homogeneity in U.S. college composition. College English, 68(6), 637-651.

Matsuda, P. K. \& Matsuda, A. (2009). The erasure of resident ESL writers. In M. Roberge, M. Siegal \& L. Harklau (Eds.), Generation 1.5 in College Composition (pp. 50-64). New York: Routledge.

Matsuda, P. K. \& Atkinson, D. (2008). A Conversation on Contrastive Rhetoric: Dwight Atkinson and Paul Kei Matsuda talk about issues, conceptualizations, and the future of contrastive rhetoric. In U. Connor, E. Nagelhout \& W. V. Rozycki (Eds.), Contrastive Rhetoric: Reaching to Intercultural Rhetoric. Amsterdam, Netherlands: Benjamins.

Matsuda, P. K., Saenkhum, T., \& Accardi, S. (2013). Writing teachers' perceptions of the presence and needs of second language writers: An institutional case study. Journal of Second Language Writing, 22, 68-86.

Miele, C. (2003). Bergen Community College meets Generation 1.5. Community College Journal of Research and Practice, 27, 603-612.

Miller-Cochran, S. K. (2012). Beyond "ESL writing": Teaching cross-cultural composition at a community college. Teaching English in the Two-Year College, September 2012, 20-30.

Muchinsky, D. \& Tangren, N. (1999). Immigrant student performance in an academic intensive English program. In M. S. L. Harklau, and K. Losey (Ed.), Generation 1.5 Meets College Composition: Issues in the teaching of writing to U.S.-educated learners of ESL (pp. 211-234). Mahwah, New Jersey: Lawrence Erlbaum Associates, Inc.

Murie, R. \& Fitzpatrick, R. (2009). Situating Generation 1.5 in the academy: Models for 
building academic literacy and acculturation. In M. Roberge, M. Siegal \& L. Harklau (Eds.), Generation 1.5 in College Composition (pp. 154-169). New York: Routledge.

Murray, J. (2009). Non-Discursive Rhetoric: Image and affect in multimodal composition. Albany, New York: State University of New York Press.

National Council of Teachers of English. (2003). NCTE Position Statement: Resolution on Composing with Non-Print Media. 2014, from http://www.ncte.org/positions/statements/composewithnonprint

Ortmeier-Hooper, C. (2008). English may be my second language, but I'm not "ESL". College Composition and Communication, 59(3), 389-419.

Paltridge, B., Harbon, L., Hirsch, D., Shen, H., Stevenson, M., Phakiti, A., \& Woodrow, L. (2009). Teaching Academic Writing: An Introduction for Teachers of Second Language Writers. Ann Arbor, Michigan: The University of Michigan Press.

Patthey, G., Thomas-Spiegel, J., \& Dillon, P. (2009). Education pathways of Generation 1.5 students in community college writing courses. In M. Roberge, M. Siegal \& L. Harklau (Eds.), Generation 1.5 in College Composition (pp. 3-24). New York: Routledge.

Peirce, B. N. (1995). Social identity, investment, and language learning. Tesol Quarterly, 29(1), 9-31.

Pratt, M. L. (1991). Arts of the contact zone. Profession, 91, 33-40.

Reid, J. (2011). "Eye" learners and "ear" learners: Identifying the language needs of international students and U.S. resident writers. In P. K. Matsuda, M. Cox, J. Jordan \& C. Ortmeier-Hooper (Eds.), Second-Language Writing in the Composition Classroom: A Critical Sourcebook (pp. 82-94). Urbana, Illinois: National Council of Teachers of English.

Reimers, D. M. (1983). An unintended reform: The 1965 Immigration Act and third world immigration to the United States. Journal of American Ethnic History, 3(1), 18 .

Riazantseva, A. (2012). "I ain't changing anything": A case-study of successful Generation 1.5 immigrant college students' writing. Journal of English for Academic Purposes, 11(3), 184-193.

Roberge, M. (2009). A teacher's perspective on Generation 1.5. In M. S. M. Roberge, and L. Harklau (Ed.), Generation 1.5 in College Composition (pp. 3-24). New York: Routledge. 
Rossman, G. B. \& Rallis, S. F. (2012). Learning in the Field: An Introduction to Qualitative Research (3rd ed.). Los Angeles, California: Sage Publications, Inc.

Salas, S., Portes, P. R., D'Amico, M. M., \& Rios-Aguilar, C. (2011). Generación 1.5: A Cultural Historical Agenda for Research at the 2-Year College. Community College Review, 39(2), 121-135. doi: 10.1177/0091552111405037

Schleppegrell, M. J. (1996). Conjunction in spoken English. Applied Linguistics, 17(3), 271-285.

Schleppegrell, M. J. (2001). Linguistic features of the language of schooling. Linguistics and Education, 12(4), 431-459.

Schleppegrell, M. J. (2013). The role of metalanguage in supporting academic language development. Language Learning, 63(1), 153-170.

Shannon, H. D. \& Smith, R. C. (2006). A case for the community college's open access mission. New Directions for Community Colleges, 136(Winter 2006), 15-21.

Shin, D., \& Cimasko, T. (2008). Multimodal composition in college ESL class: New tools, traditional norms. Computers and Composition, $2008(25), 376-395$.

Silva, T. (1994). An examination of writing program administrators' options for placement of ESL students in first year writing classes. WPA, 18(1-2), 37-43.

Silva, T. (1997). Differences in ESL and native-English-speaker writing: The research and its implications. In C. Severino, J. C. Guerra \& J. E. Butler (Eds.), Writing in Multicultural Settings. New York: The Modern Language Association of America.

Singhal, M. (2004). Academic writing and generation 1.5: Pedagogical goals and instructional issues in the college composition classroom. The Reading Matrix, $4(3), 1-13$.

Song, B. (2006). Failure in a college ESL course: Perspectives of instructors and students. Community College Journal of Research and Practice, 30, 417-431.

Stake, R. E. (2000). Case Studies. In N. K. D. a. Y. S. Lincoln (Ed.), Handbook of Qualitative Research (2nd ed., pp. 435-454). Thousand Oaks, California: Sage Publications, Inc.

Street, B. (1997). The implications of the "New Literacy Studies" for literacy education. English in Education, 31(3), 45-59. 
Street, B. (2004). Academic literacies and the 'new orders': implications for research and practice in student writing in higher education. Learning and Teaching in the Social Sciences, 1(1), 9-20.

Street, B. V. (2001). Introduction. In B. V. Street (Ed.), Literacy and Development: Ethnographic Perspectives (pp. 1-17). London, U.K.: Routledge.

Street, B. V. (2005). At last: Recent applications of New Literacy Studies in educational contexts. Research in the Teaching of English, 39(4), 417-423.

Tardy, C. M. (2005). "It's like a story": Rhetorical knowledge development in advanced academic literacy. Journal of English for Academic Purposes, 2005(4), 325-338.

Thonus, T. (2003). Serving Generation 1.5 learners in the university writing center. TESOL Journal, 12(1), 17-24.

Treat, T. \& Barnard, T. C. (2012). Seeking legitimacy: The community college mission and the honors college. Community College Journal of Research and Practice, 36, 695-712.

Wolcott, H. F. (2009). Writing Up Qualitative Research. Thousand Oaks, California: Sage Publications, Inc. 


\section{APPENDIX A \\ SEMI-STRUCTURED INTERVIEW QUESTIONS FOR THE ESL DIRECTOR}

I. Background questions:

Can you tell me a little bit about your background?

1. What is your educational background?

2. What is your educational background in ESL/TESOL?

3. How many years have you been teaching? How many years have you been teaching in the ESL/TESOL area?

4. Is English your first language? Do you know any other languages?

II. Specific program questions:

Can you tell me a bit about the ESL program at this community college?

1. What are the sub-areas of the ESL program? How do they operate together?

2. Does this program collaborate with other programs within the college (the Adult Education program, the writing program, content-area departments)? If so, how?

3. Are you familiar with the Conference on College Composition and Communication's Committee's statement on second-language writing and writers? If so, does this statement influence your curriculum or your teaching methods? If so, how? 
4. How are second-language learners placed into courses at this community college? Do learners have a choice in that placement?

III. Questions regarding long-term resident language learners in the program and the learner-participants in my study:

1. What types of writing are students been asked to do in the academic English language program/in this class?

a. What genres?

b. Are there any research-based writing tasks?

c. What is the length of those writing assignments?

d. How much work is done collaboratively on these assignments?

2. What are the goals and objectives for students' writing in the ESL program/in this class?

a. What is the focus of assessment of writing in the ESL program/this class?

b. How often do you witness students seeking help with their writing? Where do they go to get help? What kind of help is offered?

3. What are students asked to read in the ESL program? In mainstream composition and content-area courses?

a. What types of reading assignments are given?

b. How are those reading assignments introduced?

c. What in-class support is offered with reading assignments?

4. How does your program classify or define long-term resident language learners? 
a. How would you describe the literacy needs of the long-term resident language learners who have come through your program? $\mathrm{b}$. How do they differ from international students?

c. What challenges have you observed that long-term language learners have with writing?

d. What written literacy complexities have these students faced in this program?

e. What sorts of feedback do you get from the ESL instructors regarding writing by long-term resident language learners?

5. Do mainstream instructors work with the ESL program? Why or why not?

6. What kind of support is available for former ESL program students once they are in mainstream community college courses?

7. What types of writing are these students going to be asked to do in mainstreamed for-credit community college composition and content-area classrooms?

a. What genres?

b. Are there any research-based writing tasks?

c. What is the length of those writing assignments?

d. How much work is done collaboratively on these assignments?

8. What sorts of feedback do you get from the mainstream content-area course instructors regarding the writing of long-term resident language learners? 


\section{APPENDIX B \\ SEMI-STRUCTURED INTERVIEW QUESTIONS FOR THE ENGLISH 101 \\ INSTRUCTOR}

I. Background questions:

Can you tell me a little bit about your background?

1. What is your educational background?

2. What is your educational background in ESL/TESOL?

3. How many years have you been teaching?

4. Is English your first language? Do you know any other languages?

II. Specific course questions:

Can you tell me about your English 101 course section?

1. What types of writing are the students asked to do?

2. Are there any research-based writing tasks?

3. What is the length of those writing assignments?

4. What goals and objectives do you have for the students' writing for these various assignments?

5. Do your students every seek assistance with their writing, either from you or from the writing center?

6. What types of reading assignments are given?

7. How are these reading assignments introduced? 
8. What type of support is offered for reading assignments?

9. Do you work with the ESL program at all?

10. Do you encounter second language students in your classroom often?

11. Do you notice that the second language learners in your class may have different literacy needs than native English speakers in the class? What types of needs do you see ELLs having in your classroom?

12. Do multilingual students bring any additional instructional complexities to your classroom either, and, if so, are these challenges or additive to the classroom environment? 


\section{APPENDIX C \\ SEMI-STRUCTURED INTERVIEW QUESTIONS FOR THE STUDENT- \\ PARTICIPANTS}

I. Background questions:

A. Would you like to tell me a bit about yourself?

1. How old are you?

2. Why are you at this community college?

3. What are your academic and career plans?

II. Language-based questions:

B. Can you tell me about your first language?

1. What was the first language you learned?

2. Where did you learn it?

3. At what age did you learn it?

4. Do you write in your first language?

C. Can you tell me about your experience learning English?

1. At what age did you move to the U.S.?

2. Did you have any schooling in English before you came to the U.S.? If

so, what was it like? Can you describe it?

3. Do you feel as if you were prepared to take part in conversations in English in the U.S.? 
4. Were you able to understand your teachers in school in the U.S.?

5. Do speak a language other than English or your first language?

6. Do you write/compose in a language other than English and your first language?

III. Writing-specific questions:

A. Can you tell me about language and writing experiences you've had in school in the U.S.? What types of writing do you remember from your years K-12?

B. Do you enjoy writing in English? Why or why not?

C. Do you enjoy writing in your first language? Why or why not?

D. What types of writing tasks do you engage in outside of school?

E. For what types of tasks do you use your first language? your second language? Life tasks? Career tasks?

F. What are the differences between writing in your first language and writing in your second or third languages?

G. Which writing tasks do you us your first language? For which writing tasks do you use your second language?

$\mathrm{H}$. What are your strengths with writing in your first language, in your opinion?

I. What are your strengths with writing in English, in your opinion?

J. What challenges do you face writing in English, in your opinion?

$\mathrm{K}$. What challenges do you face writing in your first language, in your opinion?

L. Do you feel you are a good academic writer (in your first language or in English)? How so? or, Why not?

M. How do you approach a writing assignment? What steps do you follow? 
N. Do you like your classmates reviewing your writing? Why or why not?

O. Do you ask anyone for help with your writing? If so, whom? When? At what point? How often do you ask for help with writing assignments? If you do not seek out help, can you share with me why not?

P. How do you revise your writing?

Q. What types of writing assignments do you think you'll be asked to complete in your mainstream courses?

R. Do you feel prepared for college writing assignments after you've finished the ESL program?

S. What do you think will be the biggest writing concern you will face in your college courses after the ESL program?

T. Do you like to research? If so, what do you like about it? If not, what don't you like about it?

U. Have you done any writing projects that required research in the past? Can you describe them/it?

V. Do you enjoy reading in English? Why or why not?

W. If you enjoy reading, what types of text do you like to read?

$\mathrm{X}$. How would you describe your reading strengths? Challenges? 


\title{
APPENDIX D
}

\section{AELP LEVEL 4 LIST OF NOVELS FOR BOOK REPORT ASSIGNMENT}

\author{
Level 4 Reading List
}

Shizuko's Daughter by Kyoko Mori

The House on Mango Street by Sandra Cisneros

Open Court by Carol Clippinger

Prep by Curtis Sittenfeld

The Circuit by Francisco Jimenez

A Step From Heaven by $\mathrm{An} \mathrm{Na}$

Wait for Me by An Na

Shabanu: Daughter of the Wind by Suzanne Fisher Staples

Dragonwings by Laurence Yep

Picture Bride: A Novel by Yoshiko Uchida

Song of the Buffalo Boys by Sherry Garland

The Exchange Student by Kate Gilmore

Esperanza Rising by Pam Munoz Ryan

Goodbye, Vietnam by Gloria Whelan

My Name Is Not Angelica by Scott O'Dell

Song of the Buffalo Boys by Sherry Garland

The Land I Lost: Adventures of a Boy in Vietnam by Quang Nhuong Huynh

Blue Jasmine by Kashmira Sheth

toy Club by Amy Ian

Reaching Out by Francisco Jimenez 
APPENDIX E

JACK'S ENGLISH 101 COWBIRD ASSIGNMENT

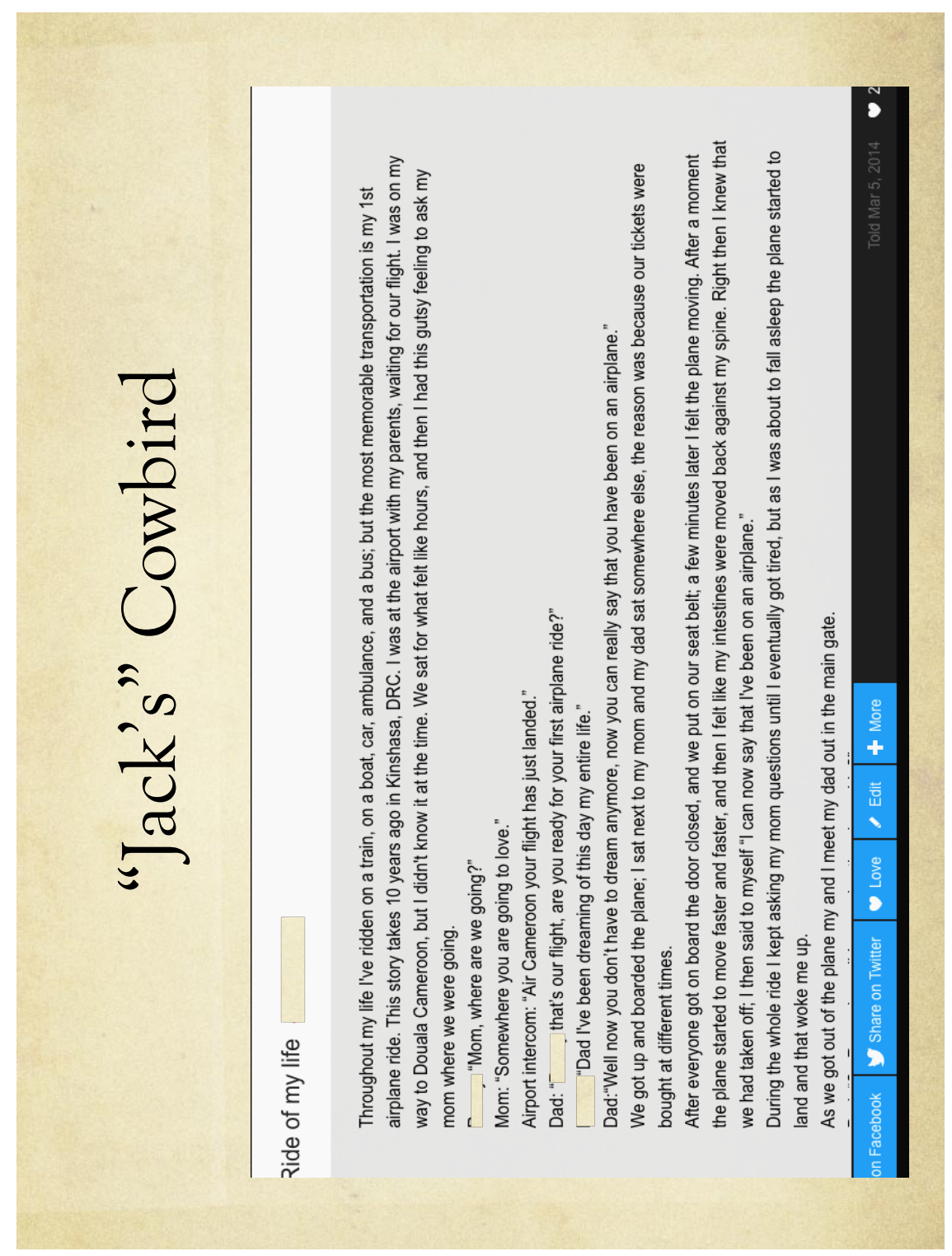

